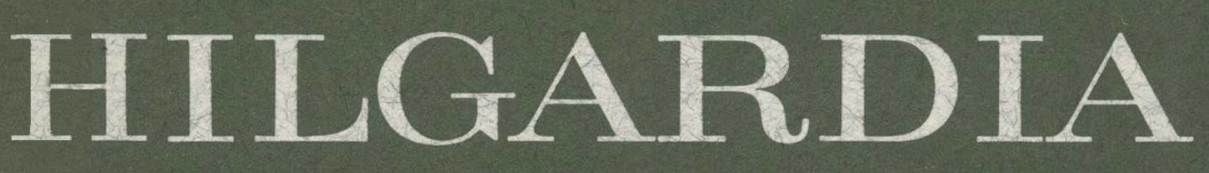

A JOURNAL OF AGRICULTURAL SCIENCE PUBLISHED BY THECALIFORNIA AGRICULTURAL EXPERIMENT STATION

Volume 34, Number $5 \cdot$ April, 1963

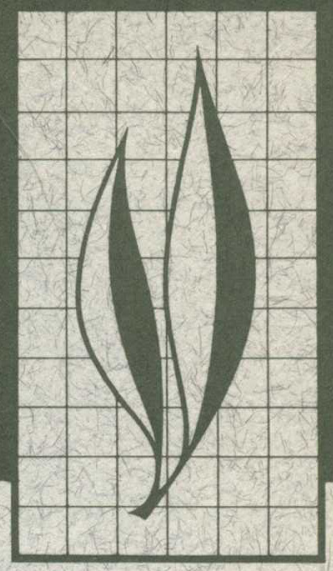

\title{
Competitive Displacement Between Ecological Homologues
}

\author{
Paul DeBach and Ragnhild A. Sundby
}




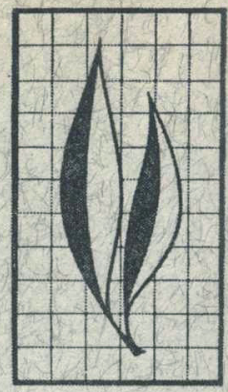

Competitive displacement among three species of parasitic $\mathrm{Hy}$ menoptera which are ecological homologues has occurred in the field in southern California. Apbytis chrysompbali (Mercet) [Hymenoptera: Aphelinidae] was eliminated in 10 years (1948-1958) from nearly all of its former range - an area of some 4,000 square miles-by Apbytis lingnanensis Compere, which was imported from the Orient in 1948. Subsequently, Apbytis melinus DeBach, another exotic from India-Pakistan, virtually displaced $A$. lingnanensis from about 500 square miles of interior climatic areas in 4 years (1957-1961), but during the same time $A$. lingnanensis precluded the establishment of $A$. melinus in the milder intermediate climatic areas of San Diego County. Competitive displacement occurred in places in spite of food [the host scale insect, Aonidiella aurantii (Maskell)] being abundant. Thus food scarcity is not necessary for competitive displacement to occur. Two other species of parasites, Comperiella bifasciata Howard and Prospaltella perniciosi Tower, which attack the same host but are not ecological homologues of the Aphytis spp., continued to coexist with Aphytis spp.

Experimental studies in laboratory population cages supported and helped to explain the field results. Single species cultures served as checks and could be maintained indefinitely. Success in single species cultures, as determined by the average population

\section{THE AUTHORS:}

Paul DeBach is Professor of Biological Control and Entomologist, Department of Biological Control, Riverside.

Ragnhild A. Sundby is Associate Professor of Zoology, Zoological Institute, Agricultural College of Norway, Vollebekk, Norway.

The assistance of John Landi and Ernest White, Laboratory Technicians, Department of Biological Control, Riverside, is gratefully acknowledged.

See inside back cover for Table of Contents. 


\section{Competitive Displacement Between Ecological Homologues ${ }^{1}$}

\section{INTRODUCTION AND REVIEW}

In recent years the once numerous insect parasite Aphytis chrysomphati (Mercet) (Hymenoptera: Aphelinidae) has undergone a rapid decline and has virtually disappeared from its former range in southern California. The causes usually attributed to the decline of an insect population were not present in this case-critical change in weather, shortage of food or places in which to live, or attack by predators. The decline was caused by the introduction of a closely related species, which apparently had an identical ecological niche and which displaced $A$. chrysomphati within a few years. Similar displacements involving other species have since occurred in the same region of southern California.

It was fortunate that during this period we were taking population censuses and otherwise closely studying the effect of these parasites in the population regulation of their host, Aonidiella aurantii (Maskell). Had it been otherwise, the displacement would likely have gone unnoticed to a large extent, since these minute parasites (usually less than $1 \mathrm{~mm}$ long) are rarely noticed by the casual observer.

The above-mentioned displacements are examples which, along with laboratory confirmation, demonstrate and illustrate the hypothesis (sometime principle) that different species having identical ecological niches (that is, ecological homologues) cannot coexist for long in the same habitat. This hypothesis will be recognized as "Gause's law" or "hypothesis," "Grinnell's axiom," and more recently as "the competitive exclusion principle." None of these terms, as will be discussed later, seems eminently acceptable; hence, we suggest "the competitive displacement hypothesis," after Grinnell's clear 1928 statement utilizing these same words (see pages 107-8, 109-10). The previous use of the terms "principle" or "law" hardly seems appropriate to a phenomenon which up to now has received so little verification under natural conditions. Perhaps the data presented in this paper will add weight to the eventual acceptance of the hypothesis as a principle.

It is apropos here to define our terms so that others may clearly understand them, even if they do not agree with our usage.

Ecological Niche-the role played by an animal based on its precise food, spatial and habitudinal requirements in a particular habitat. What an animal does and what it needs as requisites for survival and reproduction in a given

\footnotetext{
${ }^{1}$ Submitted for publication March 28, 1962. Dr. Sundby's research was performed at the University of California, Citrus Research Center and Agricultural Experiment Station, Riverside, under an appointment supported by the International Cooperation Administration under the Visiting Research Scientists Program administered by the National Academy of Sciences of the United States of America. The junior author was not involved in the field research on this problem.
} 
habitat determine its ecological niche. (For other definitions, see Gause, 1934, page 19; Elton, 1927, page 63; and Udvardy, 1959, page 276.)

It follows that individuals of different species which would have identical needs for food, shelter, and/or other essential requisites if they were present in the same habitat, would have identical niches. If only one essential component of the niches of two species, such as food, is identical, then these species have identical niches insofar as competition for food is concerned.

It will be noted that the idea of ecological niche is linked to an animal in a given habitat. It should not be confused with the physical habitat alone and it has nothing directly to do with the idea of geographical distribution. Organisms with the physical habitat alone, and it very similar ones, may be expected to exhibit varying degrees of biological and physiological differences. For instance, their fecundity and longevity will differ, and their relative extent of adaptation to meteorological extremes may differ so much that their actual or potential geographical distributions may overlap only in part. However, some species whose habits and needs are similar or identical must remain completely separate because of the action of climatic factors. In the latter case, the species have different ecological niches.

CoExIsT-live together in an identical habitat. This means habitation of spacially identical ranges.

HaBITAT - the environment of a species' natural population unit. The essential physical and biotic factors in a locality where individuals of that population normally live and reproduce.

The terms competition and ecological homologue, indicated in the title, are defined as follows:

Competition-the attempted or actual utilization by two organisms of common resources or requisites involves competition even if one does not directly harm the other in the process. An apparent abundance of food or other requisites does not deny the occurrence of competition. This definition is similar to Milne's (1961) definition, but we stress that competition and competitive displacement can occur when the supply of food (or requisites) is abundant. (See page 141: Competitive Displacement at Low Constant Parasite Densities.)

Ecological homologues-two different species having identical ecological niches. For practical purposes this applies to cases where not only is the ecological niche of one species duplicated by a second species, but the second species possesses a somewhat broader niche in the same habitat. In such cases the more limited species possesses an ecological homologue in the species with a broader niche, but the relationship is not mutual. The first species may be displaced by the second, but not vice versa. Also note that ecological niches do not have to be identical in all respects for competition and displacement to occur. If one essential component of the niches of two species is identical (such as identical food), then the two species are ecological homologues to this extent.

Competitive Displacement - the elimination, in a given habitat, of one species by another species where one has the identical ecological niche of the other. For practical purposes this applies even to cases where only one essential requisite, such as food, is identical. Also, this term is used in a broad sense to include "competitive exclusion." Actually, complete exclusion of an invader probably rarely occurs. It is likely that some individuals gain a foothold and that displacement follows.

The assumption is implicit in the hypothesis that species, however closely related and however similar in habits, have inherent biophysiological differences which will favor one over the other in a particular situation. It is also assumed that immigration of the weaker species does not occur. Of 
course, it follows that all other species would be covered by the converse hypothesis that "different species coexisting for an indefinite period in the same habitat must have different ecological niches" or, as Hardin (1960) put it, "ecological differentiation is the necessary condition for coexistence."

The hypothesis of competitive displacement in ecological homologues has become highly controversial. It has even been said to be unprovable empirically (Hardin, 1960), and we know of no substantiated claims to its proof in nature. However, Hardin apparently bases this idea on his conclusion that investigators cannot determine whether different species have identical or different ecological niches. We disagree, and the species we have worked with show that it is possible to delimit ecological niches.

Many laboratory population studies since Gause's work (1934) apparently have demonstrated the competitive displacement hypothesis but some seem to disagree (Utida, 1953). Controversy over semantics unfortunately seems to have become almost as important as acquisition and evaluation of observational and experimental evidence. It therefore seems necessary to review some of the history and controversy connected with the competitive displacement hypothesis.

The hypothesis is not new. It is present, if cryptic, in Darwin's ideas on the struggle for existence and survival of the fittest. He states (1859, Chapter 3 ), "The dependency of one organic being on another, as of a parasite on its prey, lies generally between beings remote in the scale of nature. This is often the case with those which may strictly be said to struggle with each other for existence, as in the case of locusts and grass-feeding quadrupeds. But the struggle almost invariably will be most severe between the individuals of the same species, for they frequent the same districts, require the same food, and are exposed to the same dangers. [Note that these latter phrases are the essential elements in the description of an ecological niche.] As species of the same genus have usually, though by no means invariably, some similarity in habits and constitution, and always in structure, the struggle will generally be more severe between species of the same genus, when they come into competition with each other, than between species of distinct genera. We see this in the recent extension over parts of the United States of one species of swallow having caused the decrease of another species. The recent increase of the missel-thrush in parts of Scotland has caused the decrease of the song-thrush. How frequently we hear of one species of rat taking the place of another species under the most different climates! In Russia the small Asiatic cockroach has everywhere driven before it its great congener. One species of charlock will supplant another, and so in other cases. We can dimly see why the competition should be most severe between allied forms, which fill nearly the same place in the economy of nature; but probably in no one case could we precisely say why one species has been victorious over another in the great battle of life."

It has been pointed out by Udvardy (1959) that Grinnell was perhaps the first naturalist to use the term "ecological niche" in the sense later used by Elton, and that Grinnell essentially stated the competitive displacement hypothesis in 1904 as follows:

"Two species of approximately the same food habits are not likely to remain long evenly balanced in numbers in the same region. One will crowd out the other ..."; and again, conversely, in 1917, "It is, of course, axiomatic that no two species regularly established in a single fauna have precisely the same niche relationships"; and then in 1928, "No two species in the same general territory can occupy for long identically the same ecological niche. If, by chance, the vagaries of distributional 
movement result in introducing into a new territory the ecologic homologue of a species already endemic in that territory, competitive displacement of one of the species by the other is bound to take place." This last sentence suggested the title of this paper and the proposal that "the competitive displacement hypothesis" would be an appropriate designation for the hypothesis. Aside from its historical precedence, the term "displacement" appears to fit the hypothesis better than the term "exclusion." An invading species may successfully displace an established species, hence the invader is not excluded. Exclusion can apply only to those invaders which never leave any progeny. Should an invader leave progency, it can then be displaced but not excluded. Complete exclusion is probably rare and would be observed even more rarely. Udvardy (1959) proposed that the hypothesis be called "Grinnell's axiom" rather than "Gause's law" or "Gause's hypothesis," terms which resulted from Gause's (1934) publication of "The Struggle for Existence."

In the 1920's and 1930's mathematical studies apparently corroborated Grinnell's ideas. Vito Volterra (1926) first considered the special case of competition between two species for a common food and developed equations showing that with competing species occupying the same ecological niche (in this case, eating the same food) one species will completely displace the other. Lotka (1932) arrived at the same conclusions and, according to Gause (1934), J. B. S. Haldane had come to similar conclusions in 1924.

It is interesting to note that Nicholson (1933, page 152) concluded on the basis of mathematical reasoning that "When several species of specific parasites simultaneously attack a common host species the steady state [that is, coexistence of the parasite species] is practically impossible." On the other hand, he states, "If several species of specific parasites attack a common host species in succession, the steady state [that is, coexistence of parasite species] may exist, provided each species of parasite has a greater area of discovery [that is, searching ability] than that of the parasite preceding it in the series." The first conclusion represents a special statement of the displacement hypothesis under discussion and aptly enough is illustrated by the results, reported later in this paper, of different species of Aphytis attacking the same host species simultaneously (see sections beginning on pages 118, and 124, and pages 139 and 140). The second conclusion also is illustrated later in this paper by the coexistence of Aphytis species and Comperiella bifasciata How., because these species attack different stages of the same host species (see section at top of page 128 , and also pages 153-156).

Williamson (1957) mathematically illustrated situations in which competing species could coexist, as well as at least one situation in which they could not coexist. Gause's hypothesis seems to have furnished the impetus for this work, but Williamson largely ignores the important point in the hypothesis that the competing species must have identical ecological niches and must compete in the same habitat. Williamson's paper applies mainly to the broader aspects of competition.

\section{Previous Laboratory Studies}

Gause (1934) for the first time really focused the attention of ecologists on the competitive displacement hypothesis in his book "The Struggle for Existence." He studied mixed populations of two species of protozoans, Paramecium caudatum and $P$. aurelia, and concluded that in competition for food in a uniform habitat one species will always replace the other, but the winner may be different in different habitats. Gause emphasized the agreement of his experimental results with the mathematical theory of Volterra and Lotka. He concluded in general that 
"Owing to its advantages, mainly a greater value of the coefficient of multiplication, one of the species in a mixed population [in a uniform habitat] drives the other out entirely." He also stated the hypothesis or its converse (but not in the sense of its being original with him) in its essential form several times in his book, as follows: "It is admitted that as a result of competition two similar species scarcely ever occupy similar niches, but displace each other in such a manner that each takes possession of certain peculiar kinds of food and modes of life in which it has an advantage over its competitor" (p. 19); "the equation [of Gause] does not permit of any equilibrium between the competing species occupying the same niche, and leads to the entire displacing of one of them by another .. . both species survive indefinitely only when they occupy different niches in the microcosm in which they have an advantage over their competitors" ( $p .48$ ).

Following Gause's work, laboratory study of this problem with experimental populations increased considerably and continues with strong emphasis currently. Thomas Park and colleagues have made notable contributions to this field for about two decades. Much of this work is summarized in Park 1948, 1954, 1955a, 1955b, and 1957.

Working primarily with the flour beetles Tribolium confusum Duval and $T$. castaneum (Herbst), which competed for the same food in the same habitat (laboratory universe), Park found that one species always displaces the other. The winner, however, is not always the same species. This depends on such characteristics of the habitat as temperature and enemies. Polnik (1960), working with Thomas Park and using Tribolium confusum and Latheticus oryzae Waterh., obtained the same type of results and stated as a generalization, "Laboratory experiments have shown that the end results of such [interspecies] competition is extinction for all but one species, which becomes established."

Crombie $(1945,1946)$ studied competition between different species of graminivorous insects in the same habitat (controlled laboratory universe) and found that, when specific pairs of individuals of different species competed, Rhizopertha sp. eliminated Sitotroga sp., because their larvae had the same needs and habits. But each of these species was able to survive with Oryzaephilus sp. because this species occupied a different ecological niche. But Tribolium sp. eliminated Oryzaephilus sp. except from environments in which the immature stages of the latter were especially protected, and Rhizopertha sp. was able to survive with Tribolium sp. because their needs and habits differed. He found that the biological assumptions on which the Verhulst-Pearl and the Lotka-Volterra equations are based were true for practical purposes for Rhizopertha sp. and Sitotroga sp. populations. But Crombie cautioned (1945, page 362), "It does not follow from this that these equations have any general validity. Their basic assumptions are by no means universally true and, unless they are shown to be so for a particular species under known environmental conditions, no biological deductions can be drawn from them." He concluded that two kinds of organisms will be able to survive together only if they differ in needs and habits, that is, have different ecological niches. He pointed out that in species with identical ecological niches the results of competition may vary with the conditions under which the competition occurs. In 1947, Crombie (see "Literature Cited") presented an excellent review and analysis of the literature on the subject.

Hardin (1960) discussed some of the history, ideas, and implications of the hypothesis that different species having identical ecological niches cannot ccexist for long in the same habitat. $\mathrm{He}$ termed this "the competitive exclusion 
principle" in preference to "Gause's law" or "Grinnell's axiom." Incidentally, Brown (1958) used the term "exclusion principle" with reference to Gause's ideas. We hesitate to accept this name for the hypothesis because the term "principle" implies much more formal verification than has been done, and because the word "exclusion" is misleading and not inclusive enough, while "displacement" as used by Grinnell in 1928 better explains the hypothesis (see page 107 of this textUdvardy, 1959, re: Grinnell). Hardin furnishes much food for thought in his paper and although he advocates the hypothesis he contends that it cannot be proven by empirical facts. We hold that it can, as long as the investigator can determine whether the different species being tested have identical or different ecological niches.

Several authors (Cole, 1960; Van Valen, 1960; Savile, 1960; McIntosh, 1961) responded to Hardin (1960), some in rebuttal and some in affirmation. Interesting arguments were raised and points made, but much of the discussion was a continuation of the battle of semantics. Cole (1960, page 348 ) apparently attached little importance to the question of whether ecological niches are identical or different, for he states as a more general principle than "competitive exclusion" that "no two species can remain sympatric indefinitely whether or not they compete." His use of the term "indefinitely" makes it impractical to test this hypothesis since no time limit can be placed on the test. All biologists recognize, however, that certain sympatric noncompeting species coexist over lengthy, even geologic, periods of time. One thing is clear; more investigation is needed, particularly of field populations backed up by laboratory studies.

Aside from some of the comments of Cole (1960) and Savile (1960), other authors have questioned various aspects of the hypothesis. Andrewartha and Birch (1954) rather thoroughly re- viewed the literature on the mathematical theory of Lotka-Volterra, on the controlled laboratory experiments involving mixed species populations competing for the same food in the same habitat, and on the recorded cases in nature of presumed or possible replacement of one species by another having an identical ecological niche. Of that portion of the Lotka-Volterra equations in which we are interested they say, "the theory relating to nonpredators contains a fundamental contradiction which invalidates its principal conclusions. Unfortunately, it is especially this branch of the theory that has had a great influence on ecological thought" (page 406); "In many of the experiments done by Gause..., Crombie..., and others, one species, after multiplying for a time, decreased and then eventually died out. By ignoring the limitations to the [mathematical] theory which we have discussed above, it was claimed that these experiments confirmed the hypothesis, which thus came to be widely accepted and to have a great deal of influence on ecological thought. This is unfortunate, for these mathematical models are more likely to mislead than to help in the interpretation of observations and measurements made on natural populations" (page 412). Note, however, that Crombie (1945) pointed out with respect to mathematical models that "unless their biological assumptions are shown to be true of particular organisms under specific environmental conditions such equations can only be regarded as empirical expressions incapable of yielding biological deductions, even though, as Park (1939) has pointed out, they may be useful demographic instruments." We leave it to the mathematicians to settle this controversy, but we would point out that Lotka and Volterra merely formulated in a precise manner essentially what Grinnell had previously concluded as a result of his ecological field studies. Thus, the "failure" of mathematicians to accurately 
describe a natural law does not mean that the law is necessarily wrong.

With regard to laboratory studies of mixed species populations competing for the same food in the same "habitats," Andrewartha and Birch (1954) (after discussing the published studies of Birch, Moore, Park, Gregg and Lutherman, Gause, Crombie, and others) concluded that one species comes eventually to dominate the available space (laboratory habitat), and the other dies out completely, usually after having first increased for a period before beginning to decline. Further, they emphasized that the winner is not always the same. Slight changes in temperature of the experimental universe, for instance, may result in a change in winning species. But even in crowded laboratory experiments, they state, two species may coexist provided that one does not actively harm the other and that the two differ a little in their requirements for food (italics ours). They caution, however, that the laboratory experiments should not be generalized as if they could be related directly to nature and say that "there may be special situations in nature to which they can be related directly; but, in general, any extrapolation to nature should be done with the utmost caution and with full awareness that the experimental models apply to homogeneous media in constant conditions" (page 433). They also emphasize that the laboratory results, and presumably "competition," occur only under crowded conditions. Andrewartha and Birch seem to stress the idea that examples of the competitive displacement hypothesis we are discussing in this paper are rare and unproven in nature, and hence the hypothesis is weakened. They say, "On this whole topic we agree with Mayr..., 'So far there is only scanty direct proof for the assumption that populations are kept in check by competition for space and food" " (page 465).

It must be emphasized that the na- ture of the hypothesis of competitive displacement in ecological homologues makes it difficult to cite actual cases from nature. Although species having identical ecological niches may come together from time to time, it would be fortuitous if an accurate observer were often on hand. As Hairston (1959) says, "If the outcome [of competition] has been the elimination of some species from the system, there would be no way to demonstrate the event, and observations of this sort of outcome have rarely if ever been made in nature, although it is the usual thing in laboratory experiments" (page 414). Obviously, competitive displacement is not as common a phenomenon as are many other population processes, but we consider it to be of fundamental importance, as will be discussed later. However, the converse hypothesis is of general occurrence, is perhaps just as important, and is subject to study in nature in most places with many species. Briefly the converse is that indefinitely coexisting species have different ecological niches.

Exception to the usual laboratory results was claimed by Utida (1953) who first found that when two species of bean weevils of the genus Callosobruchus competed in the same laboratory universe, $C$. quadrimaculatus completely eliminated $C$. chinensis by the fifth generation. However, when a hymenopterous parasite which parasitized the full-grown larvae of both weevil species was added to the complex, the two species of weevils continued to coexist. However, it should be noted that these tests continued for only six generations (that is, two more than were required for extermination when weevils only were tested), and it is quite possible that under the changes induced by the parasite many more generations would have been required for extinction of one weevil species by the other (see also discussion, Andrewartha and Birch, 1954, pages 424-432). This work should be pursued further before 
Utida's conclusion is accepted, namely, that two species having the same food requirements can coexist indefinitely in the same habitat providing their numbers are controlled by parasites or predators.

\section{Previous Field Studies}

The above brief review of laboratory experiments involving populations of two species competing in the same "habitat" strongly suggests that under controlled conditions the competitive displacement hypothesis always holds for ecological homologues or that, for the converse hypothesis, if coexistence of species occurs, ecological niches are different. What evidence is there from nature? Perhaps Polnik (1960) summarizes the whole case in the statement: "Competition [between species for the same food in the same habitat] in natural populations ... has been largely inferred, because of the difficulty of obtaining adequate data in the field." Also Elton and Miller (1954, page 476) say that "The field evidence about true interspecific competition is so slender that it only amounts to a few examples that seem to follow the lines of . . . laboratory experiments."

Various authors including Darwin (1859), Gause (1934), Lack (1944), Crombie (1945), Andrewartha and Birch (1954, page 457), Elton and Miller (1954), and Elton (1958) have cited examples of an invading species replacing another, often closely related, species in the field. However, the mechanism of replacement remains unexplained and it was not determined whether the competing species were ecological homologues requiring exactly the same food and/or place in which to live, although this may have been assumed. These cases include the replacement, according to Darwin (1859, page 76 ), of one species of rat by another in various climates, of the small Asiatic cockroach by its great congener in Russia, and of one species of charlock by another. Darwin says, "We can dimly see why the competition should be most severe between allied forms, which fill nearly the same place in the economy of nature; but probably in no one case could we precisely say why one species has been victorious over another in the great battle of life." Gause (1934, pages 21-22) mentioned cases of introduced carp apparently in the process of displacing other species of fish in Russia and in the United States. A definite case of complete displacement occurred in Russia whenever the long-legged crayfish, Potamobius leptodactylus Esch., was introduced into or invaded waters inhabited by the broad-legged crayfish, Potamobius astacus L. Crombie (1945) gives the well-known examples of the formerly common indigenous red squirrel, Sciurus vulgaris, being displaced in parts of Britain by the introduced gray squirrel, $S$. carolinensis, and of the black rat, Rattus rattus, being displaced in the temperate areas of Europe by the brown rat, $R$. norvegicus. Lack (1944) has reported several examples in birds. Of particular interest is the movement of the curlew, Numerius arquata, northward in Europe where it is displacing the whimbrel, $N$. phaeolus, and the concurrent movement of the whimbrel southward where it is displacing the curlew.

Andrewartha and Birch (1954, page 457) record the replacement of the Mediterranean fruit fly, Ceratitis capitata (Weidemann), around Sydney, Australia by the Queensland fruit fly, Dacus tryoni (Froggatt). They cite the finding of Mayne and Young that "When the two species, Plasmodium malariae and $P$. vivax, are injected into man, only one of them is said to persist." Other examples are discussed, a notable one being credited to Beauchamp and Ullyott, who reported concerning two planarians. When Planaria montenegrina is the only species in a stream, it is found in water ranging in temperature from $6.6^{\circ}$ to $17^{\circ} \mathrm{C}$; when $P$. gonocephala is the only species in the stream, its range is from $8.5^{\circ}$ to about 
$20^{\circ} \mathrm{C}$. However, when they occur in the same stream, $P$. montenegrina is found in water below $13^{\circ} \mathrm{C}$ and $P$. gonocephala is found in water above $13^{\circ} \mathrm{C}$. Thus each reduces the potential range of distribution of the other, and Beauchamp and Ullyott concluded that interspecific competition was responsible.

Elton (1958, pages 118-20) discusses a case of competition both for space and food-that of the slipper limpet, Crepidula sp., with the English oyster in Essex oyster beds. The limpet greatly reduces oyster populations but whether complete replacement would eventually occur and, if so, why is uncertain. More apropos, perhaps, in the case (Elton, 1958 , pages $120-22$ ) of the two species of wheat stem sawflies, both of which develop in the wheat stem, which invaded the northeastern United States in the 1880's. In eastern Pennsylvania the European wheat stem sawfly gradually displaced the invading black grain stem sawfly, so that today they have adjacent ranges with only a narrow band of overlap.

Connell (1961) referred to the work of Beauchamp and Ullyott and of Endean, Kenny, and Stephenson as illustrative of the effect of interspecific competition on the range of distribution of a species. In addition, he showed that the two species of barnacles, Chthamalus stellatus (Poli) and Balanus balanoides (L.), in the intertidal zone, occupied essentially separate zones. It was shown, however, by observation and experiment that $C$. stellatus would populate the $\boldsymbol{B}$. balanoides zone if $\boldsymbol{B}$. balanoides were removed; hence competition for space, and not physical factors, regulated the lower limit of distribution of $C$. stellatus.

The senior author is now accumulating data on a case of what appears to be competitive displacement of one species of scale insect by another in southern California. The yellow seale, Aonidiella citrina (Coquillet), was once common and generally distributed on citrus and other host plants in south- ern California; somewhat later, the very closely related California red scale, Aonidiella aurantii (Maskell), was accidentally introduced and for many years (at least 60 to 70 ) both were common, sometimes mixed in the same district and sometimes apparently occurring alone. Over the years, the California red scale gradually became distributed throughout nearly the total range of the yellow scale in southern California, and infestations of yellow scale declined. Since the yellow scale had vanished in test plots under observation for the past 10 years, it seemed possible that competitive displacement of yellow scale by its ecological homologue, California red scale, might have occurred and might have been more general. This supposition was verified by records of identifications of scale insects from the entomologists of the State Department of Agriculture and from the County Agricultural Commissioners' offices in southern California. These records were based on thousands of manhours of field inspection and many hundreds of collections. In areas where the California red scale had already invaded, the yellow scale had not been found since 1955 or, in some areas, even earlier. In some localized districts which had not been invaded by the California red scale (except perhaps recently) because of rigid quarantine precautions, careful field inspections, and eradication of incipient infestations, the yellow scale was still reported.

The displacement-which appears to be complete-of yellow scale in areas invaded by red scale over a period of many years, cannot be attributed to the use of insecticides or parasites. The same insecticides used for control of red scale fail to eradicate yellow scale in areas where the latter scale occurs alone, and, of course, no case is known of insect parasites eradicating their host over such a large and varied area as southern California. Climatic causes are ruled out because the yellow scale flourished for at least 50 to 60 years 
and still does in certain districts as yet uninvaded by the red scale. Competitive displacement of the yellow scale by the red scale appears to be the answer. The red scalc is an ecological homologue of the yellow scale in that its habits and food requirements completely overlap those of the yellow scale. For many years these two were thought to be the same species and could not be distinguished morphologically. Red scale, which occurs on the woody twigs and branches as well as on the leaves and fruit of citrus trees, has a broader niche than yellow scale, which occurs only on the leaves and fruit. Thus, the yellow scale is not an exact ecological homologue of the red scale and would not be expected to displace the latter even if the yellow scale were biologically superior to the red scale in a particular habitat or on a given tree.

There was apparently no real shortage of food to account for the displacement of yellow scale by red scale, and competition must have been limited to a completely nonaggressive search for sites in which to settle, feed, and grow, since these scales become sessile within 24 hours after the newly hatched larvae settle down to feed. These two scales have occurred together at one time or another in hundreds of thousands of acres of citrus groves, but because of insecticide usage or parasites, have only occasionally increased to the point of heavy infestation. Nevertheless, one appears to have displaced the other without any aggressive action whatsoever and without any apparent shortage of food. It is also of interest that, in the senior author's observations in many other countries, the yellow scale was common only where the California red scale did not occur or was a recent invader.

After reviewing many of the previously cited cases of displacement of one species by another (which by the very nature of the competitive displacement hypothesis cannot be expected to be numerous), Andrewartha and Birch (1954) state, "Whether in any of these cases the result may be properly attributed to a shortage of some essential resource [that is, competitive displacement in ecological homologues] or to direct interference of one species by another still remains to be found out" (page 458). In addition, they say, "If it were at all usual for the invading species to cause the extinction of the old-established ones, then one might have expected to hear more about it. On the contrary, the examples given below stand out as being rather unusual. In none of them has it been demonstrated that food or any other essential resource was in short supply, and for several of them the reverse is strongly indicated" (page 457). As the present authors have already pointed out, such rarity is to be expected. Note that Andrewartha and Birch stress that food must be in short supply for "competition" (Andrewartha and Birch would eliminate this term) to occur. We would emphasize that food scarcity or abundance is completely relative. If two species in the same habitat require exactly the same food they may be considered to be competing for that food, and, whether it is abundant or not, the success of one species in finding and eating it adversely affects the other species.

Thus, their conclusion does not hold that there was no "competition" involved in the replacement near Sydney, Australia, of one fruit fly, Ceratitis capitata, by another, Dacus tryoni, because there was no shortage of food (fruits) for the fruit flies. They predicated "some other explanation which has not yet been discovered."

Is the converse principle that "closely related species which coexist indefinitely in the same habitat have different ecological niches" supported by studies of natural populations? There seems to be more substantiation for this. Again, Andrewartha and Birch (1954) review many of the pertinent published cases, but first state a priori, "when two spe- 
cies which seem alike in their requirements are apparently living together, a search is made for some difference in their requirements or habits. Naturally [our italics], such a search is almost always successful" (page 456). Support of the converse hypothesis is evident from their conclusion that "closely related species of birds either live in different sorts of places or else use different sorts of food" (page 462). According to Polnik (1960, page 44), Tribolium confusum and Latheticus oryzae (which will not coexist in the same small laboratory universe) usually are found together in flour mills in the midwestern and southern United States, but $T$. confusum favors the upper portions of flour, while $L$. oryzae is more generally distributed, appearing to favor the bottom. She states, "it would seem that in mills these species do not come into severe competition." In other words, they may not have identical ecological niches or, if they do, they occupy habitats which overlap only in part. According to Elton and Miller (1954), Trägårdh in Sweden found that although nine species of pine bark beetles could occur in one tree, each had a particular ecological niche either in time or place. Gause (1934, page 19) states that "two similar species scarcely ever occupy similar niches, ${ }^{2}$ but displace each other in such a manner that each takes possession of certain peculiar kinds of food and modes of life in which it has an advantage over its competitor." He cites (pages 19-20) A. N. Formosov regarding four closely related species of terns, Sterna spp., which live and nest together in a definite region of a small island in the Black Sea; their interests do not clash at all because each hunts and obtains different food in different areas.

Although the studies just cited record coexistence between species which are not ecological homologues, other studies present another side of the story. Some remarks of Lawson (1958) and Kuenzler (1958) might be taken to indicate that certain of the closely related species studied by them had identical ecological niches, yet coexisted. Actually, information is not presented to show that any of the species had truly identical niches. Kuenzler studied three closely related species of wolf spiders, Lycosa spp., which live in the same sandy coastal habitats in South Carolina. He found one species to be separated ecologically from the other two by vertical stratification but stated that "the exact differences in the niches of $L$. timugua and $L$. carolinensis are not apparent from this study." Thus, this case remains an open question. Lawson studied natural enemies of hornworms on tobacco in North Carolina and stated (1958, page 519) that, "Except for the two species of Polistes, no two enemies occupy precisely the same niche in the hornworm life history. Stilt bugs attack eggs; wasps attack larvae. Tachinids oviposit on very large hornworms in the last instar and emerge from the pupae. $A$. [Apanteles] congregatus oviposits in the first three instars and emerges from the fourth and fifth. The two wasp predators are closely related species, have similar abilities, and occupy nearly the same niche." This, too, remains an open question because Lawson is referring to "the same niche in the hornworm life history" but not to the entire ecological niche of either species of Polistes. The species may have different alternate foods (prey), for example.

Andrewartha and Birch (1960, pages 228-232) take "Gause's law" to task as "to say the least an oversimplification. A growing number of ecologists is becoming unwilling to accept the so-called law as a general principle of natural population." They then discuss several examples which presumably deny "Gause's law." Only one-Ross' study of the distribution and abundance of

\footnotetext{
${ }^{2}$ Gause's definition of niche (1934, page 19) is "what place the given species occupies in a community, i.e., what are its habits, food, and mode of life."
} 
six related species of leafhoppers on sycamore trees in Illinois-seems apropos. They quote Ross to the effect that all six species appear to have identical niches; the generations of the various species mature synchronously in each locality; they hibernate together and feed in the same manner, often side by side on the same leaf. The authors say Ross found no indication that leafhoppers increased to the extent that they ran short of food or space or that one species in any way influenced the abundance of the others. This is definitely a challenge to any blind acceptance of the competitive displacement hypothesis and this case should be thoroughly studied, particularly to determine the exact ecological niche of each species involved. However, note that just previously we have referred to the case of four closely related species of terns living and nesting together, which without detailed study could easily have been assumed to have had identical ecological niches but which did not (Gause, 1934, pages 19-20). The nine species of bark beetles living on the same trees were found to have different niches (Elton and Miller, 1954). The leafhoppers would not have identical niches if they had different alternate host plants but had been brought together on the sycamore by recent migration, or if they fed primarily on different portions of the sycamore tree or even on different portions of the same leaves.

Similar, cases of the coexistence of different species of insects which apparently have identical ecological niches could undoubtedly be multiplied manyfold by a large number of entomologists. In the senior author's experience with insects of citrus trees, it is common to find several species of mealybugs, or several species of scale insects, aphids, or phytophagous mites living on the same trees, sometimes on the same fruit, leaves or twigs. Whether any of these have identical niches is an open question, but some would certainly appear to have from casual observation. However, we simply do not have the necessary detailed information to answer one way or the other. Assuming species with identical niches were occurring on the same tree, then immigration from alternate host plants or from habitats suitable to only one or the other species must be considered. If no regular immigration was involved, was the coexistence due to a recent accidental introduction, and how long then would it continue? Questions of this nature must be answered by critical study before any coexisting species can be assumed to have identical ecological niches.

\section{COMPETITIVE DISPLACEMENT BETWEEN SPECIES OF APHYTIS IN THE FIELD}

\section{General Observations}

The studies reported here were made on three closely related species of the genus Aphytis (Hymenoptera: Aphelinidae) which are minute ectoparasitic wasps (parasitoids) attacking the California red scale, Áonidiella aurantii (Maskell), in southern California. These species include Aphytis chrysomphali (Mercet), established about 1900; Aphytis lingnanensis Compere, established in 1948; and Aphytis melinus
DeBach, established in 1957. In addition, two endoparasites of the same scale, Comperiella bifasciata Howard, established in 1941, and Prospaltella perniciosi Tower, established in 1948, which are part of the same faunal complex, were studied. Other species of red scale parasites are rare and unimportant.

As parasites of the California red scale, the three species of Aphytis have identical ecological niches. This fact does not conflict with the hypothesis of 
competitive displacement because these species originally had widely separated geographical distributions in nature. As far as we know, $A$. lingnanensis is native to South China and surrounding countries, $A$. melinus to India and Pakistan, and $A$. chrysomphali probably to the Mediterranean area. Each has a simple and virtually identical life cycle. The adult oviposits externally on the body of the scale beneath the scale covering. The larva feeds as an ectoparasite by piercing the host body with its mandibles. Nearly all the body contents are consumed and pupation occurs beneath the scale covering. The adult wasp emerges after approximately 14 to 18 days at $80^{\circ} \mathrm{F}$. We know of no differences in their requisites or essential habits, and intensive studies have been made of the biology and ecology of each. The adults can be distinguished one from another only microscopically and by an expert. Each species parasitizes the same stages (2nd and 3rd instars) of the host, each host-feeds as an adult, that is, requires body fluids of the host for continued egg production, and each feeds additionally as an adult on nectar or honeydew secreted by coccids. The larvae of all three, which feed solely on the scale body, have exactly the same requirements and habits, and are so similar in appearance as to be indistinguishable - at least by us-one from the other. However, the pupae can fairly easily be distinguished. No evidence of aggressive action between adults has ever been observed. Larvae are usually solitary but two or more may develop on the same scale in the field, thus indicating little aggressive action. To our knowledge, in the area under consideration, the needs, habits, and actions of individuals of one species are identical with those of the others, except, perhaps, for a minor difference in the case of $A$. chrysomphati.

One alternate scale host is known in southern California, the oleander scale, Aspidiotus hederae (Vallot), but this scale is scarce by comparison with the
California red scale and usually does not occur on citrus, except occasionally on lemons. Studies in large citrus groves, where it has been known that no oleander scale occurred nearby, virtually preclude the consideration of this scale as a factor appreciably influencing the interactions of these three parasite populations. In any event both Aphytis lingnanensis and A. melinus readily attack this scale, so neither would appear to have an advantage. However, Aphytis chrysomphali rarely attacks oleander scale in the field, so that, in localized spots with large oleander scale populations, A. melinus and/or A. lingnanensis would have an advantage and would be able to persist if $A$. chrysomphali otherwise had the advantage on the main host, the California red scale.

Except for this, the differences between Aphytis chrysomphali and the other parasites are physiological, that is, they vary somewhat in such things as rate of development, longevity, fertility, and tolerance to temperature and humidity. The species do not cross and, in fact, $A$. chrysomphati is uniparental-females giving rise to females.

The endoparasites, Comperiella bifasciata (Chinese strain) and Prospaltella perniciosi (Oriental strain), are limited to the California red scale as a host in southern California, but they do not have exactly the same ecological niche as the three Aphytis species. This is not necessarily because they are endoparasites, but because they can attack and develop in somewhat different stages of the scale-in the second and third molts as well as instars-as opposed to the Aphytis species which are restricted to the second and third instars. (See page 147, Species Having Different Ecological Niches.) Inasmuch as all host developmental stages are represented in a California red scale population at any given time, the different stages-molts and instars-can be thought of as constituting different host "species." Theoretically, as long as 
their searching ability is adequate (see Nicholson, 1933), they have different ecological niches, and can tolerate the climate, either internal parasite should be able to coexist with the Aphytis species; that this is actually the case in certain field locations will be shown later.

\section{Field Studies}

Status of Aphytis chrysomphali Before 1948. Previous to 1948 Aphytis chrysomphali was the only species of Aphytis parasitic on the California red scale, Aonidiella aurantii, in California. Aphytis chrysomphati was an accidental immigrant which became established about 1900. Originally thought to have come from the Orient, it is probably of Mediterranean origin. Little notice was taken of it in early years, but scattered records indicate that, by the early 1920's at least, it was generally distributed in southern California citrus areas infested with red scale. When the senior author's studies of the red scale and its natural enemies began in 1947, it was confirmed by field collection and laboratory identification of reared adult parasites that $A$. chrysomphali occurred in all red-scale-infested citrus areas from San Diego to Santa Barbara and inland to the Riverside-San Bernardino area. Its abundance varied in different areas from very common to scarce. It was definitely more successful in the milder climates of the coastal areas and, in fact, was found to be responsible for regulation of host scale populations at very low levels in certain citrus groves, that is, to be effecting successful biological control (DeBach, Fleschner, and Dietrick, 1953). Its distribution in 1948 is shown in figure 1 . There is no reason to believe that this distribution had not been essentially the same since its initial establishment and dispersal or that its distribution had varied previously over a period of years, or that it would have changed in the future barring major environmental changes.

Aphytis lingnanensis vs. Aphytis chrysomphali, 1948 to 1961. In 1948, a new species of Aphytis was obtained in shipments of natural enemies of the California red scale from South China. At first this was thought to be $A$. chrysomphali, which it closely resembles, but differences in pupal coloration and the presence of males (which $A$. chrysomphali lacks) led to its culture and designation as Aphytis "A." Later it was described as the new species, Aphytis lingnanensis Compere.

Aphytis lingnanensis was cultured in large numbers in the insectary and thoroughly colonized from 1948 to 1950 throughout the areas in which $A$. chrysomphati was already established. Although several million $A$. linganensis were colonized, this represented but a small fraction of the generally established $A$. chrysomphali population. For instance, a survey by the senior author (unpublished data) of 48 Los Angeles County citrus groves in mid-1951 showed $A$. lingnanensis to be present in six groves only (having been colonized in these 1 or 2 years previously); the other 42 groves contained $A$. chrysomphali exclusively. Thus, it is clear that $A$. chrysomphali was not initially overwhelmed by the colonization of large numbers of $A$. lingnanensis. The relative progress and abundance of $A$. lingnanensis with respect to $A$. chrysomphali was followed in detail in a rather large number of citrus groves involving several hundred acres from 1949 through 1953, and less intensively in a lesser number thereafter until the present time. Initially, comparisons of two types were made regarding relative success of each species. In one type, equal numbers of $A$. chrysomphali and A. lingnanensis were colonized in adjacent plots in the same grove, which had virtually no parasite population at the start. In the other, $A$. lingnanensis was colonized in plots where $A$. chrysomphali was already established in moderate to heavy populations. The results of these studies up through 1953 have been published in 


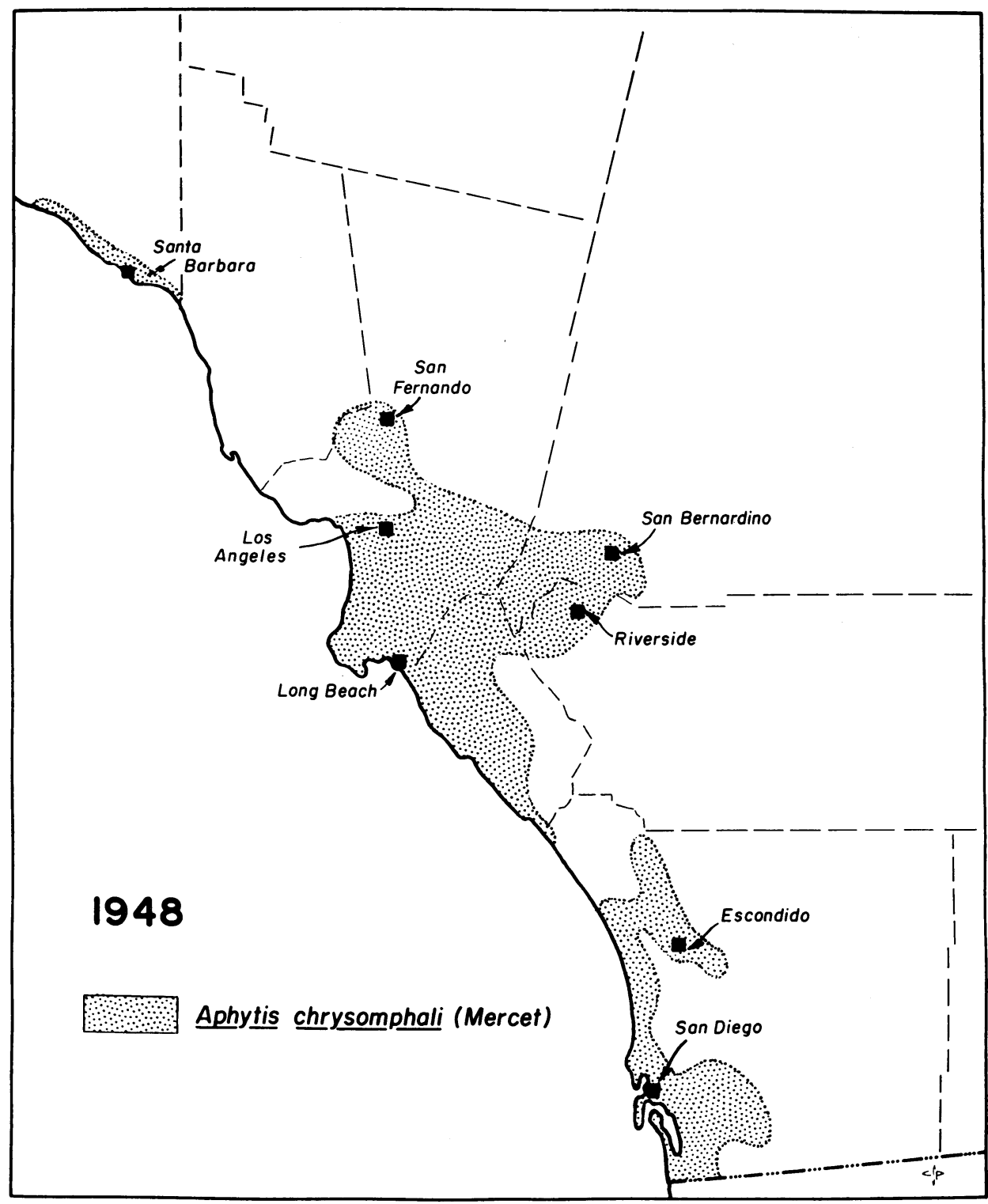

Figure 1. The distribution of Aphytis chrysomphali (Mercet) in citrus-growing areas of southern California in 1948. Semischematic. Illustration by C. S. Papp.

some detail (DeBach, 1954), and it was stated that "Unless very unusual conditions should favor $[A$.$] chrysomphati$ over "A" [=lingnanensis], it appears that $[A$.$] chrysomphali would ulti-$ mately become extremely rare in citrus groves."

Briefly, the data showed the following: (1) When equal numbers of each species were colonized in adjacent plots in citrus groves previously lacking parasites, A. lingnanensis (=Aphytis "A") spread from its plots so rapidly that in one year it constituted over $80 \%$ of the parasites in the original $A$. chrysomphati plots. (2) When A. lingnanensis was colonized during an initial period only (during part of one year) in 
field plots already having well-established populations of $A$. chrysomphali, $A$. lingnanensis generally became quite dominant (in 13 plots of 17) in the colonization area within one year (average, $70 \% A$. lingnanensis). Seven of 21 plots showed complete (100\%) replacement of $A$. chrysomphali by $A$. lingnanensis within 2 years. After 4 years, A. lingnanensis constituted an average of at least $95 \%$ of the total parasite population for all plots studied. This occurred in spite of the fact that the surrounding areas were still more or less strong sources of A. chrysomphati, except perhaps in interior citrus areas, where $A$. lingnanensis virtually eliminated $A$. chrysomphali from all plots within one year and spread into adjacent acreages rather rapidly. (3) Intensity of colonization influenced the rate at which $A$. lingnanensis attained dominance over $A$. chrysomphali, but, even with colonizations which were very light compared to the established $A$. chrysomphali populations, A. lingnanensis became dominant ( $65 \%$ of total) at the end of the second year. When the colonization of $A$. lingnanensis was medium, it constituted $77 \%$ of the total parasite population at the end of the first year. (4) Rate of dispersal of $A$. lingnanensis was relatively slow. An appreciable population movement covered only about an average of 10 tree rows per year. (5) Laboratory studies indicated that in most respects $A$. lingnanensis, as contrasted with $A$. chrysomphali, possessed superior intrinsic biological and physiological capabilities, such as higher fecundity and greater longevity.

As time went on, Aphytis lingnanensis became more and more dominant in most areas (apparently displacing $A$. chrysomphali almost completely in interior citrus areas by 1957 or 1958), but somewhat contrary to earlier expectations, $A$. chrysomphali was found to remain dominant during the period 1948 to 1955 , or later, in certain localized groves or areas in mild climatic zones along the immediate coast. However, these cases of localized dominance

TABLE 1

RELATIVE POPULATIONS OF APHYTIS CHRYSOMPHALI AND A. LINGNANENSIS DURING 1958 AND 1959 IN SOUTHERN CALIFORNIA ${ }^{1}$

\begin{tabular}{|c|c|c|c|c|}
\hline \multirow{2}{*}{ Area } & \multicolumn{2}{|c|}{1958} & \multicolumn{2}{|c|}{1959} \\
\hline & \multicolumn{2}{|c|}{ A. chrysomphali vs. A. lingnanensis } & \multicolumn{2}{|c|}{ A. chrysomphali vs. A. lingnanensis } \\
\hline & \multicolumn{2}{|c|}{ per cent } & \multicolumn{2}{|c|}{ per cent } \\
\hline Santa Barbara County... & 85 & 15 & 0 & 100 \\
\hline \multicolumn{5}{|l|}{ Los Angeles County: } \\
\hline San Fernando Valley. . & trace & 99.8 & 0 & 100 \\
\hline Pomona-Claremont....... & 5 & 95 & -2 & - \\
\hline Pasadena-Azusa-Puente.............. & 0 & 100 & - & - \\
\hline Los Angeles........................ & 26 & 74 & 0 & 100 \\
\hline Orange County ................. & 96 & 4 & 7 & 93 \\
\hline San Bernardino County .............. & 0 & 100 & 0 & 100 \\
\hline Riverside County ................... & trace & 99.9 & 0 & 100 \\
\hline \multicolumn{5}{|l|}{ San Diego County: } \\
\hline La Jolla-San Diego-Chula Vista. . & - & - & 0 & 100 \\
\hline El Cajon-La Mesa . . . . . . . . . . . . . . & - & - & 0 & 100 \\
\hline Del Mar-San Luis Rey-Oceanside- & & & & \\
\hline Rancho Santa Fe.................. & 36 & 64 & present & present \\
\hline Fallbrook-Escondido-San Pasqual. ..... & 40 & 60 & 6 & 96 \\
\hline
\end{tabular}

1 These data were obtained by collecting samples of the California red scale from unsprayed citrus trees in the field and rearing out the adult parasites in the laboratory where they were counted and mounted on slides; the proportion of the two species was then determined by microscopic examination. The number of samples taken and the sample sizes the two species was then determined by microscopic examination. The number of samples taken and the sample sizes varied from locality to locality according to the availability of scale infestations. Usually from several to 20 or more samples wew to one hundred or more. Most of the percentage figures for a given locality in the table are based on one-hundred to several hundred parasites. Totals considered to be inadequate were not included. It is emphasized that these data are given primarily for the purpose of presenting trends, that other data and observations not included here support these trends, but that the figures for any given locality may not be entirely accurate.

$2 \mathrm{~A}$ dash indicates insufficient data. 
gradually disappeared. Table 1 shows the proportions of these two species in various areas in 1958 and 1959. It is evident that $A$. chrysomphali decreased considerably from 1958 to 1959 . Continued decrease is illustrated by the facts that during a 2-year period, 1960 and 1961, A. chrysomphali was found only in (1) the Del Mar-Oceanside-San Luis Rey-Rancho Santa Fe area of San Diego County (32\% A. chrysomphati); (2) the Fallbrook-Escondido-San Pasqual area of San Diego County $(6 \%$ A. chrysomphali); and (3) the coastal strip of Orange County ( $14 \%$ A. chrysomphali in 1960; none in 1961).

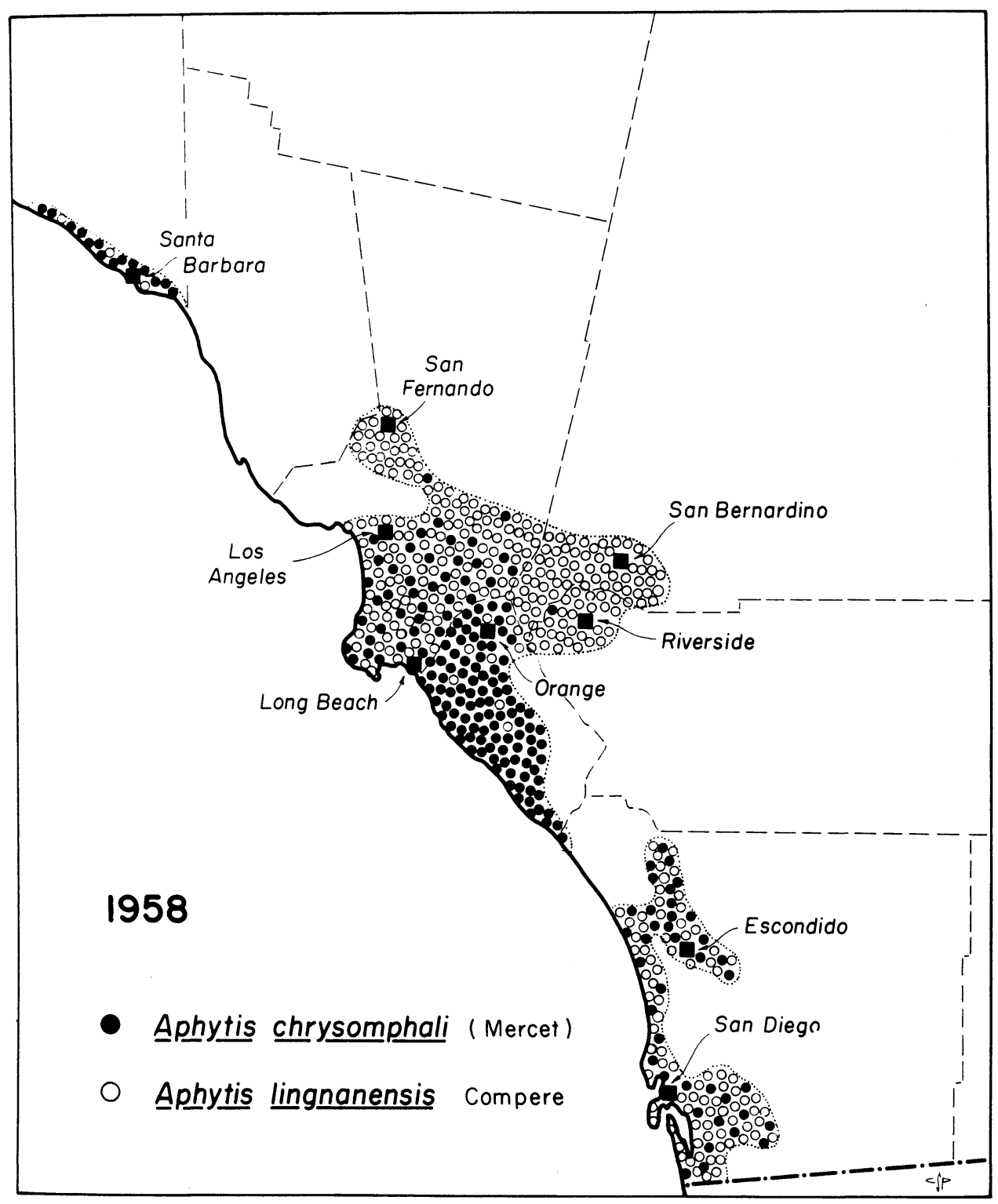

Figure 2. The distribution and relative abundance of Aphytis chrysomphali (Mercet) and Aphytis lingnanensis Compere in citrus-growing areas of southern California in 1958. Semischematic. Illustration by C. S. Papp. 


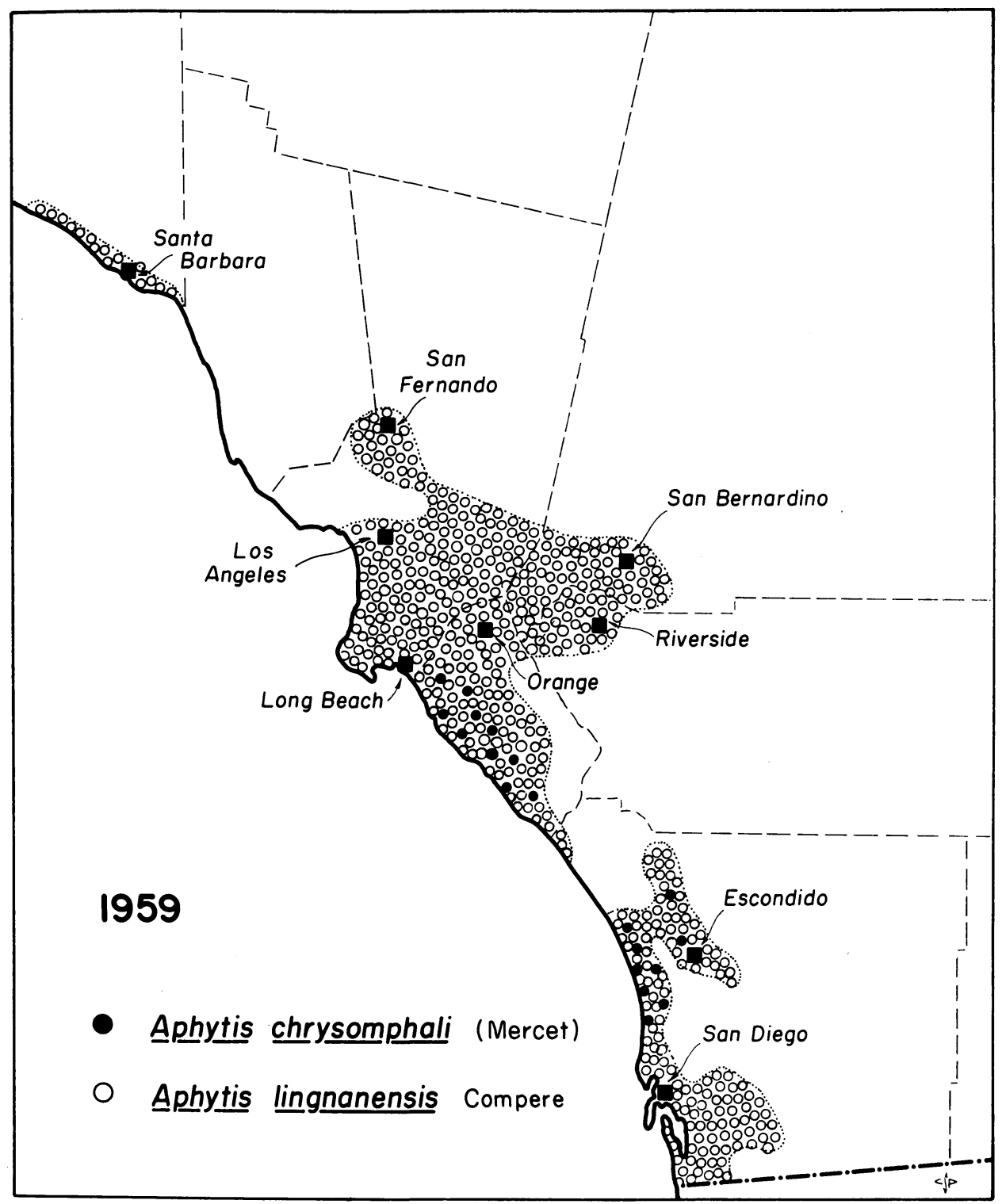

Figure 3. The distribution and relative abundance of Aphytis chrysomphali (Mercet) and Aphytis lingnanensis Compere in citrus-growing areas of southern California in 1959. Semischematic. Mlustration by C. S. Papp.

Figures 2 and 3 , derived from table 1 , show the reduced distribution of Aphytis chrysomphali with respect to $A$. lingnanensis by 1958 and 1959. By comparison with figure 1 , it can be seen that the distribution of $A$. chrysomphali became greatly restricted. As just mentioned, it became even more restricted in 1960 to
1961. Inasmuch as A. melinus was just becoming established during the 1958 to 1959 period, particularly in interior areas where $A$. chrysomphali had virtually disappeared, the decline and virtual disappearance of $A$. chrysomphali must be attributed predominantly to competition with $A$. lingnanensis. 
Laboratory experiments were planned to help explain the apparent paradox of the continued dominance of $A$. chrysomphali in certain restricted coastal sites during the 1948 to 1958 period (DeBach and Sisojevié, 1960). It was known from previous laboratory and field studies that the observed differences in abundance of $A$. chrysomphali relative to $A$. lingnanensis in different localities were not caused by other predators or parasites. Host abundance should not have been a factor because no obvious changes in host density were noticed during this period and both species of Aphytis have demonstrated their ability to exist in very low host population densities. The only logical factors which remained to influence the relative abundance of the two species were (1) meteorological factors, and (2) competition between $A$. lingnanensis and $A$. chrysomphali for the host.

Laboratory tests were made with both species to determine the effect of various temperatures as well as of intra- and interspecific competition on progeny production. These studies (DeBach and Sisojević, 1960) showed that $A$. lingnanensis possessed strong biological advantages (as measured by progeny production) over $A$. chrysomphali at the high temperatures of $77^{\circ}$ $\mathrm{F}$ and $87^{\circ} \mathrm{F}$ but that $A$. chrysomphali appeared to have equal or slightly more advantages at the relatively low temperature of $67^{\circ} \mathrm{F}$. Insofar as these constant temperatures were an index to field conditions, the laboratory studies indicated that $A$. chrysomphali might be a little better adapted to certain cool coastal areas, but that $A$. lingnanensis would be better adapted to the majority of southern California environmental conditions. These results agreed with the then known distribution and abundance of the two species in the field.

In tests on intraspecific competition, Aphytis chrysomphali showed relatively slight decreases in progeny production in response to density increase as compared to the decreases exhibited by $A$. lingnanensis. However, in tests on interspecific competition, progeny production by $A$. lingnanensis was overwhelmingly greater than that by $A$. chrysomphali, except in certain cases at the low constant temperature of $67^{\circ} \mathrm{F}$. Again, the results indicate that $A$. chrysomphati is at its best biologically and $A$. lingnanensis at its poorest at the low constant temperature $\left(67^{\circ} \mathrm{F}\right)$, and the greater success of $A$. chrysomphali with respect to $A$. lingnanensis in certain restricted coastal localities was correlated with low mean temperatures. Inasmuch as later field studies (1958 to 1961) indicated that $A$. chrysomphali was gradually decreasing in these same localities, we are again faced with an apparent paradox. The following discussion of results in the Santa Barbara area may help to explain it.

Rather curious results were obtained in the Santa Barbara area, where the biological eapabilities of $A$. lingnanensis and $A$. chrysomphali apparently are very evenly matched and as a consequence seasonal or yearly climatic variations may reverse the tendency of one to displace the other. For instance, following its colonization in 1948 and 1949, A. lingnanensis became dominant in our study plots rather rapidly, then in 1951 to $1952, A$. chrysomphali came back very strongly and virtually eliminated $A$. lingnanensis in the one plot we were checking carefully. $A$. chrysomphali also was commonly found elsewhere. In 1957 to 1958 A. chrysomphali was the most common species recovered (about $80 \%$ A. chrysomphali) in several collections, but finally, during 1959, 1960, and 1961, only A. lingnanensis was recovered. This brings to mind Park's results with flour beetles, where, with two competing species, the winner was always clear-cut and predictable under given environmental conditions-principally temperatureat either end of a range, but with intermediate environmental conditions the abilities of the two species were so 
nearly identical that the winning species appeared to be due to chance. Apparently, the competition between $A$. lingnanensis and $A$. chrysomphali in coastal localities represents a similar situation.

Aphytis melinus vs. Aphytis lingnanensis, 1957 to 1961. In 1956 and 1957, another new species, Aphytis melinus DeBach, parasitic on the California red scale, was imported from India and West Pakistan. In its native areas $A$. melinus survives rather large annual climatic fluctuations resembling those of the interior citrus areas of southern California. In Rawalpindi, Pakistan, for instance, where A. melinus is rather common, winter temperatures fall a few degrees below freezing from time to time, and summer temperatures rise to $110^{\circ} \mathrm{F}$ or higher on occasion. Because of this, there was hope that $A$. melinus might be better adapted to the interior areas of southern California than $A$. lingnanensis which came originally from the less variable climatic area of South China. Although $A$. lingnanensis had nearly replaced $A$. chrysomphali as a parasite of the California red scale in interior citrus areas by 1958 , it had not effected satisfactory biological control of the scale. The principal reason was that $A$. lingnanensis lacked sufficient tolerance to low winter temperatures and high summer temperatures, which periodically caused great reductions in the parasite populations (DeBach, Fisher, and Landi, 1955).

Field colonizations of Aphytis melinus began in the second half of 1957 and were greatly intensified in 1958 and 1959. Approximately two and onehalf million. mated female parasites were colonized during this period in some 140 plots distributed throughout all major citrus areas of southern California having red scale infestations. Recoveries of $A$. melinus which had completed one or more generations in the field were made very soon and in many places. It was quickly evident that $A$. melinus was showing the greatest rate of population increase and dispersal we had thus far witnessed for a species of Aphytis in interior areas. Recoveries from coastal area plots were not nearly as good, and population increase and dispersal were not as marked. Somewhat surprisingly, no $A$. melinus recoveries whatsoever were obtained from San Diego County plots (coastal and intermediate-coastal environments) even though more parasites were colonized here than in any other county. According to DeBach and Landi (1959), "The fact that we obtained a much higher proportion of recoveries from the San Joaquin Valley [interior area] and [southern] interior area plots than from coastal area plots does not necessarily mean that the physical environment is responsible for this. The proportion and abundance of recoveries correlates very closely with the abundance of already established natural enemies in the colonization plots.

"In the coastal counties, natural enemies were noted as already being common to abundant in every colonization plot we obtained; hence, competition for the new parasites was extreme.

"In the San Joaquin Valley counties, already established natural enemies were rated as being from absent to rare in nearly every plot obtained; hence, competition was virtually nil and the new parasites obtained a good foothold in nearly every case.

"In the [southern] interior areas, already established natural enemies were rated as being from scarce to common in most plots; hence, competition was frequently a factor and the proportion of recoveries reflects this." They go on to say, however, that "Regardless of the proportion of recoveries from plots in the various areas, if a newly introduced species of Aphytis has significant biological advantages over an established species, such as a higher reproductive capacity and a better tolerance to temperature extremes, the new one should supplant the 
old one sooner or later and the result should be an increase in the amount of natural mortality of the red scale."

Each of the species of Aphytis studied here apparently had biological advantages in certain areas. Through 1961 only three individuals of Aphytis melinus were recovered in any of the original San Diego County colonization areas, but in 1961 it was commonly found in the interior, isolated area of Pauma Valley. Apparently A. lingnanensis, which previously had become thoroughly established and highly efficient over most of the San Diego County area, was so well adapted to the local climate that it precluded the establishment of A. melinus. A. chrysomphati apparently produced the same initial effect in the restricted coastal localities in which it was still dominant in 1957 and 1958. There appears to be nothing about the climate of this area to directly preclude the establishment of A. melinus. All our knowledge and evidence would indicate that the climate was decidedly favorable for $A$. melinus. Thus, this is apparently a good example of species having identical ecological niches being unable to coexist. Similar results were obtained in the Santa Barbara area, except that $A$. melinus was recovered in fair numbers from several plots following its colonization in 1957 and 1958. It was rare, however, by 1960. None of this species was recovered during 1961 (table 2).

It will be recalled from table 1 and figure 2 that by 1958 Aphytis lingnanensis had virtually displaced $A$. chrysomphali in the interior eitrus areas of southern California, such as the San Fernando Valley and the San Bernardino-Riverside areas. In most intermediate areas, $A$. chrysomphali was greatly reduced. In most groves it could no longer be found or, at best, only a rare specimen was recovered. A. chrysomphali remained common only in a few restricted coastal sites. Thus, as an ecological homologue, $A$. melinus was competing primarily with pure $A$. ling- nanensis populations in nearly all localities.

By the end of 1958, Aphytis melinus was the only Aphytis species recovered in some of the first $A$. melinus colonization plots in the Riverside-San Bernardino area which previously contained $A$. lingnanensis populations. Thus, competitive displacement of $A$. lingnanensis by $A$. melinus occurred within about one year, or 8 to 9 generations, in the immediate environs of some colonization plots. The general progress of $A$. melinus relative to $A$. lingnanensis in various areas from 1959 to 1961 is recorded in table 2 . This table indicates that $A$. melinus is rapidly replacing $A$. lingnanensis in the interior areas of Riverside County, San Bernardino County, and in the San Fernando Valley of Los Angeles. However, $A$. melinus gives no evidence as vet of displacing $A$. lingnanensis in intermediate or coastal areas. Not shown by table 2 is the fact that $A$. melinus is currently (1961) invading areas (such as Fullerton in Orange County and Simi in Ventura County, among others) in which it was not colonized and where $A$. lingnanensis (and in some cases, $A$. chrysomphali) had usually been thoroughly established and was abundant.

The movement of $A$. melinus in the Simi area just mentioned constitutes a striking example of invasion and displacement. The Simi Valley in Ventura County is separated from the San Fernando Valley of Los Angeles County, about 10 miles away, by a barrier of barren high hills. This would appear to be quite a "desert" for an Aphytis species to eross. We established two test plots in untreated citrus groves near Simi early in 1960 to evaluate the possibility of successful biological control of California red scale in that area. Previously this area had been in a "red-scale eradication district" where insecticides were applied intensively; hence, no red scale parasites had ever been colonized here. Initial samples showed that Aphytis lignanensis had 
TABLE 2

RELATIVE POPULATIONS OF APHYTIS LINGNANENSIS AND A. MELINUS DURING 1959, 1960, AND 1961 IN SOUTHERN CALIFORNIA ${ }^{1}$

\begin{tabular}{|c|c|c|c|c|c|c|}
\hline \multirow{2}{*}{ Area } & \multicolumn{2}{|c|}{1959} & \multicolumn{2}{|c|}{1960} & \multicolumn{2}{|c|}{1961} \\
\hline & $\begin{array}{l}\text { A. ling- } \\
\text { nanensis vs. }\end{array}$ & $\begin{array}{l}\text { A. mel- } \\
\text { inus }\end{array}$ & $\begin{array}{l}\text { A. ling- } \\
\text { nanensis vs. }\end{array}$ & $\begin{array}{l}\text { A. mel- } \\
\text { inus }\end{array}$ & $\begin{array}{l}\text { A. ling- } \\
\text { nanensis vs }\end{array}$ & $\begin{array}{l}\text { A. mel- } \\
\text { inus }\end{array}$ \\
\hline & \multicolumn{2}{|c|}{ per cent } & \multicolumn{2}{|c|}{ per cent } & \multicolumn{2}{|c|}{ per cent } \\
\hline Santa Barbara County. & 100 & 0 & 95 & 5 & 100 & 0 \\
\hline \multicolumn{7}{|l|}{ Los Angeles County: } \\
\hline San Fernando Valley ................ & 50 & 50 & 6 & 94 & 4 & 96 \\
\hline Pomona-Claremont................ & \multicolumn{6}{|c|}{ ( 89 per cent $A$. melinus for the total three-year period) } \\
\hline Pasadena-Azusa-Puente ............. & -2 & $-\quad \mid 1010$ & 87 & 13 & - & - \\
\hline Long Beach. ............... & - & - & 93 & 7 & - & - \\
\hline Los Angeles .............. & - & - & 60 & 40 & 88 & 12 \\
\hline Orange County $\ldots \ldots \ldots \ldots \ldots \ldots \ldots \ldots$ & 38 & 62 & 82 & 18 & 65 & 35 \\
\hline San Bernardino County ................ & 20 & 80 & 1 & 99 & - & - \\
\hline Riverside County................... & 29 & 71 & 4 & 96 & 2 & 98 \\
\hline \multicolumn{7}{|l|}{ San Diego County: } \\
\hline Pauma Valley.... & - & - & - & - & 72 & 28 \\
\hline Oceanside........ & 100 & 0 & 100 & 0 & 99 & 1 \\
\hline All other San Diego County areas......... & 100 & 0 & 100 & 0 & 100 & 0 \\
\hline
\end{tabular}

1 See table 1 , footnote 1 , page 120 , for explanation of sampling techniques.

$2 \mathrm{~A}$ dash indicates insufficient data.

not invaded the Simi area from the nearby San Fernando Valley even though it had been common in the San Fernando area for about 10 years (1948 to 1958 ), that is, until $A$. melinus was colonized there. Initially, therefore, in 1960 A. chrysomphali was the dominant parasite in the Simi plots; however, that year a few $A$. melinus were taken, showing that this species had dispersed here naturally within only 2 years from the San Fernando Valley. Periodic colonizations were made-at least at first-of $A$. lingnanensis (a selected climate-tolerant strain) in one test plot and of $A$. melinus in the other. By early 1961, A. melinus, as might have been expected, had completely replaced $A$. chrysomphali in its own colonization plot. Surprisingly, by mid-1961, $A$. melinus had also replaced $A$. lingnanensis in the plot where $A$. lingnanensis had been heavily colonized throughout 1950 and where there had been only a low naturally occurring population of A. melinus to start with.

The ultimate distribution and abundance, relative to each other, of the three species of Aphytis must await further passage of time. Their general distribution and relative abundance in 1961 is shown in figure 4. This figure is based on the raw data, summarized in table 2, for A. lingnanensis and $A$. melinus and on data obtained for $A$. chrysomphali in the same manner, time, and place, although this latter is not included in the text or tables. It would appear that $A$. melinus will further restrict the distribution of $A$. lingnanensis and that ultimately $A$. chrysomphali may disappear from southern California. However, whether a given species will be completely and permanently excluded from a particular area is a moot question. For instance, the existence of microhabitats more suitable for species "X," within areas generally more suitable for species "Y," may appear to enable " $\mathrm{X}$ " to coexist with "Y." Also, the continuous possibility of artificial dispersal in populous southern California, such as by movement of infested plants by humans, can result in the introduction of a small pocket of one species at any particular moment into an otherwise pure population of the other. Also, we can never be quite sure of extinction in an area, because of the improbability of detecting the 


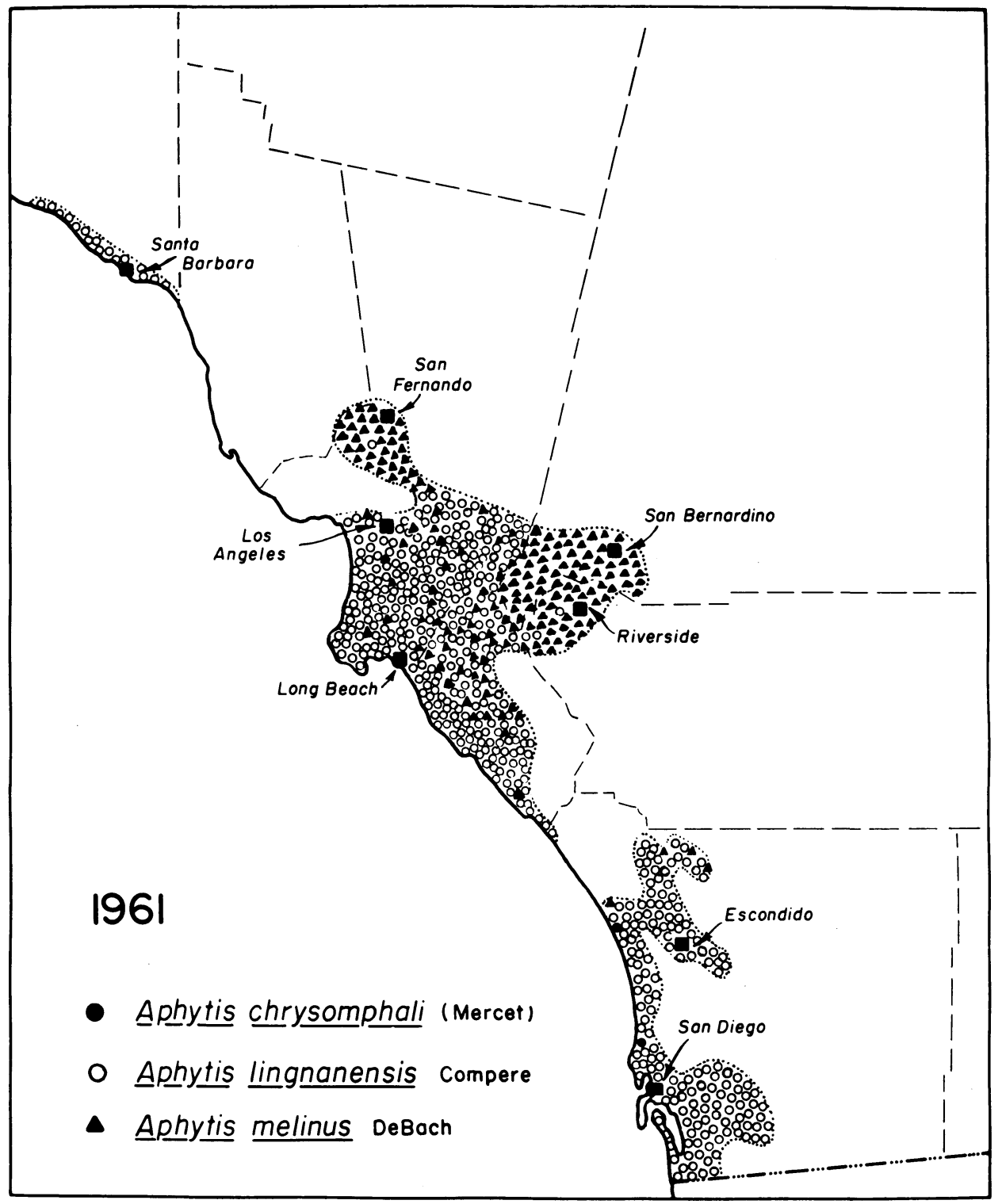

Figure 4. The distribution and relative abundance of Aphytis chrysomphali (Mercet) and Aphytis lingnanensis Compere with respect to Aphytis melinus DeBach in citrus-growing areas of southern California in 1961. Semischematic. Illustration by C. S. Papp.

presence of one individual of one species in one hundred thousand or in one million individuals of another species when that individual has to be collected at random and detected by microscopic examination of slides. 


\section{Coexistence of Comperiella bifasciata and Prospaltella perniciosi with Aphytis Species in the Field}

It was pointed out on pages 117 to 118 that although Comperiella bifasciata Howard and Prospaltella perniciosi Tower parasitize the same host species as the Aphytis species do, the former parasites do not have exactly the same ecological niche as the Aphytis species because they utilize somewhat different stages of the host. Where climatic conditions are suitable to them, they coexist with the Aphytis species and, to a lesser degree, with each other.

Both laboratory studies and field observations indicate that Comperiella bifasciata is better adapted to interior or intermediate climatic areas, whereas Prospaltella perniciosi is more commonly taken in coastal areas. Occasionally, $P$. perniciosi is found to be the most common parasite present in a sample, especially in coastal sites of San Diego County, which have also been remaining strongholds of Aphytis chrysomphali. However, substantial populations of $C$. bifasciata and, to a lesser extent, of $P$. perniciosi coexist with $A$. lingnanensis in the intermediate climatic areas of San Diego County. Because most study plots have been located in interior areas where $C$. bifasciata commonly occurred with the Aphytis species, and $P$. perniciosi was scarce, this discussion will emphasize the coexistence of $C$. bifasciata and Aphytis species. The following account based on careful monthly population studies in one plot in the Riverside area for the past 13 years will illustrate this.

Comperiella bifasciata was colonized in the Riverside area in 1941 but did not become generally distributed until about 1947. Following the establishment of Aphytis lingnanensis in 1948, C. bifasciata remained of secondary importance as a parasite of the California red scale, but was easily found and sometimes locally abundant. Then, in 1957 to $1958, A$. melinus was established. By 1961 it virtually displaced $A$. lingnanensis but not $C$. bifasciata, even though the latter is a less effective parasite of the red scale than $A$. lingnanensis is. Thus, we have the curious phenomenon of the best parasite displacing the previously best parasite but not, however, displacing the poorest one.

The possibility remains that Aphytis melinus may eventually displace $C$ omperiella bifasciata, if $A$. melinus proves to be efficient enough to reduce populations of the California red scale to such a low level that $C$. bifasciata cannot successfully find hosts.

\section{Laboratory Studies on Interspecies Competition Among Three Species of Aphytis, Comperiella bifasciata, and Prospaltella perniciosi}

\section{Species Having Identical Ecological Niches}

The Species' Biological Characteristics. The three species of Aphytis used in these experiments are all biparental, with a sex ratio of approximately 60 females to 40 males when oleander scale on lemon is used as host material. These and other biological characteristics are shown in table 3 . Such data are necessary in order to help evaluate the results of intra- and interspecific competition. According to DeBach and White (1960), the more favorable the host scale and the environment during oviposition, the greater the proportion of females to males. This is because environmental stimuli determine whether the egg is fertilized by a sperm from the spermatheca during egg laying. Fertilized eggs become females, unfertilized eggs, males. With Aphytis lingnanensis, as many as 9 fe- 
TABLE 3

BIOLOGICAL CHARACTERISTICS OF THREE APHYTIS SPECIES REARED ON OLEANDER SCALE ${ }^{1}$

\begin{tabular}{|c|c|c|c|}
\hline Characteristic & A. lingnanensis & A. fisheri & A. melinus \\
\hline 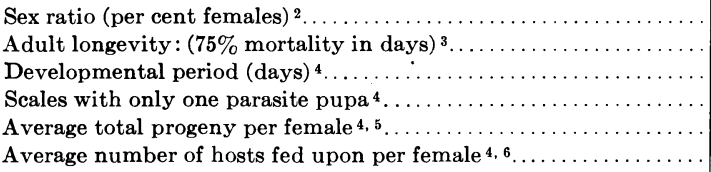 & $\begin{array}{l}63.4 \% \\
25 \\
13-14 \\
87.6 \% \\
31.8 \\
44.6\end{array}$ & $\begin{array}{l}61.9 \% \\
33 \\
13-14 \\
62.3 \% \\
25.9 \\
28.3\end{array}$ & $\begin{array}{l}62.6 \% \\
26 \\
12-13 \\
55.8 \% \\
24.1 \\
31.4\end{array}$ \\
\hline
\end{tabular}

$180^{\circ} \pm 2{ }^{\circ} \mathrm{F}$ and $50 \pm 5 \% \mathrm{RH}$.

2 Four mated females per infested lemon-10 replicates each for each species. Therefore approximately 1,000 males and females were obtained to determine the sex-ratio figure for each species.

3 The number of days given here refers to the period required for $75 \%$ mortality to occur. Therefore, the higher the figure (days) in the table, the greater the longevity. These figures were found to furnish the best comparison for relative longevity between species. Adults were fed honey during these tests but no hosts were available for oviposition.

4 Figures for each species based on 30 replicates; in each a single female was confined with a single lemon infested with
4 . 4 Figures for each species based on 30 replicates; in each a single female was confined with a single lemon infested with
approximately 250 scales. After 12 days the surviving females were transferred to new infested lemons for continued

5 Based on number of progeny reaching the pupal stage. Referred to elsewhere in text as potential fecundity, or some-
viposition. Previous studies have shown this method to produce statistically reliable results. 5 Based on number of progeny reaching the pupal stage. Referred to elsewhere in text as potential fecundity, or some-
times as actual fecundity. These tests were conducted under nearly ideal conditions; thus production of pupal progeny times as actual fecundity. These tests were conducted under nearly ideal conditions; thus production of pupal progeny
is virtually identical with actual fecundity, and actual fecundity is a good index of the relative inherent fecundities of

${ }_{6}$ This mortality of the host is in addition to that caused by parasitism, that is, by progeny production. Host-feeding is necessary to provide proteins for continued egg production.

males to 1 male have been obtained with oleander scale on banana squash as host material. The sex ratio during the current experiments indicates that the conditions for production of females were not as favorable as it may be possible to obtain, but the sex ratio was higher than that found for $A$. lingnanensis on the California red scale in the field, which is about 50:50 (DeBach and Sisojevic, 1960).

The searching ability of the species in these tests could hardly be evaluated because hosts were readily available in the confines of the laboratory universe. Relative searching ability between species could, however, account for differences in their success in the field, as will be discussed later. Hence, some attempts were made to determine if differences in searching ability existed between the three species of Aphytis.

A unit with a glass top and bottom for observation was developed, in which females were allowed to search for "hosts" at various densities. The females compared in different tests were always of the same age and were kept under the same environmental conditions, before and during experiments. No host plant was used in the searching unit in order that searching could be better observed on a plane surface. Scales were carefully removed from lemons and fastened to the lower surface of the glass top of the cage. In addition to this normal host, artificial "scales," such as sand grains and glass beads, were present. Different experiments were carried out with from 2 to 10 scales, sometimes placed near each other, sometimes far apart. Only 1 female parasite was tested at a given time. During the first day of adult life no searching was observed, regardless of the presence or absence of scales. Later a typical searching pattern emerged, in which running was interspersed with occasional short flights. The search seemed to be largely at random since the parasites very often came back to the same place. The females, being negatively geotropic and positively phototropic under this condition of confinement, spent most of the time at the top of the eage where the "hosts" were placed. The scales usually were found after a few minutes, and in most cases examination and oviposition followed. The real, as well as the artificial scales, were found and virtually the total area was covered in the search. The parasite females seemed to perceive the scales from a distance of about $1 \mathrm{~cm}$. When 


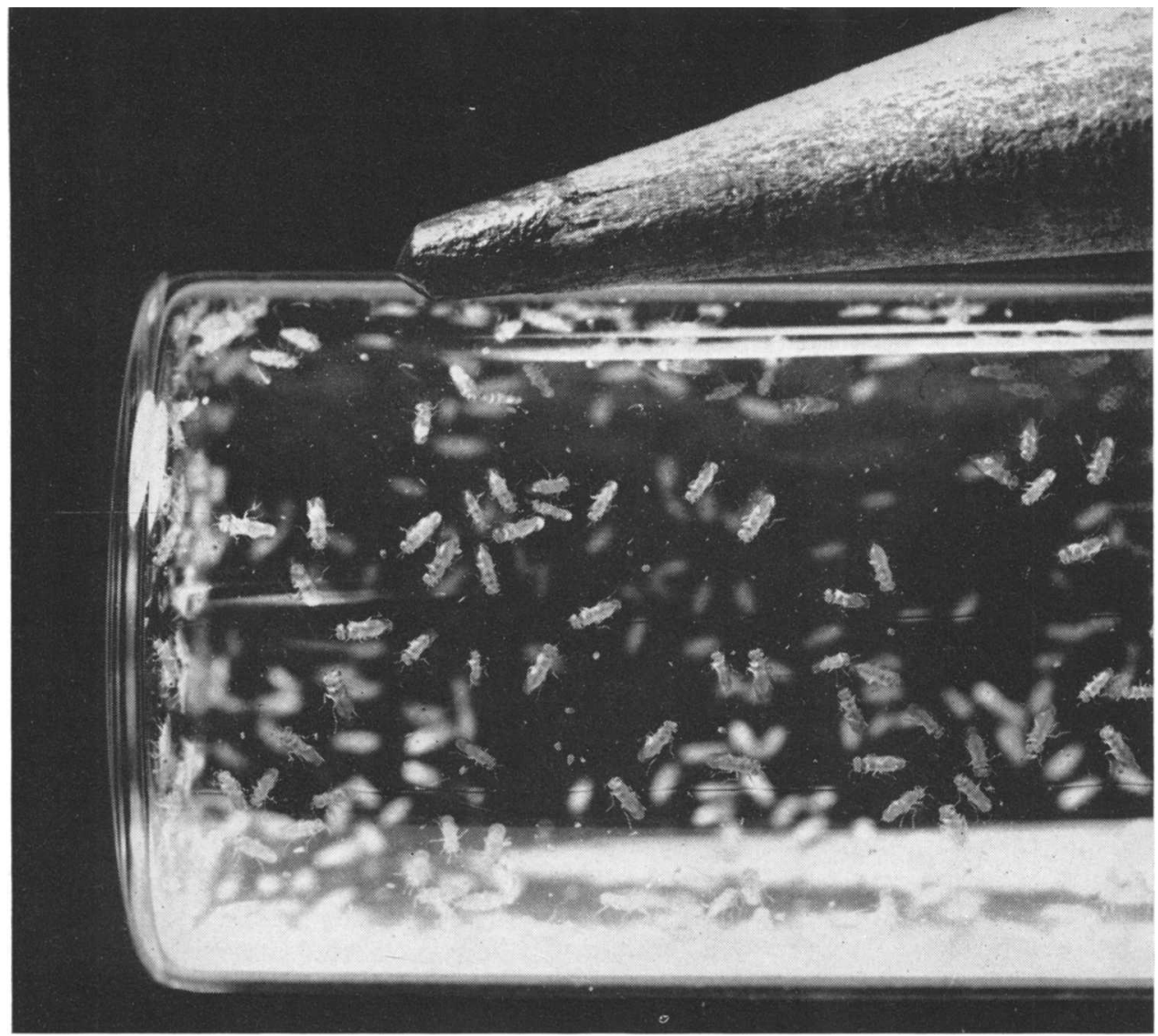

Figure 5. Aphytis lingnanensis individuals within a glass vial. The pencil point at the top illustrates the minute size of these parasites.

they were this close, the females went right to the object. Several times, glass and gum bubbles, sand grains, and shadows from sand or scales were examined. The females seemed to inspect every object within the surroundings.

The females were able to find odorless, artificial "scales" and they attempted to "sting" or oviposit in them. In the small experimental test cage used, these females were highly efficient searching organisms. No differences were observed among the three species.

Searching activities were apparently the same whether the female was placed in a glass "searching" cage or in contact with a scale-infested host plant. If placed on a lemon or on a leaf bearing 2 scales only, the female usually found the host in less than 2 minutes. Since the surface area here was smaller than that in the cage, a shorter time for host discovery was to be expected. The possibility exists that the odor from the host plant or the scale may stimulate or enhance host finding. Such a conclusion could not be drawn from these experiments.

As is frequently the case with ectoparasitic species, the Aphytis female always paralyzes the host before ovipositing. Usually she stings the scale body twice for paralysis, and these stings last from 1 to 2 minutes. The method of oviposition is similar for the three species, except that the average time spent and number of eggs deposited on each scale are different. 
Larvae of the Aphytis species studied tend to be gregarious, that is, more than one individual may develop per host. It has been shown that Aphytis lepidosaphes Compere usually lays 2 or more eggs per host and that 2 or more adult parasites usually emerge per host (DeBach and Landi, 1961). This commonly occurs also with $A$. melinus in the field. (The gregarious tendency would be expected to correlate with a lack of intraspecies aggressiveness on the part of larvae.) Laboratory observations made during the current study showed that the $A$. lingnanensis female deposits an average of 1.7 eggs per scale during an oviposition period lasting about 5 minutes. For $A$. fisheri DeBach, the figures are 2.7 eggs per scale and $91 / 2$ minutes, and for $A$. melinus, 2.8 eggs and 12 minutes. Thus, both $A$. fisheri and $A$. melinus use fewer scales than $A$. lingnanensis for the same num- ber of eggs laid. All eggs placed on a given host are usually deposited during a single oviposition period. If scales are scarce or most of them are already parasitized, more eggs are placed on each scale. As many as 4 eggs per scale are not unusual for $A$. fisheri and $A$. melinus. Occasionally, 5 or 6 may develop on one oleander scale, but the size of the pupae then is small. Usually the largest pupae are females and the smallest are males.

The developmental period (table 3) from oviposition to adult emergence is about 14 days at $80^{\circ} \mathrm{F}$ for all three species. On infested lemons parasitized during a 4-hour period, all eggs were hatched in just under 3 days. The earliest hatching was noticed for Aphytis melinus. Both the pupae and the adults developed a bit more rapidly in this species. In some tests $A$. melinus adults started to emerge after 12 days and

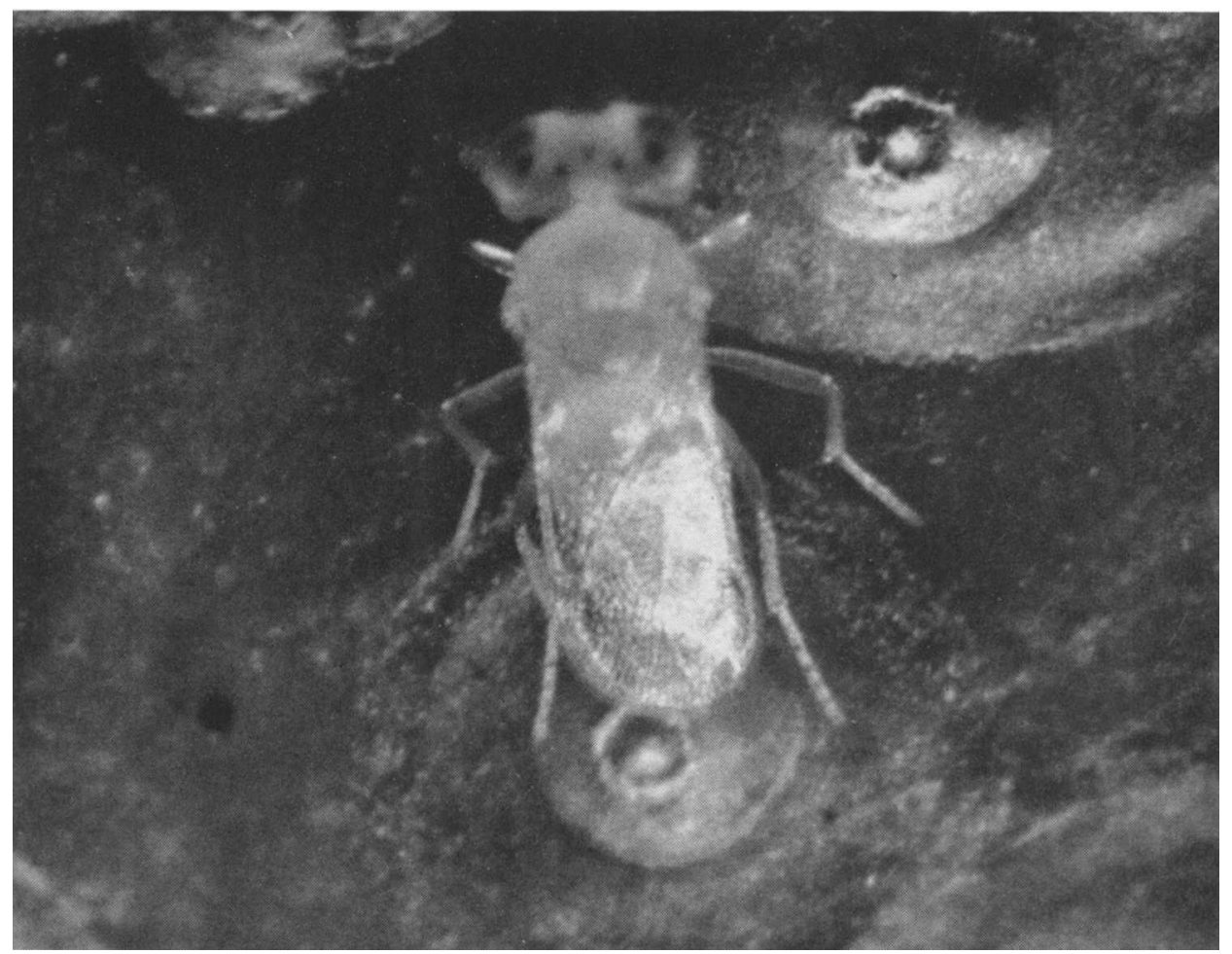

Figure 6. An Aphytis lingnanensis female ovipositing in second-instar stage of California red scale. 
reached their peak emergence on the 13th day. A. fisheri and A. lingnanensis were each about 1 day slower. For all species a few specimens emerged as late as the 17 th day.

Actual fecundity (table 3 ) was indicated by the number of progeny per female parasite which reached the pupal stage. In tests conducted under optimum conditions such as these were, virtually no mortality occurs during development of the immature stages or during emergence of the adult. Thus progeny production is virtually identical with actual fecundity, and actual fecundity is at least a good measure of the relative inherent fecundities of the species tested. One female and one male were isolated on each of 30 infested lemons for 12 days, then, if still alive, they were transferred to new lemons for continued oviposition. An excess of host scales was available. Honey is necessary as food and was available during all tests, but the female parasites also require protein, which they obtained by feeding on the scales. The host-feeding rapidly caused the death of the scales attacked, making them unsuitable sites for progeny production.

In addition to the total number of progeny, the number of pupae per scale and the number of scales killed by hostfeeding were recorded for each species. The tests also showed (table 3) that Aphytis lingnanensis at $80^{\circ} \mathrm{F}$ had the highest progeny production per female (31.8). The two other species with somewhat less, were fairly similar to one another (A. fisheri, 25.9; A. melinus, 24.1). A. lingnanensis had much the highest host-feeding rate and resultant dead hosts. A. fisheri host-fed less than A. melinus, but on the whole the two species were quite similar. The tests showed great individual differences in progeny production among the 30 females of each species used. For A. lingnanensis the highest progeny production was 74 , the lowest, 10. For $A$. fisheri the figures were 73 and 5 , and for A. melinus, 55 and 5.
Table 3 shows, in addition, that both Aphytis fisheri and A. melinus produced, on an average, more pupae per scale than $A$. lingnanensis (that is, they had the fewest scales with only 1 pupa). This could have meant that the average adult of $A$. fisheri and $A$. melinus would be smaller, which would mean that they would lay fewer eggs which would also be smaller. However, when there were 2 pupae per scale, usually one was big and the other small. The big pupa was nearly always a female and the smaller one a male. Additional oviposition tests with $A$. lingnanensis and $A$. fisheri, in which actual numbers of eggs laid were determined, showed that the fecundity of females was the same whether they had developed from scales bearing either 1 or 2 pupae. Since the scale body, at least of oleander scale, usually was not entirely consumed by one larva, there was probably enough food for at least 2 parasites. Thus a low degree of gregariousness (2 to 3 progeny per scale) should not be detrimental.

With a higher number of pupae per scale, the average pupal size definitely will decrease, resulting in smaller females with lower fecundity. During the present experiments, the species with the highest number of pupae per scale (A. melinus and $A$. fisheri) had the lowest fecundity. The cause may have been that there was less food per larva during the developmental period. On the other hand, A. lingnanensis requires a higher proportion of scales for hostfeeding in order to lay its complement of eggs. To compete with the other two species in nature, it might likely need either a higher searching capacity or a higher host density.

Oviposition normally continues from shortly after emergence until death. During the progeny production tests, about half of the females lived longer than 12 days. In longevity tests (table 3 ) the females could not oviposit because hosts were withheld, but honey was continually available as food. The tests showed that Aphytis lingnanensis 


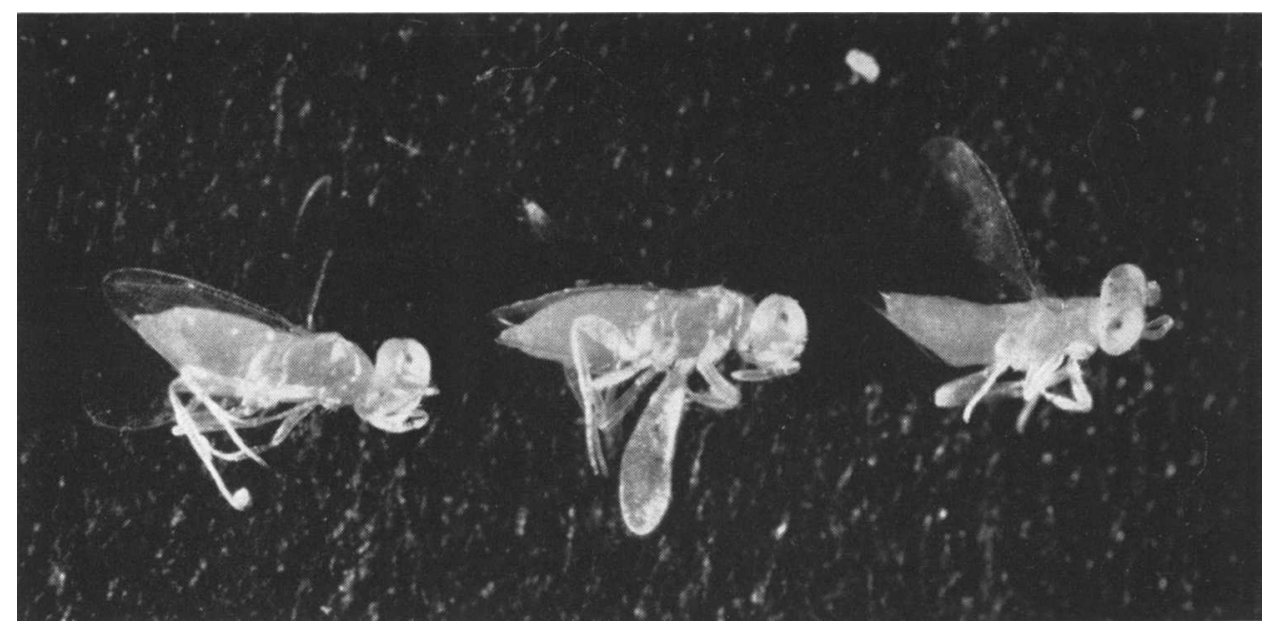

Figure 7. Freshly killed females of three species of Aphytis-from left to right, $A$. fisheri, A. lingnanensis, and A. melinus.

may live as long as 40 days; $A$. fisheri, 45 days; and $A$. melinus, 36 days. Seventy-five per cent mortality was reached after about 25 days for $A$. lingnanensis and $A$. melinus females, but after 33 days for $A$. fisheri.

Single Species Populations (Controls). To learn how the different species populations develop and behave over a period of generations in the laboratory universe, and to explain results in the interspecific cultures, a pure culture of each species was maintained.

The parasites used during the first series of experiments involving ecological homologues were Aphytis lingnanensis, A. fisheri, and A. melinus (figs. 7 and 8). A. fisheri was imported from Burma in 1957 but has failed to become established in the field. All of the species are ectoparasites and attack the California red scale during the second and third instars. This scale species constitutes the only common field host available in the areas of this study although the oleander scale also can be attacked by all three. They are, in general, more easily reared in the laboratory on oleander scale (which. they attack from the second stage on) than on red scale (DeBach and White, 1960). The pupae of the three species are usu- ally easily distinguishable. A. lingnanensis pupae have a dark, well-defined pigmentation on the midthoracic sterna and midventral abdominal plates. $A$. melinus pupae are pigmented on the midthoracic sterna only, while the pupae of. A. fisheri are unpigmented (DeBach, 1959). The adults are predominantly yellow, but $A$. lingnanensis has eryptic dark areas on the thoracic sterna, which the other two lack. Live specimens of A. lingnanensis can be distinguished under magnification by the dark areas, but adult $A$. melinus and $A$. fisheri are very difficult to distinguish from one another. They are sibling species which exhibit complete reproductive isolation. Dry adult specimens were prepared as described by DeBach (1959) before microscopic examination for identification.

The technical procedures followed were planned in order to maintain, as nearly as possible, identical experimental conditions for all species in all tests. The population rearing cages (laboratory universes, fig. 9) were so constructed that new host scale material could be added and old host material removed without removing any of the parasite population. Therefore, continuous culture was possible over an indefinite number of generations, thus re- 


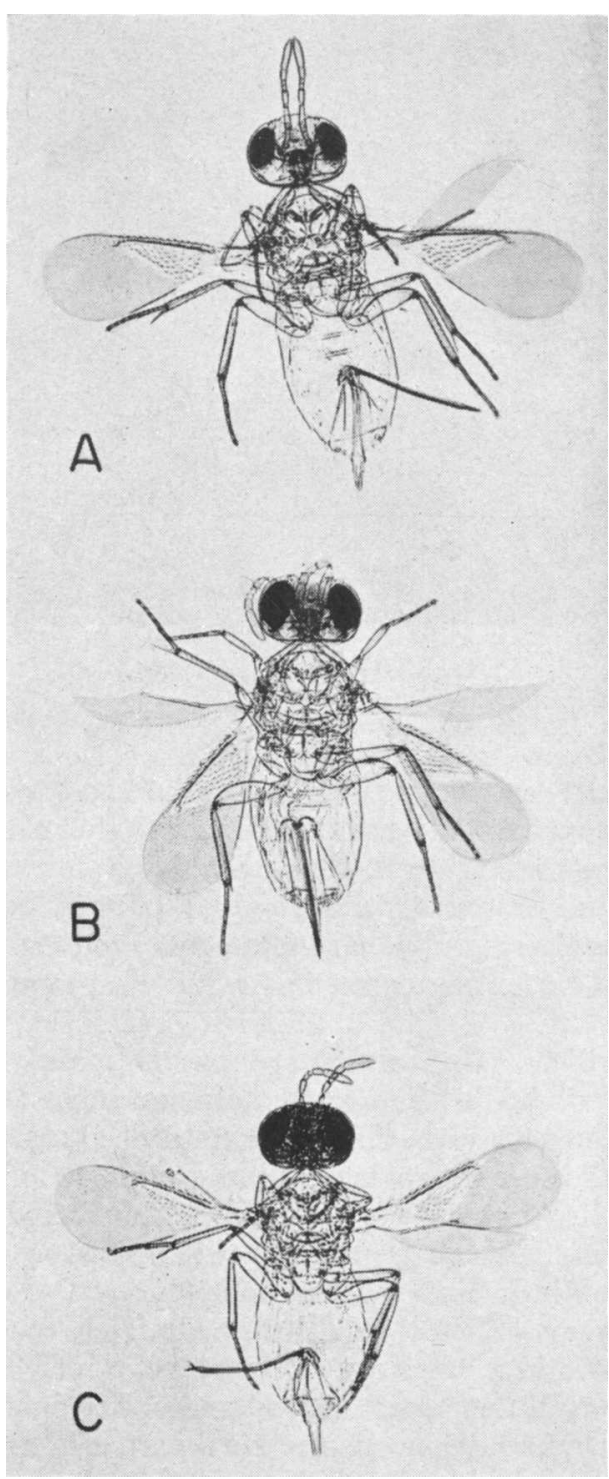

Figure 8. Photomicrographs of females from three species of Aphytis, cleared and mounted in Hoyer's solution, illustrating the striking similarity of certain species within the genus. $\mathrm{A}=$ Aphytis lingnanensis $; \mathrm{B}=$ A. melinus $;$ and $\mathrm{C}=$ A. fisheri.

sembling field conditions in this respect. All experiments were carried on at a temperature of $80 \pm 2^{\circ} \mathrm{F}$ and $50 \pm 5 \%$
RH. The host material used was oleander scale, Aspidiotus hederae (Vallot), on lemon fruit.

Each of the three cultures was started with 50 mated female parasites and 10 scale-infested lemons as host material. Lemons with about 250 scales per fruit were selected in each case, and they were compared between cultures so that each culture would have approximately identical host populations. New infested lemons were added every 14 days in an increasing number to provide adequate host material for each new parasite generation. ${ }^{3}$ While only 10 lemons were added in the first generation, the number had gradually increased to 100 in the 6 th, and to 120 in the 7th and 8th generations. Thus each generation had an abundant host population so that the parasite population could increase to a maximum over a period of at least 8 generations.

Parasitized and unparasitized scales were counted in each generation, that is, about every 17 days over a 19 -week period. In the mixed cultures, the number of scales parasitized by the different species was determined by examination of the cast pupal skins. A sample of about 5,000 scales was examined in each generation except the first, in order to determine the proportion of scales parasitized, live or dead. Also, the dead parasites in the unit were removed each time new lemons were added (approximately each generation), and the total number of females and males was counted. In the mixed cultures where it was possible (that is, except when Aphytis melinus and $A$. fisheri were cultured together), the proportion of adults between the species was also determined as a check against the parasitization counts. Since these agreed quite closely, in general, only the parasitization counts are given in the tables. All cultures were run for 19 weeks, corre-

\footnotetext{
${ }^{3}$ A "generation" is equivalent to a minimum life cycle of 14 days plus a 3 -day oviposition period, although actual generations are not discrete. Each so-called generation actually represents a count which is comprised largely of individuals of one generation, but, since the female oviposits over a period of 10 days or more, subsequent generations overlap more and more.
} 


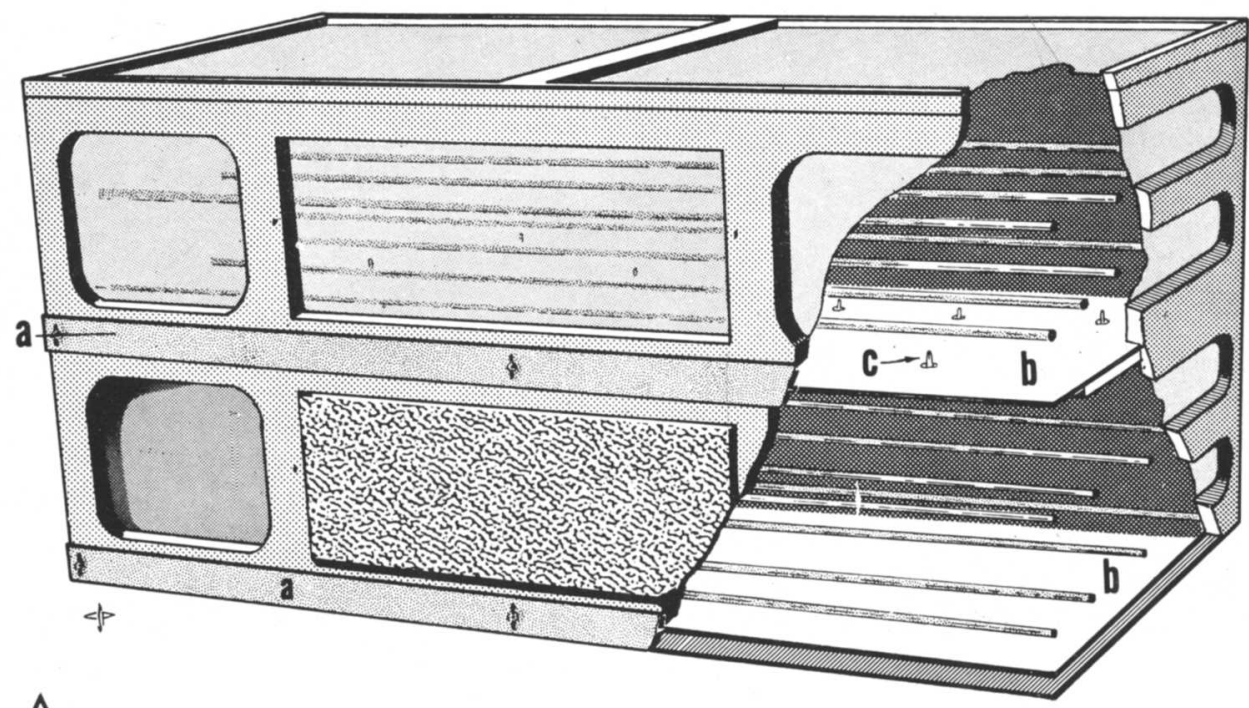

A

Figure 9. Various views of the competitive displacement cage in which self-perpetuating parasite populations may be maintained. The upper unit may be considered as the experimental universe proper; the lower unit is used merely for automatic recovery of the few parasites still developing on old scale-infested lemon fruits which must be replaced by new ones.

A. Diagrammatic drawing showing the floors (b) of the upper and lower units and the holes with loose-fitting, light-conducting lucite plugs (c) through which parasites emerging from the with loose-fitting, light-cond the darkened lower unit are attracted back into the glass-topped upper unit. The external seals (a) may be removed so that a sliding cardboard floor cover may be extracted bearing parasites which are dead or anesthetized for population counts.

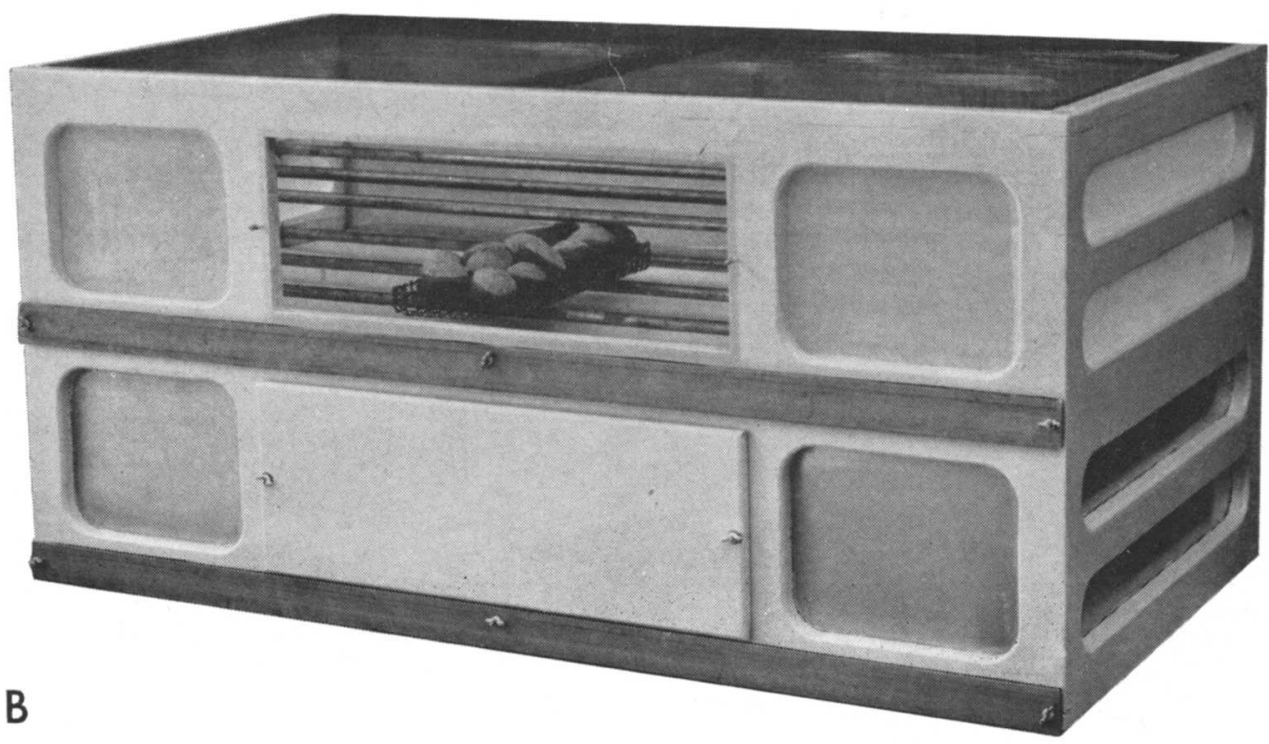

B. Photograph showing how a tray of scale-infested lemons (with bottom half waxed to prevent desiccation) rests on the bars of which there are two tiers. When in full operation, the upper unit is filled with such trays. 


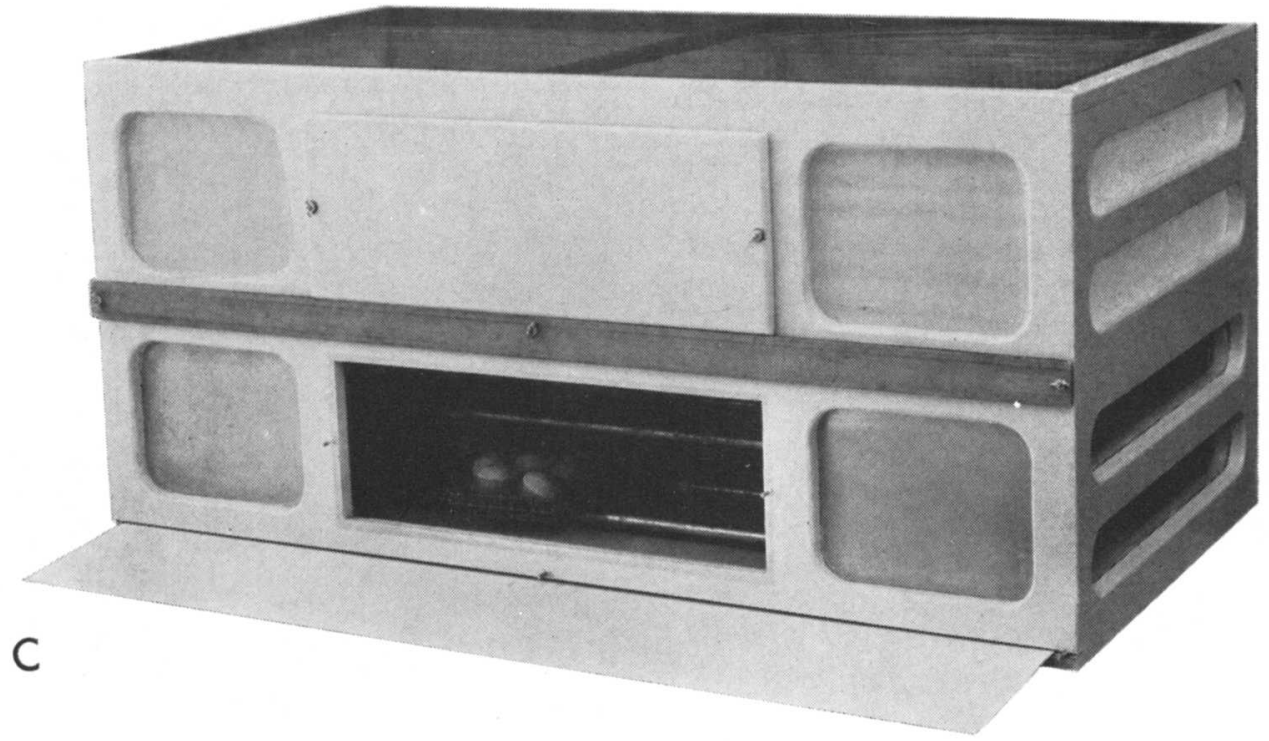

C. Photograph showing a tray of scale-infested lemons in the lower recovery unit, as well as the cardboard floor cover of this unit partially removed.

sponding to 8 generations of about 17 days each (a 14-day life cycle plus 3 day oviposition period). The condensed results are given in table 4 . The number of parasite progeny per generation in these three cultures varied from a low initial population at the end of the first generation to a peak in the 6 th generation in each case.

These results show that Aphytis fisheri attained the highest peak population density of the three species when identical amounts of food (hosts) were available to each, and that $A$. lingna-

TABLE 4

POPULATION TRENDS IN SINGLE-SPECIES CULTURES OF APHYTIS LINGNANENSIS, A. FISHERI, AND A. MELINUS ${ }^{1}$

\begin{tabular}{|c|c|c|c|c|c|c|}
\hline \multirow[b]{2}{*}{$\begin{array}{c}\text { Generation }{ }^{2} \\
\text { number }\end{array}$} & \multicolumn{2}{|c|}{ A. lingnanensis } & \multicolumn{2}{|c|}{ A. fisheri } & \multicolumn{2}{|c|}{ A. melinus } \\
\hline & Population & $\begin{array}{c}\text { Per cent } \\
\text { of scales } \\
\text { parasitized }^{3}\end{array}$ & Population & $\begin{array}{c}\text { Per cent } \\
\text { of scales } \\
\text { parasitized }\end{array}$ & Population & $\begin{array}{c}\text { Per cent } \\
\text { parasitization }\end{array}$ \\
\hline 1. & 110 & 49.1 & 283 & 44.5 & 523 & 21.9 \\
\hline 2. & 2,111 & 73.6 & 4,110 & 78.1 & 1,364 & 23.4 \\
\hline $3 \ldots$ & 5,451 & 54.5 & 8,865 & 67.3 & 3,187 & 51.6 \\
\hline $4 \ldots$ & 2,769 & 16.4 & 4,452 & 42.2 & 6,106 & 47.7 \\
\hline 5. & 8,148 & 44.3 & 9.993 & 43.3 & 12,291 & 49.0 \\
\hline $6 \ldots$ & 15,488 & 39.7 & 21,460 & 48.4 & 15,608 & $\cdot 44.4$ \\
\hline $7 \ldots$ & 7,428 & 20.5 & 14,768 & 38.1 & 15,543 & 42.5 \\
\hline 8. & 9,524 & 44.0 & 19,136 & 55.7 & 11,936 & 43.1 \\
\hline Total......... & 51,029 & $\ldots$ & 83,067 & $\ldots$ & 66,558 & $\ldots$ \\
\hline Average. & 6,379 & 42.8 & 10,383 & 52.7 & 8,320 & 40.5 \\
\hline
\end{tabular}

1 Techniques are described beginning on page 133 . Oleander scale was used as the host. 2 Each "generation" is equivalent to an average life cycle of 14 days plus a 3-day adult oviposition period. Genera-
tions are not discrete. Each so-called generation actually represents a count which is comprised largely of individuals tions are not discrete. Each so-called generation actually represents a count which is comprised largely of individuals
of one generation, but since the female oviposits over a period of 10 days or more, subsequent generations overlap more of one generation, but since the female oviposits over a period of 10 days or more, subsequent generations overlap more
and more.

${ }^{3}$ Per cent parasitization figures are based upon the number of actively parasitized scales divided by the sums of the parasitized scales plus live unparasitized scales. Scales dead from causes such as host-feeding are excluded from these calculations. Note, then, that the parasite populations listed for any given generation cannot be calculated on a theoretical basis from the per cent parasitization figures listed in the table. 
nensis attained the lowest peak density. The average number of parasites produced per generation also was highest for $A$. fisheri $(9,134)$ and lowest for $A$. lingnanensis (6,379). A. melinus was intermediate with an average of 8,320 individuals per generation. These differences are emphasized when the total number of individuals produced is considered. The $A$. fisheri culture produced 83,067 individuals; the $A$. melinus culture, 66,558; and the $A$. lingnanensis culture, only 51,029 . It might seem from these data that $A$. fisheri should have the highest fecundity of the three species and $A$. lingnanensis the lowest, but the progeny production tests (table 3 ) using isolated individuals showed that A. lingnanensis produced more progeny per female (equivalent of fecundity in these tests) than the two other species when an excess of hosts was available.

It might seem strange that in spite of a lower fecundity per female, both Aphytis melinus and $A$. fisheri in pure laboratory cultures carried for a period of 8 generations attained a higher peak population, and also maintained a considerably higher average population and a much greater total population, than $A$. lingnanensis. The reason for this may be ascribed in part to the lower amount of host-feeding by these two species (see table 3), which leaves a higher number (or proportion) of the scales available for parasite oviposition and progeny production. Another advantage for these two species appears to be a greater number of pupae per scale. If the host population is limited, less host-feeding and more progeny per scale would give $A$. fisheri and A. melinus advantages over $A$. lingnanensis, which would likely result in higher population densities. But when hosts are plentiful, as in the experiments reported in table 3, A. lingnanensis evidently would have the advantage.

The differences in population densities between the Aphytis fisheri and $A$. melinus cultures were not as marked and the reasons for the differences not as apparent. A. melinus had a slightly higher average number of pupae per scale, but host-fed a little more than $A$. fisheri (table 3 ). This may mean that given the same host population, $A$. fisheri had a slightly higher number of scales available for progeny production than did A. melinus, and therefore could build up to and maintain a higher density.

The number of parasites in each generation fluctuated considerably more for Aphytis lingnanensis and A. fisheri than for $A$. melinus. In the first generation, one might have expected the highest number of progeny for the species with the highest fecundity (Aphytis lingnanensis, as determined from table 3) but, as was shown, the reverse was obtained. At the beginning of generation 1 , the number of female parasites per infested lemon was 5. Previous tests (DeBach and Sisojevié, 1960) have shown that there is little or no competition for hosts at this density (5 parasites to $250 \pm$ scale hosts). Also no real searching was possible in these cages. The reason for the low production by $A$. lingnanensis and $A$. fisheri in the first generation may be a technical one, that is, the difference is probably apparent, not real. The first collection included not only the first generation progeny but the beginning of the second generation emergence. Since $A$. melinus has a shorter life cycle than the others, a higher proportion of second-generation specimens would be obtained in this collection. The reason for the difference between $A$. lingnanensis and $A$. fisheri is not apparent, unless in fact $A$. fisheri does develop a little faster (that is, as much as one-half day shorter life cycle) than is indicated in table 3.

At the end of each generation when the lemons were removed for counting, practically all scales were dead. Besides mortality from parasitization, death wás caused by host-feeding and, apparently, overstinging (superparasitism). On occasional scales, dead parasite pupae were observed. 


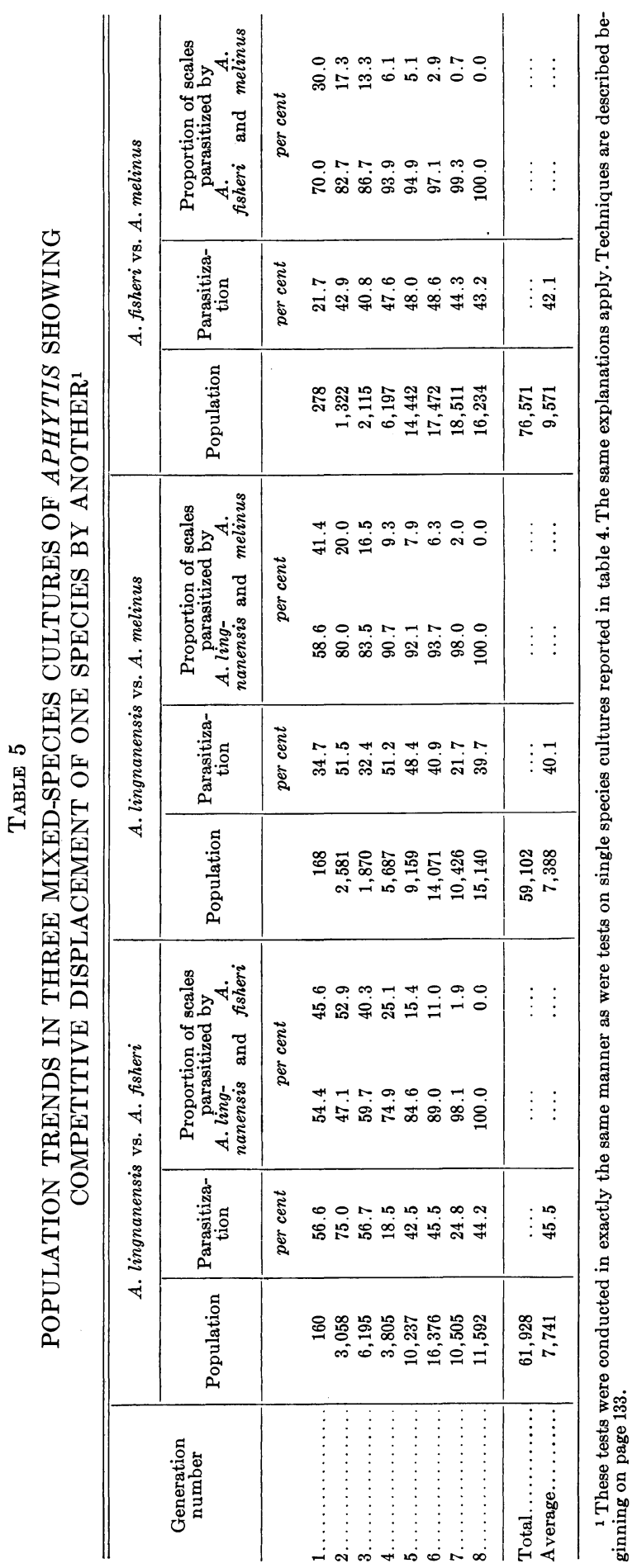


The per cent parasitization (table 4 ) in the pure cultures shows about the same variations from generation to generation as did the number of parasites. Again, the greatest variation is found in the cultures of Aphytis lingnanensis and $A$. fisheri, and the highest average parasitization is definitely found in $A$. fisheri cultures.

Judging from the oviposition and host-feeding data of table 3 , we should have expected only small differences between the per cent of hosts parasitized by $A$. fisheri and $A$. melinus.

In both cultures, nearly all the hosts were dead at the end of each generation, thus the differences may be ascribed in part to the somewhat greater amount of host-feeding in the culture of $A$. melinus, which reduced the number of scales available for parasitization.

The sex ratio in the pure cultures varied somewhat from generation to generation. For the entire period the average per cent of females for Aphytis lingnanensis was 64.7 , for $A$. fisheri 60.8 , and for $A$. melinus 61.1 . This sex ratio is essentially the same for all three species as was obtained under optimum conditions (see table 3 ).

The pure cultures showed that, in the experimental universe employed, all three species built up rapidly and maintained themselves at a very high population density. The data obtained indicates that high average (but fluctuating) populations might be maintained indefinitely in continuing tests. In single-species cultures, high potential fecundity, as shown in table 3 , was not an important determinant of the peak population nor of the average population density attained. If anything, such potential fecundity was inversely correlated with the population density attained.

Mixed Species Populations. The mixed cultures of Aphytis were set up in the same way as the pure cultures (see pages 133 and 134), using identical initial populations, techniques, and conditions. It will be recalled that the three species, Aphytis lingnanensis, $A$. fisheri, and $A$. melinus, have identical ecological niches. Counts were made in an identical manner. Again, at the end of each generation most old host material was dead but new material was added. Each species was tested simultaneously in the experimental universe against one of the others, which meant three different experiments: $A$. lingnanensis vs. $A$. fisheri, A. lingnanensis vs. A. melinus, and $A$. fisheri vs. A. melinus. Results shown in table 5 demonstrate competitive displacement between ecological homologues.

In all three cultures the same general results were obtained. In each case, starting with the same number of individuals of each of two species, only one species was left after 7 generations. Aphytis lingnanensis displaced $A$. fisheri in one series and $A$. melinus in another, and $A$. fisheri displaced $A$. melinus in the third. The changing proportions between the species is shown in table 5 by the proportionate percentage of scales parasitized by each species.

In the first generation the proportion parasitized by each species was fairly similar (except in the case of $A$. fisheri vs. $A$. melinus), but in all cases one species became dominant very soon (2nd to 4th generation), then proceeded to become more and more numerous until the other species was totally displaced by the 8 th generation.

The number of parasites per generation in each culture is given in table 5 . As in the pure cultures, the population densities varied somewhat from generation to generation for all three mixed cultures, but the average population densities attained were essentially no different than was the case with the single species cultures. The highest number of parasites $(18,511)$ was reached in the Aphytis fisheri vs. $A$. melinus culture. It will be recalled (table 4) that these two species in the pure cultures showed the highest popu- 
lation densities, particularly $A$. fisheri. Inasmuch as $A$. fisheri displaced $A$. melinus in this test, the higher density might have been expected. The $A$. lingnanensis vs. $A$. melinus culture, with a maximum number of 15,140 , had the lowest peak. Again, this seems logical because $A$. lingnanensis became dominant over $A$. melinus very rapidly, and in pure culture A. lingnanensis showed a similar low population peak. The average number of parasites for each generation as well as the total production also was highest for $A$. fisheri vs. $A$. melinus and lowest for $A$. lingnanensis vs. $A$. melinus for the same reasons. Fluctuations in the number of parasites per generation varied somewhat in intensity among all three cultures. No explanation for this is readily evident, but differences are not unexpected or extreme.

Fluctuations in per cent parasitization indirectly reflect fluctuations in numbers or vice versa but cannot be converted into numbers with the data presented (see footnote 3 , table 4 ). Reasons for variations in per cent parasitization between generations are not readily evident but the trends follow rather closely those obtained when the figures from two single species cultures are averaged.

The average per cent parasitization for the Aphytis lingnanensis vs. $A$. fisheri culture generally lies between the figures for the pure cultures. As mentioned earlier, A. lingnanensis hostfeeds more than does $A$. fisheri. In the early generations of the mixed culture, therefore, the number of scales fed on was somewhat higher than in the pure culture of $A$. fisheri, but lower than in the pure culture of $A$. lingnanensis. This means that $A$. lingnanensis had more scales available for its progeny production and $A$. fisheri had fewer than was the case in their pure cultures. The same process occurred in the other cultures. Therefore, the per cent parasitization would be expected to lie between the figures obtained for each pure culture.

As was the case in the single species cultures, these results show that the populations build up rapidly and maintain themselves at very high population densities in. spite of interspecific competition which results in the displacement of one species by the other.

Although it was shown that potential fecundity was not an important factor influencing the population densities attained in single species cultures, it would appear that fecundity as reflected by $F_{1}$ progeny production was the principal factor determining the winner in the interspecific cultures involving species having identical ecological niches. That is, the species that left the most progeny at the end of the first generation, left an even greater proportion in the second generation, and so on, until the other species was displaced. This is easily demonstrable mathematically.

Aphytis lingnanensis (potential fecundity of 31.8 progeny/female; see table 3) displaced $A$. fisheri (25.9 progeny/female) or $A$. melinus (24.1 progeny/female), and $A$. fisheri displaced $A$. melinus. Why $A$. fisheri became dominant so rapidly over $A$. melinus is not evident on the basis of the difference between their potential fecundities alone. It is important to note also that the least successful species in the single species cultures (as measured by population densities attained) was $A$. lingnanensis, yet it displaced the other two species when both were cultured together.

Analysis of Displacement in Mixed Species Cultures. The species of Aphytis used in these experiments, at least under the laboratory conditions tested, could not coexist. What were the reasons for the displacement of one species by another, and are there circumstances under which two of these species of Aphytis will exist together? The species with the highest potential fe- 
cundity (table 3 ) was the victor in each mixed species culture. However, if this were the only reason for the displacement, we should expect different displacement times. A. lingnanensis should eliminate $A$. melinus faster than it would $A$. fisheri (which it tended to do), but the displacement of $A$. melinus by $A$. fisheri should go very slowly, whereas $A$. fisheri actually became dominant over $A$. melinus very rapidly. An explanation for this apparent paradox was sought.

During the mixed-species culture experiments, the high average densities meant an average of about 50 female parasites per infested lemon; thus intensive competition for food (hosts) was present. Only a few of the potential total progeny from each female had a chance to survive. Perhaps this would favor certain species more than others. The question, therefore, naturally arose that if competition for food (hosts) was eliminated, or at least greatly reduced, how would the species react? Would they be able to coexist or, if not, how fast would they replace each other?

Competitive Displacement at Low Constant Parasite Densities. A test culture to explore the preceding questions was started with a light density of parasites. This test was designed to simulate the condition in the field where rather sparse parasite populations remain in balance or equilibrium with dense host populations. Sparse populations of species which are ineffective searchers or which are periodically restricted by adverse climatic conditions each year are often found in balance with heavy host populations. When a balance of this sort occurs, parasite population densities never become very great in relation to the host population densities, even though a great surplus of hosts is available. We planned the laboratory test culture to "duplicate" this field situation in order to ascertain if replacement of one species by another would occur even if hosts were always relatively numerous.
This mixed species culture consisted of Aphytis lingnanensis and A. fisheri and was started with 25 females of each species. The host material consisted of 10 lemons infested with oleander scale (about 250 scales per fruit), which gave the female parasites (an average of 5 per lemon) more material than necessary for their host-feeding and progeny production, as determined in previous tests (DeBach \& Sisojević, 1960). The emerged $F_{1}$ parasites were collected at the end of the first generation, from the 13 th until the 17th day. On this day, any unemerged pupae were counted and the numerical proportion between the species was determined from the adult and pupal material. However, the same initial parasite density was maintained in the culture during the whole test period by starting the culture over again in each subsequent generation with the same density of females (50) used in the first generation. The only difference was that the proportion between individuals of the two species used in each new generation was the same as that found at the end of the previous generation. This would undoubtedly happen in nature when the parasite population was in equilibrium with the host population at high host densities. The host material was replaced by 10 new scaleinfested lemons each generation.

The culture went on for 9 generations. As shown in table 6 (Actual), Aphytis lingnanensis became more and more numerous from generation to generation until it had replaced $A$. fisheri after 9 generations.

In this culture there was little or no real shortage of food. Each female had ample hosts in which to deposit all her eggs. After each generation about half the number of scales were still alive (unattacked by parasites). Thus competitive displacement occurred even in the apparent absence of any food shortage. For species with different fecundities, such a result can always be predicted on a mathematical basis. If the initial ratio between numbers of, the $\imath$ wo 
TABLE 6

COMPARISON OF ACTUAL AND THEORETICAL RATES OF DISPLACEMENT OF APHYTIS FISHERI BY A. LINGNANENSIS WITH HOSTS ${ }^{1}$ IN SURPLUS SUPPLY ${ }^{2}$

\begin{tabular}{|c|c|c|c|c|}
\hline \multirow{3}{*}{ Generation number } & \multicolumn{4}{|c|}{ Rate of displacement } \\
\hline & \multicolumn{2}{|c|}{$\begin{array}{l}\text { Actual (from culture) } \\
\text { proportion of }\end{array}$} & \multicolumn{2}{|c|}{$\begin{array}{l}\text { Theoretical (from table 3) } \\
\text { proportion of }\end{array}$} \\
\hline & $\underset{\text { nanensis }}{\text { A. ling- }}$ & to fisheri & $\begin{array}{l}\text { A. ling- } \\
\text { nanensis }\end{array}$ & to $\begin{array}{c}A . \\
\text { fisheri }\end{array}$ \\
\hline parental....... & 25 & 25 & 25 & 25 \\
\hline 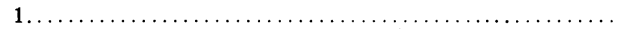 & 28 & 22 & 28 & 22 \\
\hline 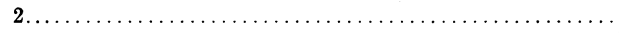 & 30 & 20 & 30 & 20 \\
\hline $3 \ldots \ldots \ldots \ldots$ & 33 & 17 & 32 & 18 \\
\hline $4 \ldots \ldots \ldots$ & 38 & 12 & 34 & 16 \\
\hline $5 \ldots \ldots \ldots \ldots$ & 42 & 8 & 36 & 14 \\
\hline $6 \ldots \ldots$ & 46 & 4 & 38 & 12 \\
\hline $7 \ldots \ldots \ldots \ldots \ldots \ldots$ & 48 & 2 & 40 & 10 \\
\hline$\ldots \ldots \ldots \ldots \ldots \ldots \ldots \ldots$ & 49 & 1 & 42 & 8 \\
\hline $9 \ldots \ldots \ldots \ldots$ & 50 & 0 & 43 & 7 \\
\hline $10 \ldots \ldots \ldots \ldots \ldots \ldots \ldots$ & . & .. & 44 & 6 \\
\hline $11 \ldots \ldots \ldots \ldots \ldots \ldots$ & . & . & 45 & 5 \\
\hline $12 \ldots \ldots \ldots \ldots \ldots \ldots$ & . & . & 46 & 4 \\
\hline $13 \ldots \ldots \ldots \ldots \ldots$ & . & . & 47 & 3 \\
\hline $14 \ldots \ldots \ldots \ldots \ldots$ & . & . & 48 & 2 \\
\hline $15 \ldots \ldots \ldots \ldots \ldots \ldots \ldots \ldots \ldots \ldots \ldots \ldots \ldots \ldots$ & . & $\cdots$ & 48 & 2 \\
\hline
\end{tabular}

1 Oleander scale.

2 See page 141 for explanation.

parasite species differed, the result would be the same but the replacement time would differ.

Based on potential fecundity (table 3 ) and the demonstration that competitive displacement between species will occur even in the presence of surplus food, we should have expected Aphytis lingnanensis to eliminate $A$. fisheri, but at the slower rate shown in the "Theoretical" column in table 6 . It appears likely, therefore, that not only $\operatorname{did} A$. lingnanensis have the advantage of a higher fecundity but it also competed more effectively in some other way in spite of the low parasite density and high food (host) density. The only two obvious possibilities are (1) competition between larvae and (2) interference between the adult females.

Competition Between Larvae. As mentioned earlier, only a few parasites, usually no more than 2 or 3 , can complete development on one scale for nutritional reasons. The females, however, do oviposit in scales already parasitized, and sometimes place more eggs on each scale than can develop. This is at least the case at high parasite densities. Larvae have also been observed to kill each other, presumably accidentally. This may happen, even if all the host body has not been consumed. On the other hand, two species of parasites have been observed to develop on the same scale at the same time.

Previous work with Aphytis lingnanensis (DeBach \& Sisojević, 1960) gave some indication that competition between larvae occurred. In order to determine this more definitely and especially to learn if larvae of different species behave differently, various numbers of newly deposited parasite eggs were transferred from the original host to unattacked scales. The eggs were transferred to new scales by removing the scale covering, and the infested lemon was then placed in a high-humidity chamber to prevent desiccation of the exposed eggs. Normal development occurred under these conditions. The eggs used were less than 24 hours old. Eggs of the same age were used for all species in all tests. After 11 days any effect of competition between larvae had 
already occurred and could be measured by counting the number of live pupae. The test combinations and the results are given in table 7 .

In the single species tests, if we consider the number of survivors occurring at a larval density of one per scale as $100 \%$, the following results are obtained:
Larval

density per scale

1
2
3

2

3
Per cent survivors

$\begin{array}{ccc}\text { A.ling- } & A . & A . \\ \text { nanensis } & \text { fisheri } & \text { melinus } \\ 100 & 100 & 100 \\ 78 & 67 & 90 \\ 60 & 66 & 94\end{array}$

These data show that larvae of Aphytis lingnanensis compete with each other and that about $40 \%$ fewer will survive if they occur 3 to a scale, rather than if the same total occur singly. The larvae of $A$. fisheri are possibly a little less competitive with their own kind

(the figure at the density of 2 per scale is obviously too low), and about $34 \%$ fewer will survive if they occur 3 to a scale, but the larvae of $A$. melinus definitely compete very little with each other. The per cent surviving at a density of 3 per scale was very nearly that of those surviving at a density of 1 per scale. This is in line with the tendency of $A$. melinus to lay more than 1 egg per scale and to produce more than 1 pupa per scale (table 3 ). The results with the other two species also agree with the data in table 3 , except that the survival of $A$. fisheri was somewhat lower than might have been expected.

It is evident from table 7 that, considering all the tests where larvae of two species competed, a density of 3 eggs per scale gave considerably fewer pupae (average, 131 per test) than the corresponding controls (average, 172 per test). However, at the density of

TABLE 7

EFFECT ON SURVIVAL OF COMPETITION BETWEEN LARVAE OF APHYTIS SPECIES

\begin{tabular}{|c|c|c|c|c|c|c|c|c|c|c|}
\hline \multirow[b]{2}{*}{ Culture } & \multirow{2}{*}{$\begin{array}{l}\text { Initial } \\
\text { density } 1 \\
\text { (eggs per } \\
\text { scale) }\end{array}$} & \multicolumn{3}{|c|}{ A. lingnanensis } & \multicolumn{3}{|c|}{ A. fisheri } & \multicolumn{3}{|c|}{ A. melinus } \\
\hline & & $\begin{array}{l}\text { Initial } \\
\text { total } \\
\text { number } \\
\text { of eggs }\end{array}$ & $\begin{array}{l}\text { Number } \\
\text { of sur- } \\
\text { vivors }\end{array}$ & expected $^{\text {Number }}$ & $\begin{array}{l}\text { Initial } \\
\text { total } \\
\text { number } \\
\text { of eggs }\end{array}$ & $\begin{array}{l}\text { Number } \\
\text { of sur- } \\
\text { vivors }\end{array}$ & $\begin{array}{l}\text { Number } \\
\text { expected }\end{array}$ & $\begin{array}{c}\text { Initial } \\
\text { total } \\
\text { number } \\
\text { of eggs }\end{array}$ & $\begin{array}{l}\text { Number } \\
\text { of sur- } \\
\text { vivors }\end{array}$ & $\begin{array}{l}\text { Number } \\
\text { expected }\end{array}$ \\
\hline & 1 & 100 & 87 & $\ldots$ & 100 & 86 & $\ldots$ & 100 & 67 & $\ldots$ \\
\hline Single species (Control) \{ & 2 & 200 & 135 & $\ldots$ & 200 & 115 & $\ldots$ & 200 & 121 & $\ldots$ \\
\hline & 3 & 300 & 157 & $\ldots$ & 300 & 171 & $\ldots$ & 300 & 189 & $\ldots$ \\
\hline $\begin{array}{l}\text { Mixed species combina- } \\
\text { tions } \\
\text { A. lingnanensis vs. }\end{array}$ & & & & & & & & & & \\
\hline $\begin{array}{l}\text { A. fisheri............. } \\
\text { A. lingnanensis vs. }\end{array}$ & 2 & 100 & 64 & 67 & 100 & 39 & 57 & $\ldots$ & $\ldots$ & $\ldots$ \\
\hline A. melinus.......... & 2 & 100 & 68 & 67 & $\ldots$ & $\ldots$ & $\ldots$ & 100 & 53 & 60 \\
\hline $\begin{array}{l}\text { A. fisheri vs. } A . \text { melinus } \\
\text { A. lingnanensis vs. }\end{array}$ & 2 & $\ldots$ & $\ldots$ & $\ldots$ & 100 & 52 & 57 & 100 & 65 & 60 \\
\hline $\begin{array}{l}\text { A. fisheri. . . . . . . } \\
\text { A. lingnanensis vs. }\end{array}$ & 3 & 200 & 81 & 104 & 100 & 28 & 57 & $\ldots$ & $\ldots$ & $\ldots$ \\
\hline $\begin{array}{l}\text { A. fisheri........... } \\
\text { A. lingnanensis vs. }\end{array}$ & 3 & 100 & 51 & 52 & 200 & 76 & 114 & $\cdots$ & $\ldots$ & $\ldots$ \\
\hline $\begin{array}{l}\text { A. melinus........... } \\
\text { A. lingnanensis vs. }\end{array}$ & 3 & 200 & 91 & 104 & $\ldots$ & $\ldots$ & $\ldots$ & 100 & 31 & 63 \\
\hline A. melinus........... & 3 & 100 & 50 & 52 & $\ldots$ & $\ldots$ & $\ldots$ & 200 & 77 & 126 \\
\hline A. fisheri vs. A. melinus & 3 & $\ldots$ & .. & $\ldots$ & 200 & 101 & 114 & 100 & 44 & 63 \\
\hline A. fisheri vs. A. melinus & 3 & $\ldots$ & $\ldots$ & $\ldots$ & 100 & 63 & 57 & 200 & 96 & 126 \\
\hline
\end{tabular}

1 This is equivalent to larval density per scale.

2100 replicates used for each initial density.

3 As measured by eggs which developed into live pupae.

3 As measured by eggs which developed into live pupae. 4 Calculated on the basis of the proportion of one species in a mixed-species test, in relation to the number of survivors
of this species obtained in the controls at the same initial density. In other words, at an initial density of 2 eggs per scale (200 total), A.lingnanensis when tested alone had 135 survivors and $A$. fisher $i$ had 115 ; therefore, at the same initial density of 2 (200) but with $100 \mathrm{~A}$. lingnanensis and $100 \mathrm{~A}$. fisheri eggs, 67-1/2 of $135-A$. lingnanensis survivors were expected, and $57-1 / 2$ of $115-A$. fisher $i$ survivors were expected. 
2 eggs per scale, there was little reduction, except for $A$. fisheri in competition with $A$. lingnanensis; hence, the competition between two species differed little from that within a single species at this larval density (2 per scale).

At the density of 3 eggs per scale, the total number of pupae obtained in all tests was $23.5 \%$ lower than would be expected from comparison with the controls. Thus, at abnormally high larval densities (that is, more than 2 per scale), competition between larvae of different species apparently is decidedly more severe than between larvae of the same species. The proportion of survivors in the mixed species cultures showed that Aphytis lingnanensis competed most efficiently for food (hosts) whether its initial larval density was $1: 2$ or $2: 1$. In combination with $A$. fisheri, $84.6 \%$ of the expected number of $A$. lingnanensis survived as compared to $60.8 \%$ for $A$. fisheri. When combined with $A$. melinus, $89.8 \%$ of the expected number of $A$. lingnanensis larvae survived, while only $57.1 \%$ of those of $A$. melinus survived. When $A$. fisheri and $A$. melinus larvae competed, the result was a survival of $95.9 \%$ of the expected number of $A$. fisheri and $74.1 \%$ of $A$. melinus.

Briefly, the results of the tests given in table 7 show that Aphytis larvae compete to a certain extent with each other. In single species competition, the tendency is slight in some species ( $A$. melinus) and fairly marked in others (A. lingnanensis). In mixed species competition, $A$. lingnanensis has an advantage over the other two species, and when $A$. fisheri competes with $A$. meli$n u s$, the former has the advantage. Both A. melinus and A. fisheri suffer more in competition with $A$. lingnanensis than with one another.

The mechanism involved in this competition needs more study. Only two factors, aggression and competition for a limited amount of food, would seem to be likely explanations. Cases of ac- tive aggression are not often seen and we would suspect that they occur accidentally. Supernumerary larvae may not only reduce the amount of food available per larva to a dangerous minimum, but may affect the nutritional quality of the scale body contents. Salt (1961) knew of no example of deliberate physical attack on each other by gregarious external parasites (which Aphytis species tend to be), but he states that accidental injury may well occur when ectoparasitic larvae contact one another. He also states that elimination of excess individuals is usually ascribed to selective starvation.

Before concluding that the preceding results indicate an overwhelming advantage for Aphytis lingnanensis or disadvantage for $A$. melinus in competitive displacement, it may be well to consider other aspects of larval competition. First, from table 3 we know that A. lingnanensis produces more than 1 pupa per scale in only $12 \%$ of the cases and, additionally, we know from extensive observation of field and laboratory material that $A$. lingnanensis usually deposits only 1 egg per scale. It is likely that this species and the other Aphytis species studied can detect parasitized hosts and, under normal conditions, avoid oviposition in them, as has been demonstrated for various other parasites. In any event, the fact that under ordinary conditions $A$. lingnanensis usually deposits only 1 egg per host should mean that usually no larval competition, either intra- or interspecific, will occur. Second, the ill effects of larval competition are not excessive. In the single test showing the most competition, where the density of $A$. lingnanensis to $A$. melinus was 2:1 larvae per scale, about $50 \%$ of the expected A. melinus larvae survived. Most other combinations resulted in minor reductions, and it will be recalled that with a larval density of 2 per scale ( 1 each of two species) much smaller reductions occurred. In other words, although $A$. lingnanensis larvae seem to compete 
TABLE 8

PROGENY PRODUCTION BY CROWDED APHYTIS FEMALES

\begin{tabular}{|c|c|c|c|c|c|c|c|}
\hline \multirow{2}{*}{ Test number } & \multicolumn{4}{|c|}{ Density of parental females } & \multicolumn{3}{|c|}{ Mean progeny per female parent 1} \\
\hline & Total & $\begin{array}{c}\text { A. ling- } \\
\text { nanensis }\end{array}$ & $\begin{array}{c}\text { A. } \\
\text { fisheri }\end{array}$ & $\underset{\text { melinus }}{A .}$ & $\begin{array}{l}\text { A. ling- } \\
\text { nanensis }\end{array}$ & $\begin{array}{c}\text { A. } \\
\text { fisheri }\end{array}$ & $\underset{\text { melinus }}{A .}$ \\
\hline & & \multicolumn{6}{|c|}{ Mixed species combinations } \\
\hline 1. & 40 & 20 & 20 & . & 9.8 & 5.3 & $\ldots$ \\
\hline 2. & 40 & 20 & . & 20 & 8.5 & $\ldots$ & 4.4 \\
\hline & 40 & . & 20 & 20 & $\ldots$ & 7.7 & 5.0 \\
\hline & & \multicolumn{6}{|c|}{ Single species } \\
\hline $4 \ldots$ & 40 & 40 & . & . & 7.0 & $\ldots$ & $\ldots$ \\
\hline & 40 & . & 40 & . & $\ldots$ & 7.1 & $\ldots$ \\
\hline $6 \ldots \ldots$ & 40 & . & . & 40 & $\ldots$ & $\ldots$ & 6.5 \\
\hline
\end{tabular}

1 Based on progeny which reached the pupal stage. Derived from 10 replicates per test. In each replicate 40 mated females were placed in a small cage on a single lemon bearing 400 to 450 scales. Each of the six tests used a total of 400 parental females which produced a total of from over 2,500 to over 3,000 progeny; the grand total of 2,400 parental females produced over 16,300 progeny. Females were allowed to oviposit for their lifetime. Oleander scale was used as the host.

more effectively than those of the other two species, this ability is rarely put to use except when parasite density is high.

Interference Between Adult Females. The density of female parasites per lemon was very high in the mixed species cultures of table 5 and the single species cultures of table 4 . It is obvious that the females in these experiments were in frequent contact with each other. This poses two questions. Do such contacts result in interference which is in some way detrimental and, if so, is it more severe between females of different species of Aphytis than between females of the same species?

To obtain information concerning these possibilities, tests were conducted with high densities of equal numbers of parental females of each species in small experimental cages. A density of 40 female parasites per lemon was used in all tests, with about 400 to 450 host scales per lemon fruit. One lemon was used in each cage, and 10 replicates constituted one test. As seen in table 8, Aphytis lingnanensis produced its greatest number of progeny per female when competing with $A$. fisheri and its lowest number in the pure culture. $A$. fisheri had its highest number of progeny when competing with $A$. melinus, while $A$. melinus produced its highest number in the pure culture. Thus, in competition, A. lingnanensis was superior to both $A$. fisheri and $A$. melinus, and $A$. fisheri was superior to $A$. melinus. However, regardless of how it may seem, we connot conclude that these results are attributable to an effect of crowding between adult females. It will be recalled that the species have different fecundities (table 3 ) and that larval competition between these species may produce certain differentially adverse effects on survival (table 7 ). If the data in table 8 are adjusted for these two effects, as shown in table 9 , the number of progeny per female obtained for each species is very near what would be expected if no adverse effects occurred from contact "interference" between adult females of different species. Thus, such interference does not seem to be of any importance in interspecific competition.

Therefore, the differences in progeny production in the mixed species combinations of table 8 result from larval competition. These results substantiate those of table 7 by showing that, in competition, A. lingnanensis is much superior to either $A$. fisheri, which shows $25 \%$ reduction in progeny, or A. melinus, which shows $32 \%$ reduction in progeny. The results also show that $A$. fisheri is superior to $A$. 
TABLE 9

COMPARISON OF EFFECT OF CROWDED AND UNCROWDED CONDITIONS ON PROGENY PRODUCTION OF MIXED APHYTIS FEMALES

\begin{tabular}{|c|c|c|c|c|c|c|}
\hline \multirow{2}{*}{ Mixed species combinations } & \multicolumn{3}{|c|}{$\begin{array}{c}\text { Crowded conditions: } \\
\text { Number of progeny obtained }\end{array}$} & \multicolumn{3}{|c|}{$\begin{array}{l}\text { Uncrowded conditions: } \\
\text { Number of progeny expected } 2\end{array}$} \\
\hline & $\begin{array}{l}\text { A. ling- } \\
\text { nanensis }\end{array}$ & $\underset{\text { fisheri }}{A .}$ & $\stackrel{A .}{\text { melinus }}$ & - $\underset{\text { nanensis }}{\text { Aing- }}$ & $\underset{\text { fisheri }}{A .}$ & $\underset{\text { melinus }}{A .}$ \\
\hline A. lingnanensis vs. A. fisheri. & 1,971 & 1,069 & $\ldots$. & 1,910 & 1,131 & $\ldots$ \\
\hline A. lingnanensis vs. A. melinus... & 1,691 & $\ldots$ & 889 & 1,739 & $\cdots$ & 841 \\
\hline A. fisheri vs. A. melinus...... & $\cdots \cdots$ & 1,537 & 996 & $\ldots \ldots$ & 1,472 & 1,061 \\
\hline
\end{tabular}

1 This progeny production represents the total obtained for each species for each test (10 replicates) as recorded under the mixed species combinations in table 8 . The same experimental specifications apply.

2 Calculations and corrections based on fecundity figures of table 3 and larval competition figures of table 7 .

melinus, which has a $23 \%$ reduction in progeny.

Although these experiments were not designed to show if there are any effects on progeny production from contact interference when adult females of the same species are crowded together, they indicate that the result would differ very little from that obtained by crowding adults of two different species.

It would seem, therefore, that the observed results of interspecific competition (that is, competitive displacement of one species by another) in the laboratory experimental universes are largely due to the difference in progeny production (equated with fecundity in table 3), which is inherent under given conditions, and to a lesser extent, they are due to competition between supernumerary larvae. The latter factor acts to emphasize or deemphasize the initial effects of differences in fecundity. It will be recalled that differences in fecundity (progeny production of table 3 ) between species had little or no effect on the average population density in single species cultures (table 4). However, in mixed-species cultures differences in fecundity (progeny production of table 3 ), which are further emphasized by larval competition, assume utmost importance. In other words, progeny production does not determine the average population density obtained in a particular universe. It does, however, determine the winner in interspecies competition between ecological homologues.

Host-feeding could be a factor influencing production of $\mathrm{F}_{1}$ progeny, but it is not thought to be so in these tests. Previous studies on Aphytis species have shown that host-feeding is avoided on scales already parasitized, and oviposition is avoided on host-fed scales. The main influence of host-feeding in these tests would seem to be on the number of scales available for oviposition. Competitive displacement has already been shown to occur regardless of scale density.

One other factor comes to mind as a possible influence on progeny production, especially at high parasite densities. When female parasites are unusually numerous with respect to hosts, the females sometimes destroy eggs already deposited, and may kill larvae and pupae during preovipositional probing. The possibility exists that species may differ in this regard, but this has not been explored. However, it was shown that when the parasite density in a mixed species culture of $A$. lingnanensis and $A$. fisheri (table 6 ) was so low as to preclude the above possibility, A. fisheri was still displaced by $A$. lingnanensis within nearly the same number of generations as in the series (table 5 ) having high parasite densities with respect to the host. This merely serves to reemphasize that competitive displacement was caused principally by 
differences in species fecundity and secondarily by competition between the larvae, or in other words by differences in production of progeny which matured and reproduced.

Relative Searching Ability. During the previous experiments, no real searching was involved, since the parasites were confined with their hosts in a limited space. In the field, relative searching ability is perhaps the most important attribute of a parasite. Ability to find hosts at low host population densities is a prerequisite for successful biological control and, of course, a great advantage in competition with other species which parasitize the same host species. To gain some information with regard to searching ability, experiments were carried out with the three species of Aphytis used in the preceding tests. In these experiments, two insectary rooms were used, a small one with artificial light only, and a large one with daylight entering through glass walls on three sides. One small lemon tree was placed in each room, and lemons infested with oleander scale were placed in these trees. The temperature of each room was $80 \pm 2^{\circ} \mathrm{F}$.

Every sixth day, 10 mated Aphytis females were released in the rooms as far as possible from the trees. This presented a rather severe problem to the few females. The females were of the same age, and kept under the same conditions before being released. The lemons were also changed every sixth day, and the previously exposed lemons kept isolated to wait for the development of any Aphytis eggs that had been deposited. The experiments ran for 2 months.

In the large room with daylight, the result was 17 scales attacked by $A p h y$ tis melinus to 9 by $A$. lingnanensis and none by $A$. fisheri. The total number of pupae obtained on these scales was 28 for $A$. melinus and 11 for $A$. lingnanensis. In the smaller room, 177 pupae of $A$. lingnanensis were obtained, 77 of $A$. melinus, and 16 of $A$. fisheri. In the large room, it seems more likely that real searching ability was tested. The tree was placed away from the windows (which attract parasites), and it seems, therefore, that the host plant itself may have attracted the females, although random movement must be considered. It would appear that $A$. fisheri is a poor searcher or is not attracted to citrus. This experiment was not extensive enough to conclude whether $A$. melinus or $A$. lingnanensis had the better searching ability. The results in the large room point to $A$. melinus.

\section{Species Having Different Ecological Niches}

The laboratory experiments showed that the three species of Aphytis which displaced or precluded the establishment of each other in the field similarly could not coexist in laboratory universes. These species have, as far as we can tell, identical ecological niches, which, in the opinion of many authors (see Introduction, pages 105 to 116 ), precludes coexistence. Stated in another way, if species coexist they have different ecological niches.

The California red scale parasites, Comperiella bifasciata Howard and Prospaltella perniciosi Tower, may coexist with each other as well as with any one of three species of Aphytis in any given field habitat. More commonly, however, $C$. bifasciata occurs with Aphytis species in intermediate or interior areas and $P$. perniciosi with Aphytis species in coastal areas. Aphytis species are, as is well known, ectoparasites; the two others are endoparasites. The ecological niches of $C$. bifasciata and $P$. perniciosi seem to differ only slightly from those of the Aphytis species. Their immature stages inhabit the molt stages of the host as well as the instar stages, whereas the Aphytis species can parasitize only the second and third instars. $P$. perniciosi and $C$. bifasciata, therefore, occur at least part of the time in stages of the host which actually are not "hosts" to the Aphytis 
species, hence competition with the Aphytis species is precluded during this period. If complete development of the parasite occurred in a molt stage, no competition whatsoever should occur with Aphytis individuals. Ordinarily, one might jump to the conclusion that different species of parasites attacking the same host species have identical ecological niches. Clearly this is not true, for a species that attacks eggs exclusively is not in competition with a species that attacks pupae exclusively, as long as the host density is adequate for each. Were this concept not true, the sequence of parasitic species which attack the developmental stages of many insect host species would furnish ample proof that competitive displacement in ecological homologues does not occur. On the basis of field observation we should expect $C$. bifasciata or $P$. perniciosi to coexist with the Aphytis species in laboratory culture. In order to test this hypothesis, singlespecies as well as mixed-species cultures were planned. California red scale had to be used as the host in these tests because $C$. bifasciata and $P$. perniciosi are specific to it.

The Species' Biological Characteristics. Aphytis lingnanensis Compere. This ectoparasite was discussed in detail previously in the text (see pages 128 to 132 ). When the host is California red scale, oviposition and host-feeding are restricted to second and early third instars, whereas with oleander scale any stage can be attacked if the host is large enough. Other biological responses are, in general, much like those obtained on oleander scale except that the ratio of females to males is usually lower when development occurs on red scale.

Comperiella bifasciata Howard. The biology of this species has been described by Compere and Smith (1927). It is a biparental species with a sex ratio near 50:50. In our progeny production tests, $55 \%$ females were obtained. During the oviposition act the female usually attacks the scale near the edge of the scale covering and deposits the egg inside the scale body. Oviposition lasts usually half a minute. If the female is withheld from hosts for awhile, oviposition may occur at the rapid rate of 9 eggs within half an hour. The female seems to prefer third instar female scales as hosts, but eggs are laid in all stages from second instar on. Occasionally, male host pupae are attacked by $C$. bifasciata in the field. This was observed in the laboratory also.

One egg is usually deposited in each host, but at a high parasite density as many as 36 parasite eggs have been found in one full-grown scale. Most supernumerary eggs hatch but the larvae die, so that never more than 1 pupa develops in each host scale. This is probably a combination of physiological and nutritional suppression, as discussed by Salt (1961). The developmental period for $C$. bifasciata is 27 to 28 days, with the egg stage comprising 5 to 6 days of this. The first parasites to emerge are always males.

Fecundity was not measured directly in these tests but was probably closely approximated by the number of progeny per female which reached the pupal or adult stage. The reason for this is that the tests were conducted under optimal conditions, so that the number of progeny which reached the adult state was probably very close to the original number of eggs laid. One newly emerged female and one male were isolated on each of 25 scale-infested lemons and left for 26 days. After this period, all the parental females were dead. The test, comprising 25 females, showed an average production per female of 47.8 progeny (table 10 ), with a maximum of 95 and a minimum of 5 . Host-feeding of Comperiella bifasciata appears to be quantitatively unimportant if it occurs at all: We observed no evidence of it during this study and Arturo L. Teran, subsequently working with the senior author, 
TABLE 10

BIOLOGICAL CHARACTERISTICS OF APHYTIS LINGNANENSIS, COMPERIELLA BIFASCIATA AND PROSPALTELLA PERNICIOSI REARED ON CALIFORNIA RED SCALE ${ }^{1}$

\begin{tabular}{|c|c|c|c|}
\hline Characteristic & A. lingnanensis & C. bifasciata & P. perniciosi \\
\hline 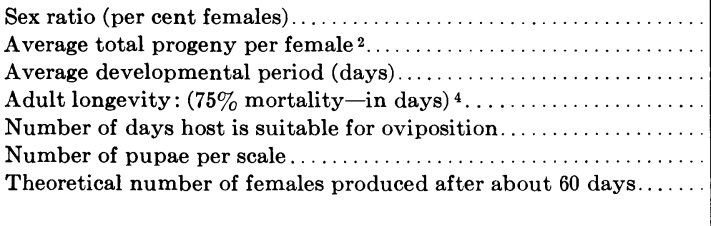 & $\begin{array}{c}35 \\
31.8 \\
13-14 \\
25 \\
10 \\
1-2 \\
14,641 \\
\text { (4 generations) }\end{array}$ & $\begin{array}{c}55 \\
47.8 \\
27-28 \\
7-8 \\
40 \\
1 \\
676 \\
\text { (2 generations) }\end{array}$ & $\begin{array}{c}100 \\
45.8 \\
20^{3} \\
21 \\
40 \\
1 \\
97,336 \\
\text { (3 generations) }\end{array}$ \\
\hline
\end{tabular}

$180 \pm 2^{\circ} \mathrm{F}$ and $50 \pm 5$ per cent $\mathrm{RH}$. See text for details of techniques.

2 Referred to elsewhere in text as fecundity. See explanation in table 3, footnote 5, page 129.

3 In second-stage scales.

4 See table 3 , footnote 3 , page 129 .

found in comparative laboratory tests (unpublished data) that $C$. bifasciata did not host-feed among third-instar California red scale, which is the stage preferred by Aphytis species for hostfeeding. Neither did Teran observe any activity by the adult females which resembled host-feeding action. However, Flanders (1944) briefly states that $C$. bifasciata sometimes host-feeds on young male and female scales. This conclusion apparently was based on observation of actions resembling host-feeding by $C$. bifasciata females.

A longevity test, in which the females were not allowed to oviposit, but where honey was continuously available as food, showed that the females may live for as long as 12 days, but that $50 \%$ mortality is reached after 6 to 7 days, and $75 \%$ mortality after nearly 8 days (table 10). Thus, the females are short lived as compared to the other two species tested, but this appears to offer little disadvantage, since Comperiella bifasciata showed the highest progeny production of the three (table 10). Although the males sometimes live as long as the females, this is not common.

Prospaltella perniciosi Tower. This parasite is a uniparental species, which produces females parthenogenetically. Males occur in other strains, but the Oriental strain, which attacks the Cali- fornia red scale, produces only females. Females attack all stages of California red scale.

The females begin to search for scales as soon as they contact the host plant (lemon fruit), and the scale is found within a few minutes. After examination, preovipositional probing usually occurs near the center of the scale covering. The time spent in penetrating the scale covering (from less than 1 minute to 15 minutes) depends on the age of the host; the older the scale, the longer it takes. However, not all attacks result in oviposition. Sometimes the host is abandoned after a few seconds of probing. Oviposition in male and younger scales usually takes 2 to 3 minutes, whereas oviposition in mature females usually takes 5 to 10 minutes. After oviposition, the female sometimes returns to the same scale recently attacked. This may happen even when previously unattacked scales are available. No evidence of host feeding was observed by the authors.

One egg usually is deposited in each host, but at very high parasite densities more eggs may be laid per host. As many as 3 eggs and 6 larvae have been found in 1 host, but only 1 parasite per host completed development. Supernumerary eggs may hatch but the excess larvae die shortly afterwards.

The egg of Prospaltella perniciosi is 
oval shaped, slightly pointed at one end, and about $0.07 \mathrm{~mm}$ in length. The day after oviposition, the egg starts to increase in size and after 2 days has reached a length of 0.12 to $0.13 \mathrm{~mm}$. A darker middle part indicates the embryonic larva, which later is easily seen through the egg covering. The egg hatches in 4 to 5 days. The first larval stage is a caudate form, as described by Benassy and Bianchi (1960), and has a length of about $0.25 \mathrm{~mm}$-nearly double that of the egg. With each subsequent molt the tail gets shorter and the full-grown larva is tailless. The larval period lasts 10 to 11 days.

The pupal skin is soft and nearly unpigmented, but the developing adult's color can be seen through the pupal skin. The pupal period lasts 4 to 5 days. The emerging parasite gnaws an oval aperture in the scale body and covering through which it escapes.

After oviposition, the host scale shows no sign of paralysis and continues to grow. However, about 7 days later, the host turns yellow. Later on, the edge of the scale body turns brown and the whole scale becomes darker, except for a lighter zone in the center, where the larva is located. The parasite pupa is always found in the center of the host.

In these studies the total developmental period for Prospaltella perniciosi varied to some extent, depending on the age and condition of the host at oviposition. The shortest developmental period-lasting 19 days-took place in the male scale. The average was about 20 days (table 10) in optimum-sized hosts. A lemon bearing all stages of scales gave rise to parasites 20 to 30 days after oviposition. About half the parasites developed in male scales. Of these, more than half emerged during the 20th to 22nd days after oviposition. Shortly afterwards parasites began emerging from second-instar female scales. Most of the parasites from thirdinstar and mature female scales emerged during the 22nd to 24th days after oviposition. When 3-day-old, firststage scales were attacked, the first parasites emerged after 25 days. It is possible that egg hatching was delayed in first-stage scales and did not occur until the scale developed to the second stage. Different figures for the development of the San Jose scale strain of $P$. perniciosi were given by Schlabritzky (1956).

Prospaltella perniciosi seems to be able to oviposit throughout its life. Females not allowed to oviposit, but continuously supplied with honey as food, lived as long as 29 days. Half of the females, however, were dead after 15 days, and $75 \%$ were dead after 21 days (table 10). This is longer than Schlabritzky (1956) found for the San Jose scale strain of this species.

Fecundity, as measured by the number of progeny which reached the pupal stage, averaged 45.8 (table 10), with 77 as maximum and 13 as minimum. The test utilized 2-week-old scales (second stage). When third-stage scales, 25 days or older, were used, the number of progeny decreased. This again indicates that older scales are not preferred ovipositional sites. When younger, secondstage scales were used as host material, more than half of the progeny occurred in male scales which indicates, perhaps, a little preference for second-stage male scales over second-stage females.

Single-Species Populations (Controls). In order better to understand and explain the results occurring in mixed-species population cultures, it was first necessary to learn how singlespecies populations behaved. Singlespecies cultures of Aphytis lingnanensis, Comperiella bifasciata, and Prospaltella perniciosi were started utilizing California red-scale-infested lemons. Red scale had to be used as the host because $C$. bifasciata and $P$. perniciosi do not attack oleander scale. The lemons bore all stages of red scale from earlyfirst to late-third instar at the time they were transferred to the parasite cultures. This host material was pro- 
duced by transferring newly born scale crawlers to the lemons twice a week for 4 weeks. Thirty crawlers were added each time, so that the lemons had a total number of 240 scales at the time they were transferred to the cultures. The cultures were started with $30 \mathrm{fe}$ male parasites and 10 lemons in each cage. New host material was added every 18 days, and the lemons remained in the cages for 72 days. After this time, the parasitized and unparasitized scales were counted. The dead parasites were taken out and counted every 18 days. The experimental universe consisted of a sleeve cage, kept at $80 \pm 2^{\circ} \mathrm{F}$ and 50 $\pm 5 \% \mathrm{RH}$.

As seen in tables 11, 12, and 13, all three species did well, and would evidently have persisted indefinitely, in single-species cultures. With Comperiella bifasciata, the number of parasites per count varied between 66 and 519 (table 12). Each count, however, does not represent a single generation although it is called such. As mentioned earlier, C. bifasciata has a developmental period of 27 to 28 days under these laboratory conditions, and population

TABLe 11

POPULATION TRENDS IN A SINGLE SPECIES CULTURE OF APHYTIS LINGNANENSIS REARED ON CALIFORNIA RED SCALE ${ }^{1}$

\begin{tabular}{|c|c|c|}
\hline Generation number & Population & $\begin{array}{c}\text { Per cent } \\
\text { parasitization }\end{array}$ \\
\hline $1 \ldots \ldots \ldots \ldots \ldots$ & 23 & 10.0 \\
\hline $2 \ldots \ldots \ldots \ldots \ldots \ldots \ldots$ & 26 & 6.7 \\
\hline $3 \ldots \ldots \ldots \ldots \ldots \ldots \ldots$ & 38 & 8.2 \\
\hline $4 \ldots \ldots \ldots \ldots$ & 260 & 1.7 \\
\hline $5 \ldots \ldots \ldots \ldots \ldots \ldots \ldots$ & 427 & 5.9 \\
\hline $6 \ldots \ldots \ldots \ldots \ldots \ldots \ldots$ & 241 & 4.1 \\
\hline $7 \ldots \ldots \ldots \ldots \ldots$ & 199 & 10.9 \\
\hline $8 \ldots \ldots$ & 140 & 14.3 \\
\hline $9 \ldots \ldots \ldots \ldots$ & 105 & 12.8 \\
\hline $10 \ldots \ldots \ldots \ldots$ & 531 & 7.5 \\
\hline $11 \ldots \ldots \ldots \ldots$ & 1,723 & 0.7 \\
\hline $12 \ldots \ldots \ldots \ldots \ldots$ & 1,477 & 0.1 \\
\hline $13 \ldots \ldots \ldots \ldots \ldots$ & 425 & 1.2 \\
\hline Average....... & 431.9 & 6.5 \\
\hline
\end{tabular}

$180^{\circ} \pm 2^{\circ} \mathrm{F}$ and $50 \pm 5$ per cent $\mathrm{RH}$. Techniques are described beginning on page 150 . The culture was maintained for 8 months corresponding to about 14 notes $1-3$, page 136 , for explanation.
TABLE 12

POPULATION TRENDS IN A SINGLE SPECIES CULTURE OF COMPERIELLA $B I F A S C I A T A^{1}$

\begin{tabular}{|c|c|c|}
\hline Generation number & Population & $\begin{array}{c}\text { Per cent } \\
\text { parasitization }\end{array}$ \\
\hline $1 \ldots \ldots \ldots \ldots \ldots \ldots$ & 120 & 13.0 \\
\hline $2 \ldots \ldots \ldots \ldots$ & 66 & 6.3 \\
\hline $3 \ldots \ldots \ldots \ldots$ & 277 & 9.2 \\
\hline $4 \ldots \ldots \ldots \ldots \ldots$ & 126 & 8.4 \\
\hline $5 \ldots \ldots \ldots \ldots \ldots \ldots$ & 139 & 11.8 \\
\hline $6 \ldots \ldots \ldots \ldots$ & 169 & 11.5 \\
\hline $7 \ldots \ldots \ldots \ldots \ldots \ldots$ & 188 & 21.0 \\
\hline $8 \ldots \ldots \ldots$ & 212 & 16.6 \\
\hline $9 \ldots$ & 198 & 14.9 \\
\hline $10 \ldots \ldots \ldots \ldots \ldots \ldots$ & 425 & 16.5 \\
\hline $11 \ldots \ldots \ldots \ldots \ldots$ & 369 & 10.6 \\
\hline $12 \ldots \ldots$ & 519 & 16.3 \\
\hline $13 \ldots \ldots \ldots \ldots \ldots \ldots \ldots$ & 277 & 13.3 \\
\hline $14 \ldots \ldots \ldots$ & 226 & 19.2 \\
\hline Average. . & 236.5 & 13.5 \\
\hline
\end{tabular}

1 Host: California red scale; temperature: $80^{\circ} \pm$ $2^{\circ} \mathrm{F}$ with $50 \pm 5$ per cent $\mathrm{RH}$. Techniques are described beginning on page 150 . The culture was main. tained for $8 \frac{1 / 2}{2}$ months, corresponding to about 9.3 actual generations.

counts (Generation number) were made every 18 days (that is, $1 \frac{1 / 3}{3}$ counts per generation). The counts, however, give a good index as to how the populations fluctuated from generation to generation. The $C$. bifasciata culture was maintained for about $81 / 2$ months.

The number of parasites in the Aphytis lingnanensis culture (table 11) fluctuated more than the number in the Comperiella bifasciata culture. The A. lingnanensis culture ran for 8

TABLe 13

POPULATION TRENDS IN A SINGLE SPECIES CULTURE OF PROSPALTELLA PERNICIOSI

\begin{tabular}{|c|c|c|}
\hline Generation number & Population & $\begin{array}{c}\text { Per cent } \\
\text { parasitization }\end{array}$ \\
\hline $1 \ldots \ldots \ldots$ & 358 & 14.4 \\
\hline $2 \ldots \ldots \ldots$ & 529 & 10.7 \\
\hline $3 \ldots$ & 743 & 11.0 \\
\hline $4 \ldots$ & 881 & 9.1 \\
\hline $5 \ldots$ & 907 & 4.4 \\
\hline $6 \ldots \ldots \ldots \ldots \ldots$ & 1,014 & 0.7 \\
\hline Average. & 738.7 & 8.4 \\
\hline
\end{tabular}

1 Host: California red scale; temperature $80^{\circ} \pm$ $2^{\circ} \mathrm{F}$ with $50 \pm 5$ per cent $\mathrm{RH}$. Techniques are de scribed beginning on page 150 , except that this culture was maintained in a smaller universe, as described on page 152. The total period was $3 \frac{1}{2}$ months; corresponding to 5.3 actual generations when second stage scales are used as hosts. 
months. In this case, each so-called generation represented about $1 \frac{1}{2}$ actual generations but, again, the index to population trends was the important thing. As seen in table 11, the number of parasites ranged between 23 and 1,723 during the course of the test. The marked decreases in the number of parasites following peaks very probably resulted from overstinging (superparasitism) and excessive host-feeding in relation to the host population. The data in table 4 and table 11 differ because each set was obtained using different hosts in different types of laboratory universes. Since the oleander scale is a much better laboratory host for $A$. lingnanensis than the red scale, much higher parasitization always results when it is used (see DeBach and White, 1960).

Cultures of Prospaltella perniciosi were unsuccessful in the type of cage used to culture Aphytis lingnanensis and Comperiella bifasciata. Although the host material was at suitable stages, only a few parasites developed. Apparently $P$. perniciosi does not do well in the insectary unless closely confined to the host-bearing lemons. Finally, a smaller glass container, which brought the parasites in close contact with the host material, proved successful. Results obtained with this culture are given in table 13. The number of parasites varied between 358 and 1,014 and, although this culture ran for only $3 \frac{1}{2}$ months, the indications are that it could have been maintained indefinitely at the approximate densities recorded.

It should be borne in mind that the scale-infested lemons remained in the cages for about 8 weeks before being rotated, and that they were attacked by the parasites as long as live scales were present. The scale populations on these lemons in the different cultures presented quite distinctive facies at the end of this period. On the lemons of the $A$. lingnanensis culture, nearly all the scales were dead either from parasitization or host-feeding. Only a few or very often no scale crawlers were produced, and only a few male scales survived to emerge as adults. Because of rapid mortality, the scales appeared much the same in size and number as at the time the lemons were initially introduced for parasitization. On the lemons from the $\dot{C}$. bifasciata culture, some scales were still alive when the lemons were removed after 8 weeks. At the time the counting started, many crawlers had been produced, and a great number of male scales had emerged. In this culture the number of scales increased during the 8-week period. In the $P$. perniciosi culture, the number of scales increased even more. Many crawlers had been produced and many males had emerged, so that the lemons were nearly covered with new scales.

These differences may be explained by the behavior peculiar to each species. As mentioned earlier, the host-feeding activity of Aphytis lingnanensis kills many scales. Because of this host-feeding, $A$. lingnanensis needs more scales to produce the same number of progeny as either of the two other species do. Thus, even though Prospaltella perniciosi produces more progeny per lemon, $A$. lingnanensis has more effect on the scale population. We obtained no evidence for such host-feeding by $P$. perniciosi or Comperiella bifasciata.

Prospaltella perniciosi maintained the highest average population density during these experiments but, as mentioned previously, during this period the number of scales increased considerably. Aphytis lingnanensis utilized virtually the total amount of host material available, whereas Comperiella bifasciata was intermediate in this respect. The average per cent parasitization was highest for $C$. bifasciata and lowest for $A$. lingnanensis; $P$. perniciosi was intermediate. Apparently neither fecundity (progeny production, table 10) nor per cent parasitization (tables $11,12,13)$ are good indices to population densities obtained in the singlespecies laboratory cultures. C. bifasci- 
$a t a$, with the highest fecundity, maintained the lowest average population density. It also showed the highest average per cent parasitization. It will be recalled that somewhat similar results were obtained with the cultures of the three species of Aphytis (table 4).

In spite of the lowest degree of parasitization in these experiments, $A$. lingnanensis, would seem to be a more efficient parasite than the other two from the standpoint of host population regulation.

Mixed-Species Populations. The mixed-species culture of Aphytis lingnanensis, Comperiella bifasciata, and Prospaltella perniciosi was set up in the same way as the single-species cultures, and with techniques and conditions as identical as possible. The culture was started with the same initial density (that is, 30 parental females) as used with each pure culture, which in this case meant 10 females of each of the three species. The test culture was maintained for about 8 months.

The results are given in table 14 . It will be noticed that no data for Prospaltella perniciosi are included in this table. This is because no $P$. perniciosi was produced. In order to determine if this had occurred by chance, another mixed-species culture was started, but again no $P$. perniciosi was produced. Finally, a third mixed-species culture was started in a smaller container, in
TABLE 14

POPULATION TRENDS SHOWING COEXISTENCE IN A MIXED SPECIES CULTURE OF

APHYTIS LINGNANENSIS AND COMPERIELLA BIFASCIATA ${ }^{1}$

\begin{tabular}{|c|c|c|c|}
\hline \multirow{2}{*}{$\begin{array}{c}\text { Generation } \\
\text { number }\end{array}$} & \multicolumn{2}{|c|}{ Population } & \multirow{2}{*}{$\begin{array}{l}\text { Total per } \\
\text { cent para- } \\
\text { sitization }\end{array}$} \\
\hline & $\begin{array}{c}\text { A. ling- } \\
\text { nanensis }\end{array}$ & $\begin{array}{c}\text { C. bi- } \\
\text { fasciata }\end{array}$ & \\
\hline $1 \ldots \ldots \ldots$ & 6 & 0 & 10.4 \\
\hline $2 \ldots \ldots$ & 8 & 19 & 12.8 \\
\hline $3 \ldots \ldots$ & 19 & 16 & 12.2 \\
\hline $4 \ldots \ldots$ & 68 & 178 & 10.8 \\
\hline $5 \ldots$ & 202 & 100 & 2.0 \\
\hline $6 \ldots \ldots$ & 197 & 160 & 2.6 \\
\hline $7 \ldots \ldots \ldots \ldots$ & 63 & 21 & 5.0 \\
\hline $8 \ldots \ldots \ldots$ & 56 & 2 & 15.6 \\
\hline $9 \ldots$ & 69 & 5 & 10.5 \\
\hline $10 \ldots$ & 254 & 15 & 9.5 \\
\hline $11 \ldots$ & 567 & 81 & 1.5 \\
\hline $12 \ldots \ldots$ & 530 & 75 & 0.4 \\
\hline $13 \ldots \ldots \ldots$ & 154 & 11 & 6.7 \\
\hline Average. & 168.7 & 52.5 & 7.7 \\
\hline
\end{tabular}

${ }^{1}$ Reared on California red scale. Experimental conditions and techniques the same as given for table 11. Total period involved was 8 months, approximately 14 actual generations for $A$. lingnanensis and about 9 for C. bifasciata.

the same way as was finally done for the single-species culture of $P$. perniciosi. This time $P$. perniciosi got started, but was eliminated after three generations (table 15). P. perniciosi was numerous in the $\mathrm{F}_{1}$ generation, but deceased rapidly.

Aphytis lingnanensis and Comperiella bifasciata coexisted for the duration of the test (8 months) shown in table 14. A. lingnanensis was more numerous

TABLE 15

POPULATION TRENDS. IN A MIXED SPECIES CULTURE OF APHYTIS LINGNANENSIS, COMPERIELLA BIFASCIATA AND PROSPALTELLA PERNICIOSI

Showing competitive displacement of $P$. perniciosi but coexistence of A. lingnanensis and $C$. bifasciata ${ }^{1}$

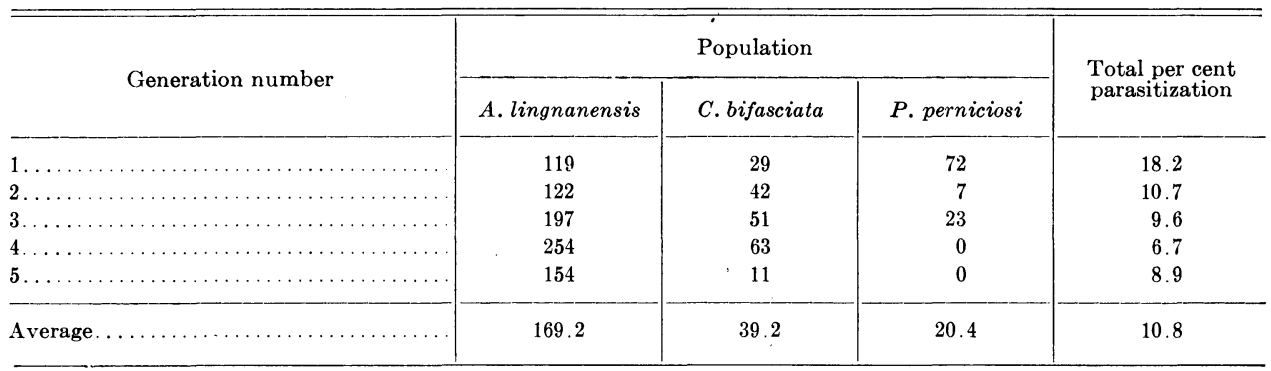

1 The same experimental conditions apply as for table 11, except that a smaller universe was used. 
than $C$. bifasciata most of the time, which is in accordance with the results of the single-species cultures (tables 11 and 12). Only on a few occasions did any lemons have more scales parasitized by $C$. bifasciata than by $A$. lingnanensis. It should be recalled that in these cultures each infested lemon could bear several generations of parasites. The per cent parasitization was higher than that obtained for the singlespecies culture of $A$. lingnanensis, but lower than that for $C$. bifasciata. However, the average total population of parasites (221.2) was a little less than that obtained for $C$. bifasciata when it was cultured alone, and only about one half that obtained for Aphytis lingnanensis cultured alone. Reasons for this are not readily apparent.

In spite of apparent coexistence at places in the field, why did only two of these three California red scale parasites coexist under laboratory conditions? The species' "optimal" biological characteristics (shown in table 10) suggest some causes. All three species appear to have relative advantages and disadvantages. Aphytis lingnanensis has the advantage of the shortest developmental period, only about half that of Comperiella bifasciata. On the other hand, A. lingnanensis has the lowest fecundity (progeny production) and the poorest sex ratio. A. lingnanensis also host-feeds, which reduces the number of hosts available for oviposition, but to counteract this it may have more than 1 pupa per scale, in contrast to the other two species. Since Prospaltella perniciosi is a uniparental parasite, males, which are a waste reproductively speaking, are not produced. It has a shorter developmental period than $C$. bifasciata and nearly as many progeny.

Based on the developmental period, progeny production, and sex ratio for the three species, we should, after 60 days, have about four generations of Aphytis lingnanensis, two generations of Comperiella bifasciata and three gen- erations of Prospaltella perniciosi (table 10). If all their offspring survived and reproduced, and if the fecundity and sex ratio remained the same, we would have the number of females of each species listed in the bottom line of table 10. This shows that $P$. perniciosi has by far the greatest potential to build up a population rapidly, but is still not able to coexist with the other species in our laboratory universe. Perhaps there were adverse factors in this universe, aside from the two other competing species, which were not recognized by us. It has already been emphasized that single-species cultures of $P$. perniciosi are not always easy to maintain.

The three species attack or prefer different stages of the host scale. Aphytis lingnanensis is able to parasitize red scale only during the second and third instars, and prefers the third, which means a maximum of only 10 days out of the host's life cycle of about 45 days. The two other parasites seem to be able to attack nearly all stages-both instar and molt_ of the scale, but Prospaltella perniciosi prefers to oviposit in second instars, while Comperiella bifasciata prefers third instar and mated female scales. About half the progeny of $P$. perniciosi develop in male scales, whereas $C$. bifasciata is rarely found in males. Aphytis lingnanensis commonly parasitizes but does not prefer early second-stage males.

This indicates, as previously discussed, that the three species have slightly different requisites and so perhaps should be able to coexist. On theoretical grounds and from field observations we expected them to coexist under laboratory conditions. We can only project some educated guesses about their failure to do so. During these experiments, the females came into contact with each other much more frequently than would usually be the case in the field. The experiments (tables 5, 8, and 9) with the three different mixedspecies cultures of Aphytis showed that 
this contact interference between species did not affect fecundity. The Aphytis species closely resemble one another in morphology, color, size, and action. The species in the last experiments differ markedly from one another. Comperiella bifasciata is much the largest. Prospaltella perniciosi is a little smaller than Aphytis lingnanensis. Both $P$. perniciosi and $C$. bifasciata are dark, while the Aphytis spp. are golden yellow. Their actions are quite different; hence the Aphytis spp. or $C$. bifasciata, or both, may actively interfere as adults with $P$. perniciosi.

In order, perhaps, to shed a little light on what happened in the mixedspecies culture (table 15), the effect on progeny production of inter- and intraspecific contact interference between adults of the three species was tested. In these tests, the same numbers of individuals were confined together in a small container, using a density of 4 females per lemon fruit. Some tests combined $2 A$. lingnanensis with $2 C$. bifasciata females; others, $2 A$. lingnanensis with $2 P$. perniciosi females; and yet others, $2 C$. bifasciata with 2 $P$. perniciosi females. For the controls, 4 females of each species were tested alone. The results are shown in table 16. Progeny production in the various combinations differed considerably. $A$. lingnanensis and C. bifasciata had about the same progeny production whether tested alone or with each other, but they both had a higher progeny production when tested with $P$. perniciosi than when tested alone. $P$. perniciosi had a much higher progeny production when tested alone, and a much lower progeny production when tested together with A. lingnanensis (31\% of expected) or with C. bifasciata $(69 \%$ of expected).

In this test we must consider not only an effect from interference between the females, but also from competition between the larvae. In experiments where females of Aphytis lingnanensis were confined with scales containing fullgrown larvae of Prospaltella perniciosi, no oviposition seemed to occur, at least no $A$. lingnanensis developed on this material. It seems quite likely that $A$. lingnanensis will not attack scales which have previously been oviposited in by an internal parasite but this has not been tested. In any event, in these tests (table 16) there were plenty of scales available to each female for oviposition, hence larval competition should have been at a minimum. In spite of this, the results show severe competition between $A$. lingnanensis

TABLE 16

EFFECT OF INTER- AND INTRASPECIFIC INTERFERENCE BETWEEN ADULTS ON PROGENY PRODUCTION BY APHYTIS LINGNANENSIS, COMPERIELLA BIFASCIATA AND PROSPALTELLA PERNICIOSI

\begin{tabular}{|c|c|c|c|c|c|c|c|}
\hline \multirow{2}{*}{ Test number } & \multicolumn{4}{|c|}{ Density of parental females } & \multicolumn{3}{|c|}{ Mean progeny per female ${ }^{1}$} \\
\hline & Total & $\begin{array}{c}\text { A. ling- } \\
\text { nanensis }\end{array}$ & $\begin{array}{c}\text { C. bi- } \\
\text { fasciata }\end{array}$ & $\begin{array}{l}P . \text { per- } \\
\text { niciosi }\end{array}$ & $\begin{array}{l}\text { A. ling- } \\
\text { nanensis }\end{array}$ & $\begin{array}{c}\text { C. bi- } \\
\text { fasciata }\end{array}$ & $\begin{array}{l}P . p e r- \\
\text { niciosi }\end{array}$ \\
\hline & & \multicolumn{6}{|c|}{ Mixed species combinations } \\
\hline $1 \ldots$ & 4 & 2 & 2 & $\ldots$ & 29.8 & 27.2 & $\ldots$ \\
\hline $2 \ldots$ & 4 & 2 & . & 2 & 57.5 & $\cdots$ & 5.3 \\
\hline $3 \ldots$ & 4 & . & 2 & 2 & $\cdots$ & 34.2 & 11.9 \\
\hline & & \multicolumn{6}{|c|}{ Single species } \\
\hline $4 \ldots \ldots \ldots$ & 4 & 4 & . & . & 33.7 & $\ldots$ & $\ldots$ \\
\hline $5 \ldots \ldots \ldots \ldots$ & 4 & .. & 4 & . & $\cdots$ & 26.6 & $\cdots$ \\
\hline $6 \ldots \ldots \ldots \ldots$ & 4 & . & . & 4 & $\ldots$ & $\ldots$ & 17.1 \\
\hline
\end{tabular}

1 Ten replicates were used to obtain the mean progeny figures. In each replicate a small cage was used containing 4 mated females on each lemon which bore 400 to 450 scales. In each test, the total progeny production of 40 parental females ranged between a minimum of 684
California red scale was the host. 
and $P$. perniciosi which greatly reduced the fecundity of the latter. Contact interference between adults (that is, disturbance) would seem to offer the most likely explanation. Between $C$. bifasciata and $A$. lingnanensis adults, little or no competition appeared to exist. Table 16 shows about the same progeny production per female whether these species were tested alone or in combination with each other. The lower number of progeny obtained from $C$. bifasciata with respect to $A$. lingnanensis in the mixed-species culture (table 14), as compared to the results obtained in table 16, may be explained by the fact that fewer scales were available for oviposition since $A$. lingnanensis caused host-feeding mortality in a universe with a relative shortage of hosts. In the present test (table 16) a surplus of hosts was present so that host-feeding by $A$. lingnanensis did not seriously restrict the number of hosts available to $C$. bifasciata.

Past work has emphasized that $A$. lingnanensis host-feeds on and kills third-instar scales, but little data were available concerning the effect of hostfeeding or ovipositional probing on mortality of first-stage or second-instar scales. It was reasoned that if young scales were killed in this manner, those which would have been preferred by Prospaltella perniciosi for oviposition might largely be destroyed. Tests therefore were run to determine if the younger scales were killed by $A$. lingnanensis. Females of $A$. lingnanensis were placed on lemons bearing scales ranging in age from 5 to 14 days. Examination 12 days later showed that nearly all scales were dead. No parasite progeny developed on the youngest scales; however, on the somewhat older scales some parasite pupae were observed. This proves that even scales too small to bear parasite larvae are killed by $A$. lingnanensis and this, of course, in a mixed-species culture would greatly reduce the potential of $P$. perniciosi, which prefers to oviposit in second-instar scales.

When this is considered, together with the adverse effects on $P$. perniciosi from interference between adults (table 16), we may have the explanation for the elimination of $P$. perniciosi from the mixed-species culture (table 15). It should also be emphasized here that although $P$. perniciosi has coexisted with Aphytis species, and in some localities with Comperiella bifasciata, for about 12 years, there are indications that $P$. perniciosi populations are decreasing and may even have disappeared in some areas. Data are not extensive enough as yet to demonstrate this with certainty. Originally, $P$. perniciosi became established (1949) when A. chrysomphali was still the dominant red scale parasite. Perhaps there was less competition with $A$. chrysomphali than there is with the other Aphytis species. We know that $A$. chrysomphali has a lower fecundity and host-feeds less than $A$. lingnanensis under most conditions (DeBach and Sisojevié, 1960). Today (December, 1961), $P$. perniciosi remains common only in strictly coastal areas; these are the localities where $A$. chrysomphati also has survived the longest.

The mixed-species tests on species having similar, but different, ecological niches shows that it is possible for such species to coexist but that they may not do so under certain conditions.

\section{DISCUSSION AND CONCLUSIONS}

This paper is primarily devoted to the consideration of competitive displacement between ecological homologues. The latter comprise different species having identical ecological niches. Coexistence is shown to be pos- sible between species having only slightly different ecological niches, but no assumption or inference. is made that competitive displacement (or less drastic population changes) never occurs as a result of interaction between 
species having different ecological niches. We are simply not emphasizing the latter aspects of competition here. Furthermore, no assumption is made that competitive displacement between ecological homologues is one of the leading aspects of natural control, of the regulation of animal population densities or of their distribution in nature, or, for that matter, that competitive displacement is the most important aspect of the field of competition. The probability is great that competitive displacement between ecological homologues is a fairly rare occurrence in nature because relatively few species have identical ecological niches. On the other hand, this does not mean that it is unimportant.

We stress these points principally because when Patten (1961) advocated "that the principle of competitive exclusion be regarded as only a small segment of a broad class of interspecific phenomena," he was voicing an opinion held by some other ecologists who consider that the "principle" has been overstressed. We, and probably most ecologists, have never considered the "principle" to encompass more than a phase of the field of interspecific competition. We cannot agree with Patten that the continued recognition of the principle (or hypothesis) at "law" status can only interfere with a healthy development of concepts whose further disquisition it tends to block. Indeed, the hypothesis or principle actually may prove to be a biological "law," albeit with a restricted application. The restricted nature of the "principle" certainly distinguishes it and separates it from other phases of competition and population interaction. Thus there should be no conflict regardless of whether we are dealing with a hypothesis, a principle, or a law.

\section{Past Work}

A rather large body of laboratory experiments on ecological homologues grown in mixed-species cultures has shown that competitive displacement of one species by the other always occurs. The winner, however, is not always the same. When physical or biological characteristics undergo change, the expected victor may be displaced.

Various field observations involving quite a few species of animals have indicated that competitive displacement has occurred in nature. Usually, however, the mechanism of displacement has not been demonstrated nor was it certain that competing species were ecological homologues.

\section{Present Work}

Laboratory Studies. Experiments at a controlled temperature of $80^{\circ} \mathrm{F}$ on mixed-species cultures of any two of the three ecological homologues, Aphytis lingnanensis, $A$. fisheri, and $A$. melinus, showed that one species always completely displaced the other within 8 generations. A. lingnanensis won over each of the others, and $A$. fisheri displaced $A$. melinus. It was shown that displacement would occur in the presence of a surplus of food (hosts); that is, food shortage is not a necessary requisite for competitive displacement. Differences in relative fecundity and survival of immature stages, as reflected by $\mathrm{F}_{1}$ progeny production at $80^{\circ} \mathrm{F}$, appear to explain the results. Differences in inherent fecundity between species may be sufficient explanation under certain conditions. Some aggressive competition occurred between larvae of different species, but this was a minor factor which was mirrored in the resultant progeny production. Since interspecific competition between adults was no more severe than intraspecific competition, it was not a factor in competitive displacement. Relative searching ability was not a factor in these tests inasmuch as the parasites were confined in a limited universe with their hosts.

Mixed-species experiments with species having only slightly different ecological niches (Aphytis lingnanensis, Comperiella bifasciata, and Prospal- 
tella perniciosi) showed that coexistence can occur but not necessarily. When these three were cultured together, $A$. lingnanensis and $C$. bifasciata continued to coexist, but $P$. perniciosi was eliminated. The difference in ecological niches between $A$. lingnanensis and $C$. bifasciata is extremely slight since both parasitize the same host.

Field Studies. Three species of Aphytis having identical ecological niches were observed in the field and used in experiments for as long as 14 years in some cases. All three are parasites of the California red scale on citrus in southern California. A. chrysomphati was generally distributed throughout the citrus-growing areas of southern California when these studies were started in 1947. A. lingnanensis was introduced from China and established in 1948 . It proceeded to virtually replace $A$. chrysomphali in interior and intermediate climatic areas by 1958. $A$. melinus was introduced from India and Pakistan in 1956 to 1957 and became established at once. By 1961, it had almost completely displaced $A$. lingnanensis in interior climatic areas. However, $A$. lingnanensis precluded the successful establishment of $A$. melinus in the intermediate climatic areas of San Diego County, where the physical environment certainly is favorable to $A$. melinus. The fact that $A$. melinus can win under certain conditions showed that larval competition (which was shown to favor $A$. lingnanensis in the laboratory studies) was not a fundamental factor in competitive displacement between these species.

The displacement of Aphytis lingnanensis by $A$. melinus in interior climatic areas would not have been predicted from the laboratory studies, which showed $A$. lingnanensis to be the winner and to have apparently significant biological advantages, such as greater progeny production. Why then did $A$. melinus replace $A$. lingnanensis in certain field areas? Several likely possibilities come to mind, principally:
(1) the searching ability of $A$. melinus may be somewhat better than that of $A$. lingnanensis so that, in an environment where each otherwise has very similar biological abilities, A. melinus might win; (2) A. melinus may be better adapted than $A$. lingnanensis to the physical aspects of the interior climatic areas; past work has shown $A$. lingnanensis populations to be periodically depressed by winter cold and summer heat; and (3) the most likely explanation, which we failed to recognize earlier, may be that $A$. melinus does not prefer the oleander scale as a host. The laboratory mixed-species tests with three species of Aphytis were made on oleander scale alone. We knew from previous studies that $A$. lingnanensis and some other species of Aphytis did better in the laboratory on oleander scale than they did on California red scale, and we assumed that this applied to $A$. melinus. We have recently conducted tests which indicate that the $\mathrm{F}_{1}$ progeny production of $A$. melinus on California red scale is greater than on oleander scale. Inasmuch as the California red scale is by far the predominant host in the field, this may largely explain why $A$. melinus can do better under certain conditions in the field than the laboratory experiments indicated it could.

Aphytis chrysomphali is now (end of 1961) apparently restricted to a few localities along the immediate coast. It was shown (DeBach and Sisojevié, $1960)$ that the environmental conditions in such areas probably represent the optimum for $A$. chrysomphali but are suboptimum for $A$. lingnanensis. The result may be that the relative competitive abilities of the two are rather evenly matched in these localities (see discussion, page 123).

Regardless of which species has been the winner in particular climatic areas of southern California, absolute shortage of food would not seem to have been a critical factor. This was shown to be the case in the laboratory studies. In 
the interior areas where first $A$. lingnanensis was introduced and displaced $A$. chrysomphali, and then later $A$. melinus was introduced and displaced $A$. lingnanensis, their food, the California red scale, is one of the most common insects on citrus and on many ornamentals. Displacement of one species by another has been observed in citrus groves having continuously heavy California red scale infestations.

During this entire period (1948 to 1961) two species (Comperiella bifasciata and Prospaltella perniciosi), whose ecological niches differ only slightly from those of the Aphytis species, have coexisted with one or another species of Aphytis in the field. They all parasitize the California red scale. The only apparent difference in their niches is that the Aphytis species cannot attack certain host stages that the other two do. C. bifasciata coexists with the Aphytis species in interior and, to a lesser extent, in intermediate climatic areas. It is a common parasite and sometimes more numerous than the Aphytis species at certain times or places. It does not occur along the coast. $P$. perniciosi is very rare in interior areas and most common, sometimes dominant, in certain restricted coastal localities, principally in San Diego County. C. bifasciata has coexisted with the Aphytis species since its introduction from China in 1941, and P. perniciosi has coexisted with the Aphytis species since its introduction from China in 1949. P. perniciosi was once much more common in interior areas and more, promising in general than it is today (DeBach, 1953). Perhaps its gradual displacement is occurring. When $P$. perniciosi was first colonized in 1949 A. chrysomphali constituted its main competition, but $A$. chrysomphali subsequently was displaced in most areas by $A$. lingnanensis. Most evidence indicates that $A$. chrysomphali would offer less competition to $P$. perniciosi than would $A$. lingnanensis. It may be significant that $P$. perniciosi was most common during 1960 in coastal areas of San Diego County where A. chrysomphali was also found to be most common. It will be recalled that $P$. perniciosi failed to coexist along with $A$. lingnanensis and $C$. bifasciata in a mixed culture.

These field studies and their laboratory counterparts emphasize that very slight differences in the ecological niches of two or more species may permit coexistence. If two species of scale parasites attack the same stage of the host, one species will be displaced. If different stages of the host are attacked, the species may coexist, other conditions being suitable. In the present cases, the differences are so slight that the average observer might take their niches to be identical and hence conclude that ecological homologues can coexist. It could well be that some claims of. this nature, such as Ross' observations (1957) on "coexistence" between different species of leafhoppers on the same plant, would show upon further study that the species studied possessed slight, but significant, differences in ecological niches.

\section{The Mechanism of Competitive Displacement}

From studies of natural selection and population geneties we know that the winner, or dominant form, needs only a slight selective advantage. Such an advantage merely means that the organism in question produces more $F_{1}$ progeny than a competing strain. Since individuals are of the same species, their ecological niches will nearly always be identical, unless perhaps the strains have nearly evolved to species status and have acquired different food or other essential habits.

The same applies to competitive displacement between ecological homologues. The winner need have an advantage only in actual progeny production (as measured by $F_{1}$ progeny survival and reproduction-not number of eggs laid or young produced). As Har- 
din (1960) puts it, "No difference in rates of multiplication can be so slight as to negate the exclusion principle"; and "Competitive differences that are so small as to be unmeasurable by direct means will, by virtue of the compound-interest effect, ultimately result in the extinction of one competing species by another."

The ultimate determinant of the winner in any case of competition between ecological homologues is the production by one of the most progeny which reach maturity and reproduce themselves. Many factors aside from the intrinsic fecundity of a species will influence the production of progeny and their survival to reproducing adulthood. Such factors can result in great variations in progeny production. Depending then on the relative effects of these factors on different species in diverse environments, one species may win in one environment, the other species in another.

Physical factors, interspecific aggressiveness, interference, or combat between adults or young may influence the number of eggs laid, of young produced, or of survivors to adulthood, and these may determine the winner. But, even when factors differentially adverse to species $\mathrm{A}$ are operating, unless under certain conditions they reduce the progeny production of species $\mathrm{A}$ below that of its ecological homologue, species $B$, species A will displace species B. Direct acts of aggression are not necessary for competitive displacement between ecological homologues to occur. It will occur between two species which are no more aware of, or just as indifferent to, each other as individuals of the same species would be. Also, the laboratory results (table 6) showed, and our field observations and experiments confirmed, that absolute shortage of food is not a requisite for competitive displacement.

The exact type of food required and the place and time of obtaining it would appear to be the most eritical factors determining if one species is an ecological homologue of another. However, with some species, a need for the same "lebensraum" (space in which to live) may be the key factor. All other factors, such as attack by parasites or temperature (if tolerable), are incidental influences on the $\mathrm{F}_{1}$ progeny production which may determine the winner between two ecological homologues but which by themselves would not eradicate one species or the other in a given habitat. When considering whether the food utilized by different species is exactly the same, it should be clear that organisms feeding simultaneously on a given plant do not necessarily utilize the same food and hence are not necessarily ecological homologues. Some may feed on leaves, even on only one surface; some, on or in twigs; some, on flowers, fruits, or perhaps only seeds; and so on ad infinitum. Also, some species may feed on seedlings or new leaves only; others may feed only on the same plant in its mature stages. Even though these various organisms occur in the same habitat and feed on the same general food they are not ecological homologues and hence might coexist.

Among insect parasites and other animals, relative searching ability is a highly important biological characteristic. Parasites which can find hosts (food), and thus leave progeny when hosts are scarce, obviously have an advantage over a species which can survive on the same hosts only when they are abundant and easy to locate. Although the latter species may have a high intrinsic fecundity, its poor searching ability will result in decreasing progeny production as host populations decline. Below certain host-population levels it will die out. Thus, in a given habitat it is clear that the latter species can be displaced by one which has a lower intrinsic fecundity but which is an efficient searcher. This is because the efficient searcher is capable of regulating food (or host) population densities below the level at which the poorer 
searcher can exist (Nicholson, 1933, pages 144, 152). Although differences in searching ability may not be readily apparent or measurable in laboratory studies on competition, it should be borne in mind that they may play a key role in the results obtained between competing species in the field.

There are many conditions under which ecological homologues can appear to coexist in a particular habitat. Theoretically, they could coexist if each had an identical progeny production but we, along with Hardin (1960), adhere to "the axiom of inequality, which states that no two things or processes, in a real world, are precisely equal." In his attempt to show that species having identical ecological niches can coexist in the same habitat, Cole (1960, page 349 ), interestingly enough, utilizes in his mathematical illustration two hypothetical species that have identical progeny (seed) productions.

There may be, however, some special situations in which ecological homologues could coexist in the same habitat. For instance, coexistence would seem possible between two ecological homologues each of which had the same two (or more) kinds of alternate foods (or hosts), providing one species had the greater $F_{1}$ progeny production on one food (host) and the other species had the greater progeny production on the alternate kind of food. Other possibilities, including some discussed by Hutchinson and Lack, are mentioned by Utida (1953, page 306) whose conclusion-that two competing species which do not coexist can do so if both are attacked by a common parasitehas been questioned on page 111 of this paper.

Some conditions under which ecological homologues may appear to coexist are: (1) They appear to have identical ecological niches but really do not. They actually have minute, unnoticed-but important-differences in ecological niches, such as Comperiella bifasciata and Aphytis species do. (2)
They inhabit adjacent habitats and, therefore, migration results in overlapping. This may occur when one is superior (the winner) in one habitat and the other is the winner in an adjacent, slightly different, habitat. The distance involved can be small and the separately maintained reservoirs can permit survival of both, with resultant overlapping and apparent coexistence. (3) One may have an alternate but cryptic food (or host), whereas the other (actually the superior one) does not. The first is able to survive on its alternate food. (4) Periodic migration from relatively long distances may permit temporary mixing and apparent coexistence. Seasons which temporarily favor the invader could provide even more confusion for the observer. (5) Accidental transfer through human agency or commerce could produce results as in (4) above, although probably less frequently and for shorter durations. However, frequent, transfers again could lead to considerable confusion. (6) Coexistence may be apparent merely because enough time has not elapsed for displacement to occur. Coexistence can be apparent at any moment following an invasion up to the time one species is eliminated. The time required for elimination may be long if the invader has but a slight advantage over the established species.

\section{The Importance of Competitive Displacement}

As an actual occurrence in nature, competitive displacement between ecological homologues may be rather unusual. This is because most species probably dó not have ecological homologues. Those that do undoubtedly seldom come together. Most important, the cases in which this occurs are rarely observed by man. Thus, the occurrence of competitive displacement between ecological homologues, although not common, is undoubtedly thought to be more rare in nature and of less significance by far than it actually is. 
We have been privileged to record the definite occurrence of competitive displacement in ecological homologues in nature. The results are certainly much more drastic than would occur following most types of interspecific action. The results could also be most perplexing to the ecologist. How could one explain the failure of Aphytis melinus to become established in most of San Diego County where the climate should be ideal for it and where it was colonized in large numbers in many sites with abundant food (hosts) present? This would present quite a paradox, if we did not know that $A$. lingnanensis was already well established in San Diego County, that the two species are ecological homologues, and that $A$. lingnanensis displaced $A$. melinus in laboratory cultures.

We would be hard put to explain the distribution of the three species of Aphytis studied if we tried to do it on the basis of a presumed effect from meteorological factors alone. We know that each species, by itself, can exist throughout the citrus areas of southern California. However, an observer making a study today would find three species with more or less distinct areas of distribution and with little or no evidence of competition between them except where $A$. melinus and $A$. lingnanensis currently overlap. Having missed the process of displacement, he would be unable to correctly explain the current distribution except by guesswork or by appropriate laboratory studies, which even then would only make the guesswork more educated. This discussion should make it clear that competitive displacement can be of great importance, yet cryptic, in any given ecological field study.

The hypothesis of competitive displacement between ecological homologues, if true, is of utmost importance in evolution. Inasmuch as ecological homologues cannot coexist, evolution involving changes in the ecological niche of the evolving form must occur before the evolving and the ancestral forms can exist in the same habitat. Differentiation is the key to coexistence. Any form developing a slightly different ecological niche, principally a somewhat different food, would have a great selective advantage and might eventually become reproductively isolated and develop into a distinct species even in the same habitat. Before reproductive isolation can occur, adaptive races which at least use different foods and perhaps differ otherwise, must evolve from the ancestral species. Eventually the new species can coexist with the original one. Regardless of how much a strain has changed morphologically, if it has not developed a different ecological niche it will still be competing with the parental form. If it eventually becomes reproductively isolated, one or the other will be replaced. As soon as an adaptation to different food occurs, this adapted segment of the population can expand to fill the potential of the new food supply. Reproductive isolation can then follow without competitive displacement of one species by the other. The adaptation to different niches and the resultant diminution of competition would appear to be one of the high roads to evolution.

Ecological homologues probably arise from the development of physical or climatic barriers across the range of a species. This gives rise to the geographical isolation of two or more segments of the original population. Ultimately, reproductive isolation may develop in these segments without a simultaneous change in food or other essential requirements. The resultant species would be ecological homologues.

The hypothesis assumes considerable importance in biological control work where multiple species of natural enemies are frequently introduced in attempts to obtain efficient regulation of pest insect populations. In cases where more than one species of natural enemy is known to attack precisely the 
same host stage, we would suspect them to be ecological homologues and not to be able to coexist in the same habitat. If one species is already established on a given host (or host stage) is it wise to introduce an ecological homologuea competitor? According to the hypothesis, the imported species should either displace the previously established one or itself be excluded. If it replaces the original species, it is because the new one leaves more progeny. This should result in better population regulation of the host. New ecological homologues should be sought which have a better searching ability and higher progeny production in the new habitat. This, of course, may depend on a satisfactory adaptation to the physical environment of the new habitat.

A seeming paradox may occur when a newly introduced parasite replaces a former one by competitive displacement. The new one, after it has eliminated the old one, may exist at a much lower average population density than its predecessor even though it had to leave more progeny than the original species in order to displace it. However, because it leaves more progeny, it follows that it finds more hosts and that its searching capacity is probably better. The higher the searching capacity of a parasitic species, the lower it will maintain the host population density, other things being equal, and therefore the scarcer the parasites will be. Thus it sometimes follows that "a good parasite is a scarce parasite." It is well to bear this in mind in searching for new parasites to import for biological control projects.

\section{SUMMARY}

Competitive displacement between ecological homologues, known also as Gause's Law and the Competitive Exclusion Principle, is defined and reviewed in detail. In the field in southern California from 1948 to 1958 competitive displacement of Aphytis chrysomphali (Mercet) by an introduced exotic ecological homologue (from China, 1948), A. lingnanensis Compere, took place throughout nearly all of the former range of $A$. chrysomphali-an area of about 4,000 square miles. Subsequently, $A$. melinus DeBach, another introduced exotic ecological homologue (from India and Pakistan, 1956 and 1957) of the two aforementioned species, virtually displaced $A$. lingnanensis from interior climatic areas (about 500 square miles) during the period 1957 to 1961. This displacement appears to be continuing and spreading. Originally, displacement occurred at many separate foci; thus these can be considered equivalent to many replicated tests. It is emphasized that host scales (food) were abundant and were never thoroughly utilized in interior climatic areas. Thus, an absolute food shortage is not necessary for competitive displacement to occur. In the intermediate climatic areas of San Diego County, $A$. lingnanensis precluded the establishment of $A$. melinus. These species are external parasites of the California red scale, Aonidiella aurantii (Maskell). Meanwhile, two species (Comperiella bifasciata Howard and Prospaltella perniciosi Tower) which are internal parasites of the same scale host but whose ecological niches differ slightly from those of the Aphytis species (that is, they are not ecological homologues), have continued to coexist with one or another species of Aphytis in the field.

Experimental studies in controlled laboratory universes at $80^{\circ} \mathrm{F}$ with mixed-species populations of any two of the three ecological homologues, Aphytis lingnanensis, A. melinus, and A. fisheri, showed that one species always eliminated the other. A. lingnanensis was the winner over either of the others, and $A$. fisheri eliminated $A$. melinus. Evaluation of the species' biological characteristics showed the spe- 
cies with the highest number of $F_{1}$ progeny to be the winner in any paired interspecific competition. Under conditions of the tests, inherent fecundity was the factor of most consequence, although aggressive competition between larvae favored $A$. lingnanensis slightly. The latter fact is interpreted as equivalent to giving $A$. lingnanensis a slightly greater advantage in progeny production. Had physical or other conditions of the tests been changed, the winners very likely would have been different, as was demonstrated by the field results where $A$. lingnanensis won in certain localities and $A$. melinus in others. Although relative searching ability was not a factor in the laboratory populations, its importance in the field is emphasized. Parallel laboratory tests with single-species populations of the same three Aphytis species showed that high fecundity was not correlated with success as measured by average population density attained, even though relative progeny production determine the winner in mixed-species populations. An experimental model was tested, on the premise that the parasite population was in balance with a host population which existed at high host densities (as would be the case in the field with a relatively ineffective parasite). In this test equal initial numbers of $A$. lingnanensis and $A$. fisheri were confined with a large surplus of hosts. The total parasite population and the host population were held constant over a period of generations, but the proportion of each species changed according to their relative progeny production in the preceding generation. $A$. lingnanensis - whose progeny production was higher-eliminated $A$. fisheri after 9 generations, thus demonstrating that host (food) scarcity is not necessary for displacement to occur.

In controlled laboratory universes at $80^{\circ} \mathrm{F}$, experimental studies with mixedspecies populations of three species having slightly different ecological niches (they attack different stages of the same host) showed that Aphytis lingnanensis and Comperiella bifasciata coexist but that Prospaltella perniciosi is displaced. Relative fecundity as determined in single-species tests does not explain the displacement. Other reasons are discussed. These results agree with the situation in the field except that $P$. perniciosi has coexisted with the Aphytis species and $C$. bifasciata in some areas for about 13 years. However, field observations indicate that the distribution and abundance of $P$. perniciosi is gradually decreasing. 


\section{LITERATURE CITED}

ANDREwartha, H. G., and L. C. Birch

1954. The distribution and abundance of animals. The University of Chicago Press, Chicago, Illinois. $782 \mathrm{p}$.

1960. Some recent contributions to the study of the distribution and abundance of insects. Ann. Rev. Entomol. 5: 219-242.

Benassy, C., and H. Bianchi

1960. Sur l'ecologie de Prospaltella perniciosi Tower (Hym. Aphelinidae), parasite specifique importe de Quadraspidiotus perniciosus Comst. (Hom. Diaspidinae). Entomophaga $5(2): 165-181$.

Brown, William L., JR.

1958. Some zoological concepts applied to problems in evolution of the hominid lineage. Am.

COLE, L. C. Scientist $46(2): 151-158$

1960. Competitive exclusion. Science 132(3423) : 348-349.

COMPERE, H., and H. S. SMITH

1927. Note on the life history of two Oriental chalcidoid parasites of Chrysomphalus. Univ. California Publ. Entomol. 4 : 63-73.

CONNELL, JOSEPH H.

1961. The influence of interspecific competition and other factors on the distribution of the barnacle Chthamalus stellatus. Ecology 42(4) : 710-723.

Crombie, A. C.

1945. On competition between different species of graminivorous insects. Roy. Soc. London, Proc., Ser. B(132) : 362-395.

1946. Further experiments on insect competition. Roy. Soc. London, Proc., Ser. B(133):76109.

1947. Interspecific competition. J. Animal Ecol. 16: 44-73.

DARWIN, CHARLES

1859. On the origin of species. Reprinted 1909. Cassell and Co., Ltd., London. $430 \mathrm{p}$.

DeBach, PaUL

1953. The establishment in California of an Oriental strain of Prospaltella perniciosi Tower on the California red scale. J. Econ. Entomol. 46(6): 1103.

1954. Relative efficacy of the red scale parasites Aphytis chrysomphali Mercet and Aphytis "A" on citrus trees in southern California. Portici Lab. Zool. Gen. e Agr. Boll. (Filippo Silvestri) 33: 135-151.

1959. New species and strains of Aphytis (Hymenoptera, Eulophidae) parasitic on the California red scale, Aonidiella aurantii (Mask.), in the Orient. Entomol. Soc. Am. Ann. $52(4)$ : $354-362$.

DeBach, Paul, T. W. Fisher, and John Landi

1955. Some effects of meteorological factors on all stages of Aphytis lingnanensis, a parasite of the California red scale. Ecology 36(4): 743-753.

DeBach, Paul, C. A. Fleschner, and E. J. Dietrick

1953. Natural control of the California red scale in untreated citrus orchards in southern California. Seventh Pacific Sci. Congr. Proc. 4: 236-248.

DeBach, Paul, and John Landi

1959. New parasites of California red scale. California Citrograph 44(9): 290, 301-304

1961. The introduced purple scale parasite, Aphytis lepidosaphes Compere, and a method of integrating chemical with biological control. Hilgardia 31(14): 459-497.

DeBach, Paul, and Pelagija Sisojević

1960. Some effects of temperature and competition on the distribution and relative abundance of Aphytis lingnanensis and A. chrysomphali (Hymenoptera: Aphelinidae). Ecology 41(1): 153-160.

DeBach, Paul, and Ernest B. White

1960. Commercial mass culture of the California red scale parasite, Aphytis lingnanensis. California Agr. Expt. Sta. Bull. 770. 58 p.

ELton, C. S.

1927. Animal ecology. Sidgwick and Jackson, London. $207 \mathrm{p}$.

1958. The ecology of invasions by animals and plants. Methuen and Co., London. $181 \mathrm{p}$

Elton, C. S., AND R. S. MiLLER

1954. The ecological survey of animal communities, with a practical system of classifying habitats by structural characters. J. Ecol. 42: 460-496.

Flanders, Stanley E.

1944. Observations on Comperiella bifasciata, an endoparasite of diaspine coccids. Entomol. Soc. Am. Ann. 37(3): 365-371. 
Gause, G. F.

1934. The struggle for existence. Williams and Wilkins Co., Baltimore. $163 \mathrm{p}$.

HaIrston, NeLson G.

1959. Species abundance and community organization. Ecology $40(3): 404-416$.

HARDIN, GARRETT

1960. The competitive exclusion principle. Science 131(3409): 1292-1298.

KUENZLER, EDWARD J.

1958. Niche relations of three species of lycosid spiders. Ecology 39(3): 494-500.

LACK, D.

1944. Ecological aspects of species formation in passerine birds. Ibis 86: 260-286.

LAWSON, F. R.

1958. Some features of the relation of insects to their ecosystems. Ecology 39(3): 515-521.

LoTkA, A. J.

1932. The growth of mixed populations: Two species competing for a common food supply.

Washington Acad. Sci. J. 22: 461.

McIntosh, RoBert P.

1961. Competitive exclusion principle. Science $133(3450): 391$.

Milne, A.

1961. Mechanisms in biological competition: definition of competition among animals, $p$. 40-61. In: Symposia, Soc. Exptl. Biol. 15.

Nicholson, A. J.

1933. The balance of animal populations. J. Animal Ecol. 2(1): 132-178.

PARK, T.

1948. Experimental studies of interspecies competition. I. Competition between populations of flour beetles, Tribolium confusum Duval and Tribolium castaneum Herbst. Ecol. Monogr. 18: 265-308.

1954. Experimental studies on interspecies competition. II. Temperature, humidity and competition in two species of Tribolium. Physiol. Zool. 28: 177-238.

1955a. Ecological experimentation with animal populations. Sci. Month. 81: 271-275.

1955b. Experimental competition in beetles with some general implications, p. 69-82. In: The numbers of man and animals. Oliver and Boyd, Ltd., London, for the Institute of Biology.

1957. Experimental studies on interspecies competition. III. Relation of initial species proportion to competitive outcome in populations of Tribolium. Physiol. Zool. 30: 22-40.

Patten, Bernard C.

1961. Competitive exclusion. Science 174(3490) : 1599-1601.

POLNIK, AMELIA

1960. Effects of some intraspecies processes on competition between two species of flour Ross, H. H. beetles, Latheticus oryzae and Tribolium confusum. Physiol. Zool. 33(1): 42-57.

1957. Principle of natural coexistence indicated by leaf-hopper populations. Evolution 11: 113-129.

SALT, GEORGE

1961. Mechanisms in biological competition: competition between insect parasitoids, p. 96119. In: Symposia Soc. Exptl. Biol. 15.

SAVILE, D. V. O.

1960. Limitations of the competitive exclusion principle. Science 132(3441): 1761.

SCHLABRITZKY, E.

1956. Prospaltella perniciosi Tower-ein Beitrag zur biologischen Bekämpfung. Mitt. Biol. Bund. Berlin-Dahlem 31: 53-55.

Udvardy, Miklos F. D.

1959. Notes on the ecological concepts of habitat, biotope and niche. Ecology 40(4): 725-728.

UTIDA, SYUNRO

1953. Interspecific competition between two species of bean weevil. Ecology 34(2): 301-307.

VAN VALEN, LEIGH

1960. Further competitive exclusion. Science 132(3440): 1674-1675.

VOLTERRA, Vito

1926. Variazioni e fluttuazioni del numero d'individui in specie animali conviventi. $R$. Accad. Naz. dei Lincie Mem., Ser. 6, Vol. 2.

Williamson, M. H.

1957. An elementary theory of interspecific competition. Nature 180(4583): 422-425. 
density attained, was not correlated with inherent fecundity. When any two of the three species-Aphytis fisheri DeBach, A. melinus, and A. lingnanensis-were cultured together, one species always eventually eliminated the other. Differences in $F_{1}$ progeny production explained the results. Inherent differences in fecundity were largely responsible for the differences in $F_{1}$ progeny production, but aggressive competition between larvae tended to modify inherent fecundity. Competition between adults was not a factor in competitive displacement, but relative ability to find hosts in the field when hosts are scarce is important. Physical environmental conditions also affect $F_{1}$ progeny production; hence, in different environments the winner in competition may differ.

When $A$. lingnanensis and $A$. fisheri were cultured together with a constant surplus of hosts, $A$. fisberi was eliminated after nine generations. This corroborates the field observations that food (host) scarcity is not necessary for competitive displacement to occur. Aphytis lingnanensis and Comperiella bifasciata, which have slightly different ecological niches, were shown to coexist in laboratory cultures as they do in the field. However, Prospaltella perniciosi was displaced. Reasons for this are discussed. Mechanisms of competitive displacement and the importance of competitive displacement in population ecology are also discussed.

\section{CONTENTS}

Introduction and Review....... 105

Competitive Displacement between Species of Aphytis in the Field. 116

General Observations ........ 116

Field Studies ............. 118

Status of Aphytis chrysomphali before $1948 \ldots \ldots \ldots 118$

Aphytis lingnanensis vs. Aphytis chrysomphati: 1948 to $1961 \ldots \ldots \ldots \ldots \ldots . \ldots 118$ Aphytis melinus vs. Aphytis lingnanensis: 1957 to 1961.124

Coexistence of Comperiella bifasciata and Prospaltella perniciosi with Aphytis species in the Field 128

Laboratory Studies on Interspecies Competition Among Three Species of Aphytis, Comperiella bifasciata, and Prospaltella perniciosi ................. 128 Species Having Identieal Ecological Niches ............ 128
The Speeies' Biological Characteristics ............ 128

Single-Species Populations (Controls) ............ 133

Mixed-Species Populations .... 139 Analysis of Displacement in Mixed-Species Cultures.... 140 Species Having Different Ecological Niches ........... 147

The Species' Biological Characteristics ........... 148

Single-Species Populations (Controls) ........... 150

Mixed-Species Populations. .. 153

Discussion and Conclusions. .... 156

Past Work .............. 157

Present Work ............ 157

The Mechanism of Competitive

Displacement .......... 159

The Importance of Competitive

Displacement .......... 161

Summary .............. 163 
The journal HILGARDIA is published at irregular intervals, in volumes of about 650 to 700 pages. The number of issues per volume varies.

Single copies of any issue may be obtained free, as long as the supply lasts; please request by volume and issue number from:

\section{Agricultural Publications \\ 207 University Hall \\ University of California \\ Berkeley 4, California}

The limit to nonresidents of California is 10 separate titles. The limit to California residents is $\mathbf{2 0}$ separate titles.

The journal will be sent regularly to libraries, schools, or institutions in one of the following ways:

1. In exchange for similar published material on research.

2. As a gift to qualified repository libraries only.

3. On a subscription basis $-\$ 7.50$ a year paid in advance. All subscriptions will be started with the first number issued during a calendar year. Subscribers starting during any given year will be sent back numbers to the first of that year and will be billed for the ensuing year the following January. Make checks or money orders payable to The Regents of The University of California; send payment with order to Agricultural Publications at above address. 